ESCOLA DE ENGENHARIA DE SÃO CARLOS

PROGRAMA DE PÓS-GRADUAÇÃO EM ENGENHARIA MECÂNICA

\title{
DESENVOLVIMENTO DE SISTEMA COMPUTACIONAL PARA CÁLCULO DE PROPRIEDADES ELÁSTICAS E ANÁLISES DE TENSÃO - DEFORMAÇÃO EM COMPÓSITOS LAMINADOS POLIMÉRICOS.
}

\section{DANIELA GAVASSA}

Dissertação apresentada à Escola de Engenharia de São Carlos da Universidade de São Paulo, como parte dos requisitos para obtenção de título de Mestre em Engenharia Mecânica.

Área de Concentração: Engenharia Mecânica Orientador: Prof. Associado Jonas de Carvalho 


\section{DEDICATÓRIA}

Aos meus pais, Olívio e Elza pelos inúmeros esforços e sacrifícios por uma educação e formação com qualidade, e ao meu namorado Jurandir, por sua compreensão e paciência nos momentos difíceis. É por meio das pequenas atitudes que vemos a grandeza dos sentimentos. 


\section{AGRADECIMENTOS}

Primeiramente a Deus por todas as dádivas já presentes em nossas vidas e por aquelas que ainda virão.

Ao professor Jonas de Carvalho, minha eterna gratidão, por sua generosidade, bondade, pela oportunidade de concluir o mestrado e pelo o apoio técnico e didático concedido durante o processo de orientação do trabalho.

Aos Professores do programa de pós-graduação do SEM, que nos ajudaram a fazer da proposta o desafio.

Á secretaria do programa de pós-graduação do SEM pelos encaminhamentos necessários dos assuntos administrativos.

Aos amigos Edgar Gomes dos Santos, Fernando Justilin e Hitoshi Taniguchi mestrandos do programa de pós-graduação do SEM, pela amizade, pelos momentos de descontração e pelo compartilhamento de conhecimentos, experiências e dificuldades.

Ao meu amigo Rael Gugelmin Cunha, pelos ensinamentos que contribuíram para o desenvolvimento deste estudo.

As minhas amigas do coração Daiane C. Veroni Gonçalves, Grazielle Feliciani Barbosa, Juliana Dagnoni e Soraia Almeida pela força e estímulo constante durante todas as etapas deste trabalho.

A todos os amigos de fato que me motivaram e incentivaram para o ingresso, continuidade e conclusão do programa de mestrado. 


\section{EPÍGRAFE}

"Ainda que eu tivesse o dom da profecia, o conhecimento de todos os mistérios, e de toda a ciência ainda que eu tivesse toda a fé, a ponto de transportar montanhas, senão tivesse o amor, eu não seria nada".

(Coríntios, 13:2) 


\section{RESUMO}

GAVASSA, D. (2009). Desenvolvimento de sistema computacional para cálculo de propriedades elásticas e análises de tensão - deformação em compósitos laminados poliméricos. São Carlos, 2009. 129 p. Dissertação (Mestrado) - Escola de Engenharia de Escola de São Carlos, Universidade de São Paulo.

Durante os últimos anos tem-se observado um aumento crescente no uso de materiais compósitos. Isto se deve principalmente devido às vantagens que os mesmos apresentam em relação aos materiais convencionais tais como: alta resistência e rigidez associado à elevado desempenho estrutural, baixo peso e boa resistência à corrosão e oxidação, dentre outros. Contudo, o uso de materiais compósitos em projetos estruturais exige um bom conhecimento de suas propriedades elásticas e ferramentas adequadas para análise de falhas destes materiais. Algumas ferramentas comerciais já foram desenvolvidas, entretanto estas ferramentas apresentam arquitetura fechada que, na maioria das vezes, não permitem implementações específicas para as necessidades de cada usuário. Este trabalho desenvolve um sistema computacional para cálculo de propriedades elásticas e estadas de tensão - deformação nas diferentes camadas de laminados poliméricos, utilizando plataforma JAVA em código aberto e de baixo custo. Após a entrada dos dados de materiais e seqüência das lâminas, o sistema calcula as propriedades elásticas bem como o estado de tensões e deformações nas diferentes camadas, propiciando assim a aplicação de diferentes critérios de falhas. O sistema foi validado em estudos de caso da literatura com resultados satisfatórios.

Palavras-chave: Laminados, compósitos, falhas, elasticidade, análise de tensões. 
GAVASSA, D. (2009). Development of a computational system for calculation of elastic properties and stress analysis of laminated polymer composites. São Carlos, 2009. 129 p. Dissertation (Masters degree) - Escola de Engenharia de São Carlos, Universidade de São Paulo.

During the past years a growing increase in the use of composite materials has been observed. This is due mainly to the advantages they present in relation to conventional materials such as: high strength and stiffness associate with low weight, good resistance to corrosion and oxidation and others. However, the use of composites in structural applications demands a good knowledge of their elastic properties as well as computational tools for failure analysis of these materials. Some commercial tools have been already developed, however these packages do not allow specific users implementations. This work develops a computational system for calculation of elastic properties and stress analysis along the different layers of a polymeric laminate, using JAVA platform in open code with low cost. After the material data input and laminate sequence, the system calculates the elastic properties as well as the stress state in the different layers, thus allowing the application of different failure criteria. The system was validated in literature case studies with satisfactory results.

Keywords: Laminates, composites, failure, elasticity, stress analysis. 


\section{LISTA DE FIGURAS}

FIGURA 2.1 - Classificação dos Materiais de Engenharia. 10

FIGURA 2.2 - Organograma de classificação dos materiais compósitos. 12

FIGURA 2.3 - Exemplos de compósitos reforçados: (a) por partículas aleatórias; (b) por fibras descontínuas unidirecionais; (c) por fibras descontínuas aleatórias; (d) por fibras contínuas unidirecionais.

FIGURA 2.4 - Efeito da deformação ao redor da fibra na matriz sob tensão: (a) fibra

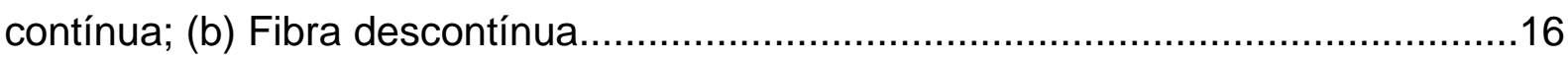

FIGURA 2.5 - Planos de simetria ortogonais de uma lâmina. 32 FIGURA 2.6 - O sistema de coordenadas 1-2 refere-se à lâmina e o sistema x-y ao laminado. .35

FIGURA 2.7 - Nomenclatura do laminado. 39

FIGURA 2.8 - Fluxograma para determinação da rigidez e tensões atuantes no laminado. .42

FIGURA 2.9 - Ciclo de vida de um software. .58

FIGURA 2.10 - Configuração de um Sistema de Banco de Dados. 62

FIGURA 2.11 - Níveis de Abstração de uma Base de Dados. .63

FIGURA 2.12 - Modelo mostra Mudanças na Base de Dados e na Realidade 64

FIGURA 2.13 - Projeto da Base de Dados. 69

FIGURA 2.14 - Diagrama de Entidade - Relacionamento (DER)...........................70

FIGURA 2.15 - Esquema Lógico de Dados com as Abordagens citadas.................71

FIGURA 2.16 - Modelo com os Níveis de Visão de Dados.....................................72

FIGURA 2.17 - Modelo ilustra os diversos enfoques da Linguagem SQL .79 
FIGURA 2.18 - Diagrama ilustra a manipulação de objetos na linguagem SQL 81

FIGURA 2.19 - Objetivos de um projeto orientado a objetos. 84

FIGURA 2.20 - Princípios de projeto orientado a objetos. .85

FIGURA 2.21 - Processo de compilação e execução de um programa em Java. .89

FIGURA 3.1 - Ambiente de Programação Netbeans IDE 6.0.1...... .94

FIGURA 3.2 - Diagrama de Tabelas do Modelo Relacional do

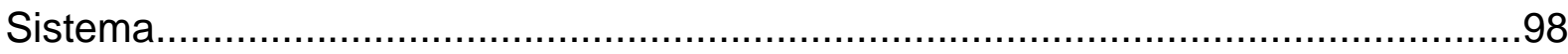

FIGURA 3.3 - Tela Principal do Software SISLAM............................................99

FIGURA 3.4 - Tela de Cadastro das Fibras do Sistema..................................100

FIGURA 3.5 - Tela Detalhes da Fibra do Sistema..........................................100

FIGURA 3.6 - Tela de Cadastro das Resinas do Sistema..................................101

FIGURA 3.7 - Tela Detalhes da Resina do Sistema.......................................101

FIGURA 3.8 - Tela de Cadastro dos Compósitos do Sistema............................102

FIGURA 3.9 - Tela Detalhes do Compósito do Sistema...................................102

FIGURA 3.10 - Tela de Cadastro dos Laminados do Sistema..........................103

FIGURA 3.11 - Tela Detalhes dos Laminados do Sistema...............................104

FIGURA 3.12 - Tela de Inserção de Novas Camadas dos Laminados no

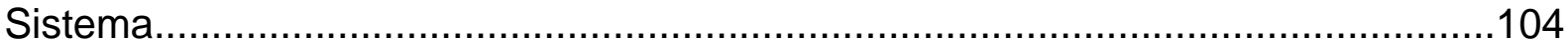

FIGURA 3.13 - Tela de Cadastro dos Carregamentos do Sistema......................105

FIGURA 3.14 - Tela Detalhes dos Carregamentos do Sistema..........................105

FIGURA 3.15 - Tela de Cadastro das Novas Análises Geradas no Sistema.........106

FIGURA 3.16 - Tela Detalhes dos Resultados das Análises Geradas no

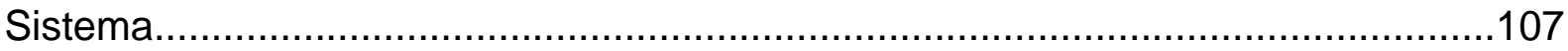


FIGURA 4.1 - Matriz de Rigidez Reduzida Extensional, calculada no sistema.

FIGURA 4.2 - Dados para lâmina $1\left(0^{\circ}\right)$ no plano de simetria 111

FIGURA 4.3 - Dados para lâmina $2\left(90^{\circ}\right)$ no plano de simetria. 112

FIGURA 4.4 - Dados para lâmina 3 ( 45ํ).

FIGURA 4.5 - Dados para lâmina $4\left(-45^{\circ}\right)$ no plano de simetria.

FIGURA 4.6 - Matriz ABBD.

FIGURA 4.7 - Inversa da Matriz ABBD.

FIGURA 4.8 - Distribuição de tensões normais na direção x-X. .115

FIGURA 4.9 - Distribuição de tensões normais na direção y-y..... .115

FIGURA 4.10 - Distribuição de tensões de cisalhamento na direção xy...........

FIGURA 4.11 - Matriz ABBD. 116

FIGURA 4.12 - Inversa da Matriz ABBD. 117

FIGURA 4.13 - Distribuição de tensões normais na direção x-X. .118

FIGURA 4.14 - Distribuição de tensões normais na direção y-y..... .118

FIGURA 4.15 - Distribuição de tensões de cisalhamento na direção x-y. 119 


\section{LISTA DE TABELAS}

Tabela 4.1 - Propriedades da fibra e resina utilizadas. 110

Tabela 4.2 - Tensões calculadas nas diferentes lâminas (camadas) do laminado para $1^{\circ}$ caso de estudo 114

Tabela 4.3 - Tensões calculadas nas diferentes lâminas (camadas) do laminado para $2^{\circ}$ caso de estudo 117 


\section{LISTA DE ABREVIAÇÕES E SIGLAS}

ANSI - American National Standard Institute

ASTM - American Society for Testing and Materials

API's - Interface de Programação de Aplicativos

BD - Banco de Dados

CPD - Controle de Processamento de Dados

CPU - Unidade Central de Processamento

DBA - Administrador da Base De Dados

DDL - Linguagem de Definição de Dados

DER - Diagrama de Entidade - Relacionamento

DIN - Deutsche Industrien Normen

DML - Linguagem de Manipulação de Dados

ES - Engenharia do Software

E-R - Entidade - Realacionamento

IBM - International Business Machines

IDES - Ambientes Integrados de Desenvolvimento

ISO - International Organization for Standardization

FPF - First Ply Failure

GUI's - Interfaces Gráficas com o Usuário

$\mathbf{H C l}$ - Human - Computer Interface

HSQLDB - Hyperthreaded Structured Query Language Data Base

JVM - Máquina Virtual Java

LPF - Last Ply Failure

MCRF - Materiais Compósitos Reforçados por Fibra 
MCR - Materiais Compósitos Reforçados

MER - Modelo de Entidade - Relacionamento

MPL - Mozilla Public License

SGBD - Sistema Gerenciador de Banco de Dados

SPL - Sun Public License

SQL - Linguagem Estruturada de Pesquisa

TCL - Teoria Clássica dos Laminados 


\section{LISTA DE SÍMBOLOS}

$[\bar{Q}] \quad-$ Matriz de rigidez reduzida transformada

[k] - Matriz de rigidez

$[S]^{-1}-$ Matriz de rigidez reduzida para o estado plano de tensões

[S] - Matriz de flexibilidade reduzida da lâmina

$[T]^{-1}$ - Matriz inversa da matriz de transformação de coordenadas

$[T]^{-T}$ - Matriz transposta da inversa da matriz de transformação de coordenadas

[T] - Matriz de transformação de coordenadas

$\left\{k^{\circ}\right\}$ - Curvaturas do laminado

$\{\mathrm{F}\} \quad-$ Vetor força nodal $[\mathrm{N}]$

$\{\mathrm{u}\} \quad-$ Vetor deslocamento nodal $[\mathrm{m}]$

A - Área da seção transversal total $\left[\mathrm{m}^{2}\right]$

$A_{f} \quad$ - Área da seção transversal da fibra $\left[\mathrm{m}^{2}\right]$

$d_{f} \quad$ - Diâmetro da fibra $[\mathrm{m}]$

$E_{1} \quad$ - Módulo de elasticidade da lâmina na direção $1[\mathrm{~Pa}]$

$E_{2} \quad$ - Módulo de elasticidade da lâmina na direção $2[\mathrm{~Pa}]$

$E_{f} \quad$ - Módulo de elasticidade da fibra $[\mathrm{Pa}]$

$E_{m} \quad$ - Módulo de elasticidade da matriz $[\mathrm{Pa}]$

$E_{x} \quad$ - Módulo de elasticidade da lâmina na direção da fibra [Pa]

E $\quad$ - Módulo de elasticidade da lâmina na direção transversal à fibra [Pa]

$E_{z} \quad$ - Módulo de elasticidade da lâmina na direção transversal à fibra [Pa]

$G_{12}$ - Módulo de cisalhamento da lâmina relativo ao plano 1-2 [Pa]

$G_{f} \quad$ - Módulo de cisalhamento da fibra $[\mathrm{Pa}]$ 
$G_{m} \quad$ - Módulo de cisalhamento da matriz [Pa]

$G_{x y} \quad$ - Módulo de cisalhamento da lâmina relativo aos planos xy [Pa]

$G_{x z} \quad$ - Módulo de cisalhamento da lâmina relativo aos planos xz [Pa]

K $\quad$ - K- ésima lâmina do laminado

$l_{c} \quad$ - Comprimento crítico da fibra [m]

$I_{f} \quad$ - Comprimento da fibra $[\mathrm{m}]$

$N \quad$ - Número de furos da barra de alinhamento

$P_{c} \quad$ - Certa propriedade do compósito

$P_{i} \quad$ - Propriedade associada ao i-ésimo constituinte

$r_{f} \quad-$ Raio da fibra [m]

$V \quad-$ Volume total $\left[\mathrm{m}^{3}\right]$

$V_{f} \quad-$ Volume da fibra $\left[\mathrm{m}^{3}\right]$

$v_{c r i t} \quad$ - Fração volumétrica crítica de fibra

$v_{i} \quad$ - Fração volumétrica do i - ésimo constituinte

$X_{c} \quad$ - Qualquer propriedade do compósito

$X_{m} \quad$ - Qualquer propriedade da matriz

$X_{f} \quad$ - Qualquer propriedade da fibra

\section{LETRAS GREGAS}

$\sigma_{m}^{*} \quad$ - Tensão na matriz correspondente à deformação de ruptura da fibra [Pa]

$\hat{\varepsilon}_{m} \quad$ - Deformação de ruptura da matriz

$\hat{\varepsilon}_{f} \quad$ - Deformação de ruptura das fibras

$\sigma_{f}^{*} \quad$ - Tensão na fibra correspondente à deformação de ruptura da matriz [Pa] 
$\hat{\sigma}_{m} \quad$ - Tensão última à ruptura da matriz $[\mathrm{Pa}]$

$\lambda \quad$ - Fração volumétrica de fibra

$\theta$ - Rotação do sistema arbitrário do laminado x-y para o sistema da lâmina 1-2

$\sigma_{1} \quad$ - Tensão na direção do eixo principal [Pa]

$\varepsilon_{1} \quad$ - Deformação correspondente

$v_{12}$ - Coeficiente de Poisson da lâmina relativo ao plano 1-2

$\sigma_{2} \quad$ - Tensão na direção do eixo principal $[\mathrm{Pa}]$

$\varepsilon_{2} \quad$ - Deformação correspondente

$v_{23} \quad$ - Coeficiente de Poisson da lâmina relativo ao plano 2-3

$\varepsilon_{3} \quad$ - Deformação correspondente

$\sigma_{6} \quad-$ Tensão de cisalhamento $[\mathrm{Pa}]$

$v_{f} \quad$ - Coeficiente de Poisson da fibra

$\sigma_{f} \quad-$ Tensão de ruptura à tração da fibra [Pa]

$\tau_{f} \quad-$ Tensão de ruptura ao cisalhamento da interface [Pa]

$v_{m} \quad$ - Coeficiente de Poisson da matriz

$v_{x y} \quad$ - Coeficiente de Poisson da lâmina relativo ao plano xy

$v_{x z} \quad$ - Coeficiente de Poisson da lâmina relativo ao plano xz

$v_{y z} \quad$ - Coeficiente de Poisson da lâmina relativo ao plano yz

$\left\{\varepsilon^{\circ}\right\}$ - Deformações do plano médio do laminado

ÍNDICES SUPERIORES

$\wedge \quad-$ Designa a resistência a tração no limite de ruptura 
* - Designa a tensão na matriz ou fibra correspondente à deformação de ruptura da fibra ou da matriz, respectivamente.

o - - Referência ao plano médio do laminado. 


\section{SUMÁRIO}

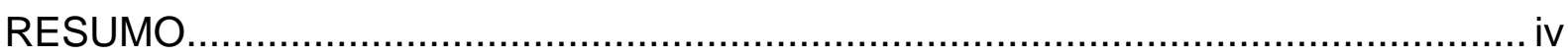

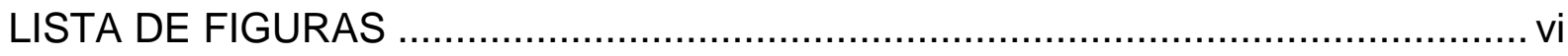

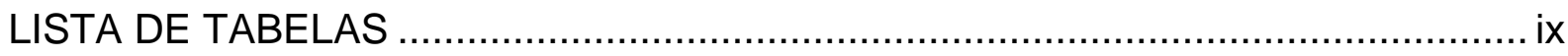

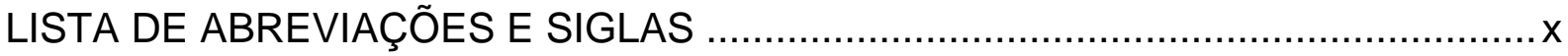

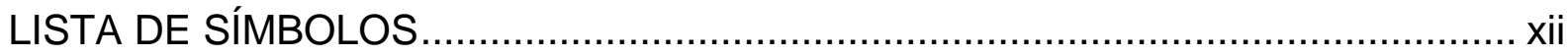

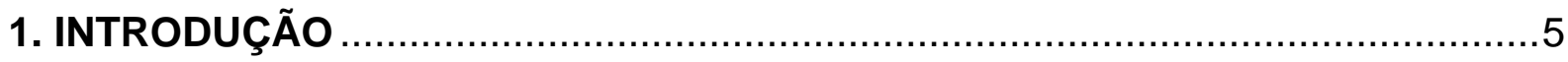

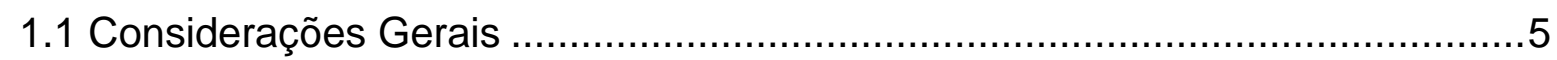

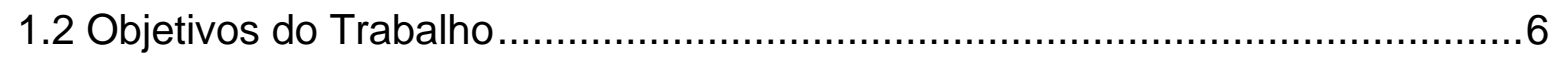

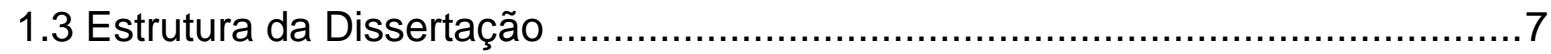

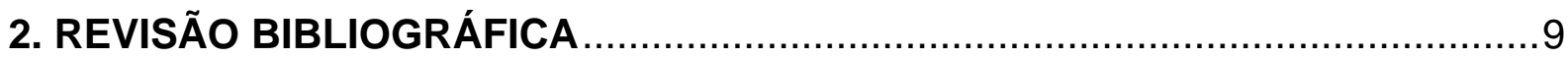

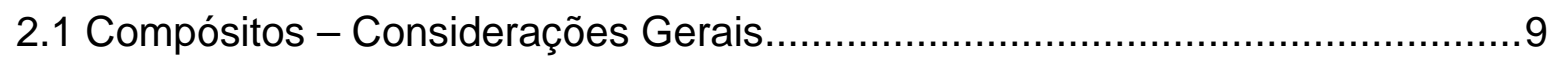

2.1.1 Definição, Classificação e Características dos Materiais Compósitos .....11

2.1.2 Constituintes - Matrizes, Fibras, Resinas e Interface Fibra/Matriz............13

2.1.3 Vantagens, desvantagens e aplicações ...........................................20

2.1.4 Cálculo das Propriedades Elásticas de um Laminado ...........................23

2.1.5 Definição e Aplicação da Teoria Clássica dos Laminados (TCL) ..............31

2.1.6 Caracterização Mecânica por Métodos Experimentais ...........................45

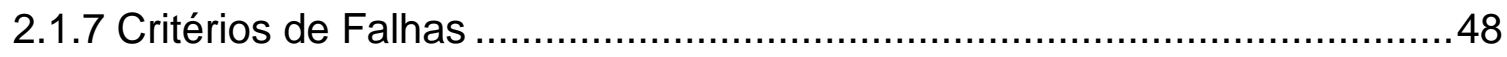

2.1.8 Critério de Tsai Wu.................................................................. 51

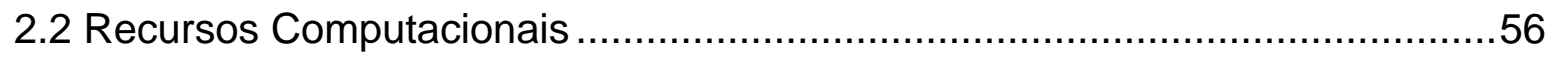

2.2.1 Processo de Desenvolvimento de um Software ..................................56

2.2.2 Considerações sobre Engenharia de Software ..................................57

2.2.3 Considerações sobre Interfaces Gráficas com o Usuário - (GUI's) ..........61 
2.2.4 Sistema Gerenciador de Banco de Dados (SGBD). 62

2.2.4.1 Introdução 62

2.2.4.2 Vantagens de um Sistema Gerenciador de Banco de Dados 65

2.2.4.3 Capacidades de um Sistema Gerenciador de Banco de Dados 66

2.2.4.4 Conceitos e Arquiteturas de um Sistema Gerenciador de Banco de Dados (SGBD). 68

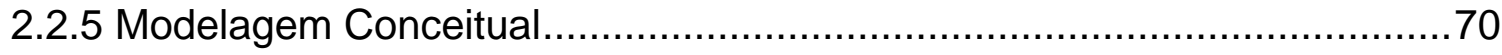

2.2.5.1 O Projeto de Banco de Dados ….....................................................

2.2.5.2 Modelo Entidade - Relacionamento (MER) ....................................73

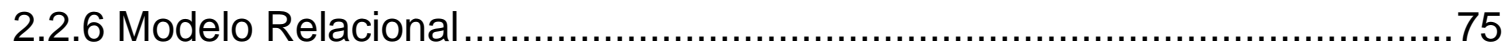

2.2.6.1 Principais Vantagens da Abordagem Relacional .............................75

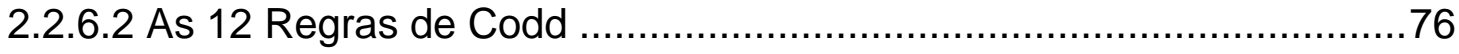

2.2.6.4 Regras de Integridade do Modelo Relacional ..................................78

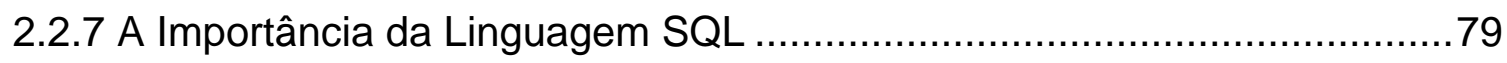

2.2.8 Projeto Orientado a Objetos - Objetivos, Princípios e Padrões .................84

2.2.8.1 Objetivos do Projeto Orientado a Objetos ........................................84

2.2.8.2 Princípios de Projeto Orientado a Objetos.......................................86

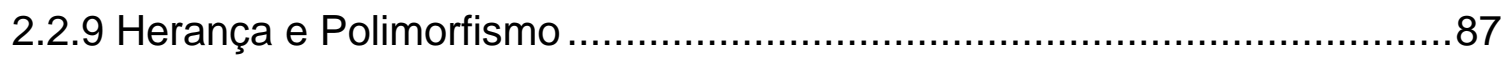

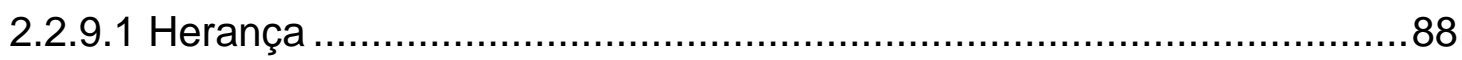

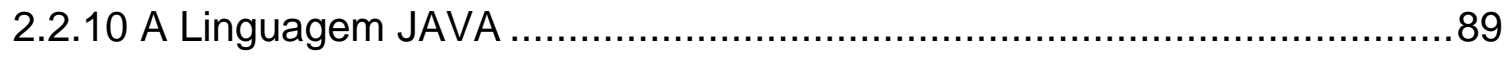

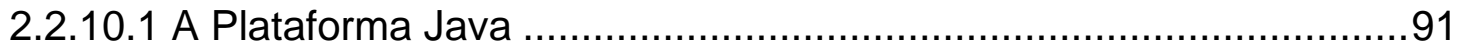

2.2.10.2 Ambientes de Desenvolvimento na Linguagem Java ....................92

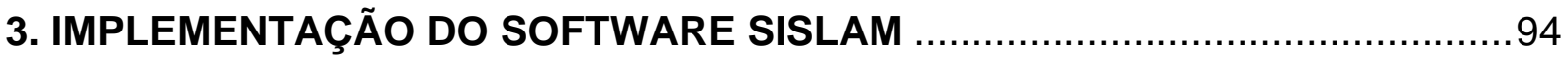

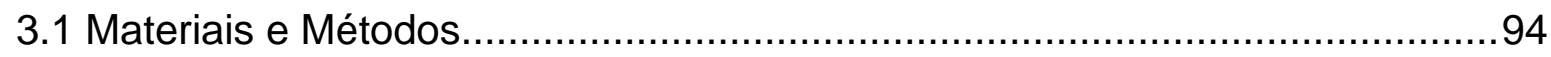

3.2 Definição e Características do Ambiente de Desenvolvimento Netbeans .......95 
3.3 Sistema Gerenciador de Banco de Dados HSQLDB ..................................97

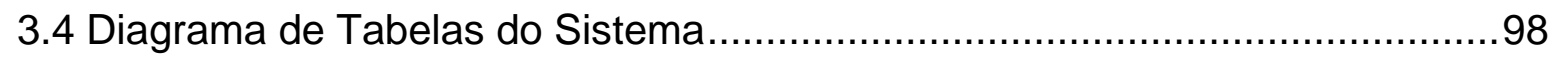

3.5 Construção das Interfaces Gráficas dos Módulos do Sistema........................99

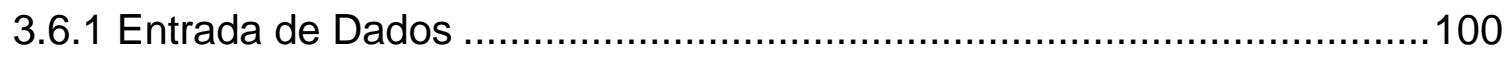

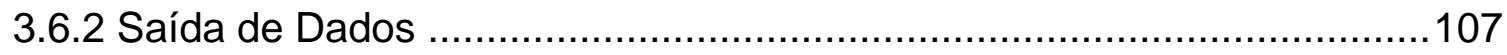

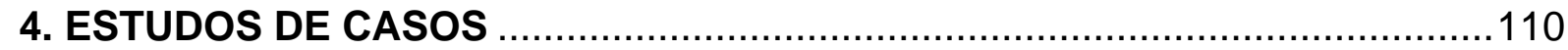

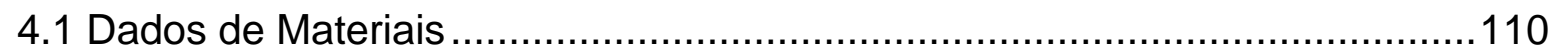

4.2 Caso 1: Laminado simétrico com cargas normais e de flexão .......................112

4.2 Caso 2: Laminado não simétrico com cargas normais ...............................117

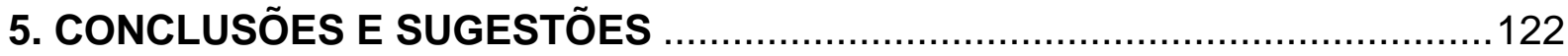

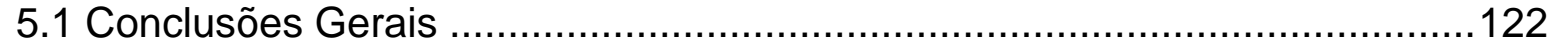

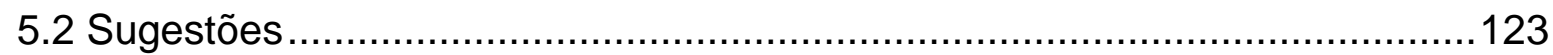

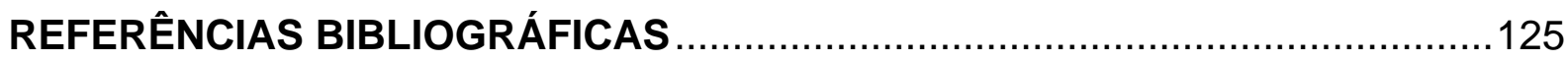




\section{Capítulo I}

\section{INTRODUÇÃO}

\subsection{Considerações Gerais}

Na década de 50 aproximadamente surgiram os primeiros trabalhos envolvendo materiais compósitos com o desenvolvimento de projetos estruturais apresentados pela indústria aeronáutica, com o objetivo de produzir materiais de alto desempenho estrutural associado à baixa densidade, fator primordial para as aeronaves. Atualmente, os compósitos têm sido aplicados nos mais diversos setores tais como: automotivo, marinha, ferroviário, construção civil e área médica. Os materiais compósitos se destacam por inúmeras vantagens oferecidas como: baixo peso associado à alta rigidez e resistência mecânica, alto desempenho devido à versatilidade na customização das propriedades dos materiais de acordo com a necessidade do projeto e baixo custo relativo quando comparados aos demais materiais.

Podemos encontrar diferentes definições para os materiais compósitos, dependendo da área de pesquisa. (CARVALHO, 1996) define os materiais compósitos com a união química ou mecânica de dois ou mais materiais com diferentes propriedades de maneira a gerar um produto final com características físico-químicas superiores àquelas dos materiais individuais. 
Para (CARVALHO, 1996), o processo tradicional de manufatura de materiais compósitos tem se aperfeiçoado ao longo dos anos. A necessidade de componentes com novas geometrias, peças com alto desempenho estrutural associados ao crescente uso de materiais compósitos, tem tornado mandatório o desenvolvimento de algoritmos e rotinas de otimização dos dados de processos em geral.

Este trabalho propõe o desenvolvimento de um Sistema Computacional para Cálculo de Propriedades Elásticas e Estados de Tensão - Deformação nas Diferentes Camadas em Compósitos Laminados Poliméricos;

\subsection{Objetivos do Trabalho}

De acordo com o enfoque apresentado anteriormente, este trabalho desenvolve um Sistema Computacional para Cálculo de Propriedades Elásticas e Estados de Tensão - Deformação nas Diferentes Camadas em Compósitos Laminados Poliméricos. Para isso, o usuário fornece os dados de entrada referente aos materiais: Fibra, Resina, Compósito, número de camadas do Laminado e Carregamento. Finalizada a etapa dos cadastros o sistema calcula as propriedades elásticas do laminado aplicando a regra das misturas exibindo os resultados das análises geradas para cada camada do respectivo laminado.

Os objetivos deste trabalho são:

- Fazer um levantamento dos sistemas computacionais disponíveis comercialmente, visando estudar suas características e aplicações;

- Desenvolver um Sistema Computacional para Cálculo de Propriedades Elásticas e Estados de Tensão - Deformação nas Diferentes Camadas em Compósitos Laminados Poliméricos; 
- Definir uma linguagem computacional adequada para programar o código fonte do sistema;

- Projetar e implementar plataforma computacional com interface gráfica amigável, flexível e funcional que possibilita atualizações dos módulos em implementações futuras;

- Fazer testes de validação apresentando os resultados das análises geradas em estudos de caso da literatura.

\subsection{Estrutura da Dissertação}

O trabalho foi organizado de forma a apresentar a sequência dos temas necessários para o seu desenvolvimento, abordando os conceitos relacionados ao cálculo das propriedades elásticas de compósitos laminados, os recursos computacionais utilizados, as rotinas desenvolvidas e a discussão dos resultados obtidos. Deste modo foram propostos cinco capítulos e as referências bibliográficas citadas, segundo o seguinte conteúdo:

1. Introdução - é apresentada a proposta de trabalho, seus objetivos, a justificativa e o conteúdo do trabalho.

2. Revisão Bibliográfica - a revisão bibliográfica apresenta o contexto no qual o trabalho está inserido. A revisão apresenta definição, classificação e características dos materiais compósitos, cálculo de propriedades elásticas, teoria clássica dos laminados e técnicas de trabalho auxiliado por uma série de recursos computacionais. 
3. Implementação do Software SISLAM: são apresentadas as implementações do software SISLAM, detalhando o funcionamento individual de cada módulo do sistema tais como: ambiente de desenvolvimento, sistema gerenciador de banco de dados, gerenciamento dos dados de entrada e saída e resultados esperados.

4. Estudos de Caso: são apresentados os resultados obtidos em testes de validação realizados em dois diferentes laminados.

5. Conclusões e Sugestões - verificam se os objetivos do trabalho foram alcançados, suas limitações e sugestões para trabalhos futuros.

6. Referências Bibliográficas - contém as fontes das referências bibliográficas utilizadas para o desenvolvimento do trabalho. 
CAPÍTULO II

\section{REVISÃO BIBLIOGRÁFICA}

\subsection{Compósitos - Considerações Gerais}

Existem, patenteados, mais de 50.000 materiais de engenharia dos quais o projetista pode selecionar. Esses diferentes materiais derivam de matérias comuns (como por exemplo, cobre, ferro e bronze) que encontram - se disponíveis em nosso meio a centenas de anos e mais recentemente os materiais avançados (como por exemplo, compósitos, cerâmicas e aços de alto desempenho). Atualmente os engenheiros e projetistas devido às inúmeras opções de materiais, encontram um grande desafio para selecionar corretamente um material e um processo industrial para determinada aplicação. É difícil estudar esses materiais individualmente, então, é necessária uma classificação mais abrangente para simplificação e caracterização do mesmo. Estes materiais, dependendo das características principais (como por exemplo, dureza, resistência, densidade e temperatura de fusão), podem ser divididos em quatro categorias: Metais, Polímeros, Cerâmicos e Compósitos. A FIGURA (2.1) nos mostra esquematicamente a definição dos materiais. 


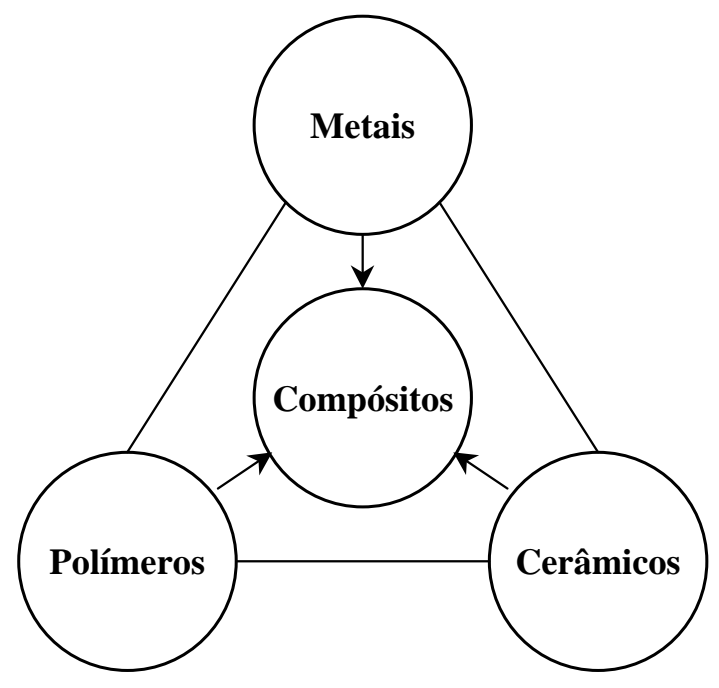

FIGURA 2.1 - Classificação dos Materiais de Engenharia. (Adaptado por BEAUMONT, 1989).

Segundo (BEAUMONT, 1989), observa-se na história da humanidade, que dentre as diversas maneiras de avaliação do padrão de vida de um país ou sociedade, o consumo de materiais de engenharia por indivíduo, disponíveis na forma de bens e serviços, pode ser uma das mais explícitas. Os bens manufaturados quer sejam de consumo ou produção, são obtidos por meio da conversão dos materiais de engenharia, adicionando - Ihes valor. A história tem demonstrado que quanto mais eficientemente os sistemas de produção são capazes de realizar esta conversão, maior será o padrão de vida da sociedade.

$\mathrm{Na}$ década de 60 começaram a aparecer às primeiras aplicações de Materiais Compósitos Reforçados por Fibra - MCRF ou MCR. Segundo (FILHO, 2001), uma série de pesquisas realizadas pela Royal Aircraft Establishment em Farnborough, na Inglaterra, levaram ao descobrimento da fibra de carbono, material altamente resistente e rígido, que se tornou sem dúvida uma revolução nos materiais de engenharia. O grande estímulo no uso dos MCRF está relacionado à combinação de 
alta resistência e rigidez com baixa densidade, o que proporciona uma grande eficiência estrutural destes materiais, combinação que impulsiona os estudos destes materiais até os dias atuais.

\subsubsection{Definição, Classificação e Características dos Materiais Compósitos}

Ainda hoje não há uma definição adequada para materiais compósitos. (CARVALHO, 1996) define os materiais compósitos pela união química ou mecânica de dois ou mais materiais com propriedades diferentes, que quando se unem, formam um novo material com características físico - química superiores às propriedades iniciais individuais.

Conforme (REINHART \& CLEMENTS, 1987) definem um compósito como uma combinação macroscópica de dois ou mais materiais distintos, havendo uma interface reconhecível entre eles. Nesta combinação, os constituintes retêm suas identidades, digo, eles não se dissolvem ou se descaracterizam completamente, atuando em conjunto e fazendo com que as propriedades do compósito sejam superiores às de cada constituinte individualmente. Porém, em virtude dos compósitos serem normalmente empregados, devido às suas propriedades estruturais, a definição pode ser restringida a incluir somente aqueles materiais que contenham um reforço e um material aglomerante. O aglomerante tem como função manter os reforços unidos, transmitindo a estes o carregamento aplicado, enquanto os reforços têm como função suportar os carregamentos transmitidos pelo aglomerante.

Deste modo, os compósitos têm, tipicamente, uma ou mais fases descontínuas envolvidas por uma fase contínua. A fase descontínua (reforço) é, usualmente, mais rígida e mais resistente do que a fase contínua (aglomerante), 
denominada de matriz. Na condição de assegurar o reforço, geralmente deve haver uma fração volumétrica substancial da fase descontínua.

Quanto à classificação dos compósitos, a geometria da fase descontínua é um dos principais parâmetros a ser considerado, visto que as propriedades mecânicas dos compósitos dependem da forma e das dimensões do reforço. Descrevem-se os reforços usualmente como sendo fibrosos ou particulados. Por esta razão, (MATTHEWS \& RAWLINGS, 1994) classificam os compósitos com base na geometria dos seus componentes estruturais FIGURA (2.2), separando-os em compósitos reforçados por fibras e reforçados por partículas.

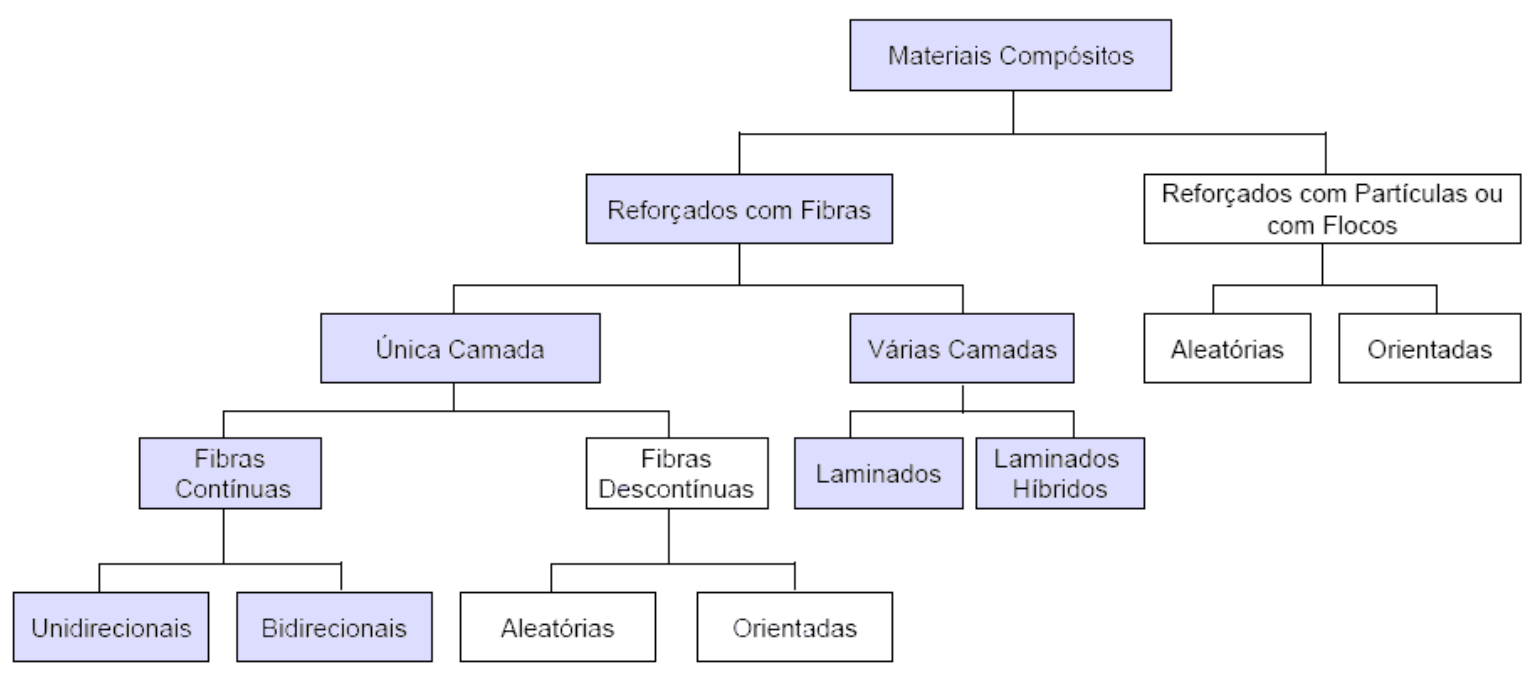

FIGURA 2.2 - Organograma de classificação dos materiais compósitos.

(Adaptado por MATTHEWS \& RAWLINGS, 1999).

O reforço fibroso caracteriza - se por seu comprimento ser muito maior do que a dimensão da sua seção transversal (diâmetro). Entretanto, esta relação do comprimento com o diâmetro, conhecida como razão de aspecto (aspect ratio), pode 
variar consideravelmente. A FIGURA (2.3) mostra, esquematicamente, alguns exemplos de compósitos reforçados por partículas e por fibras.

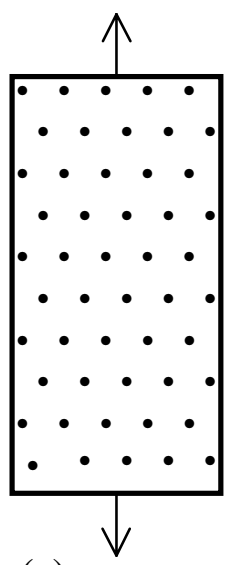

(a)

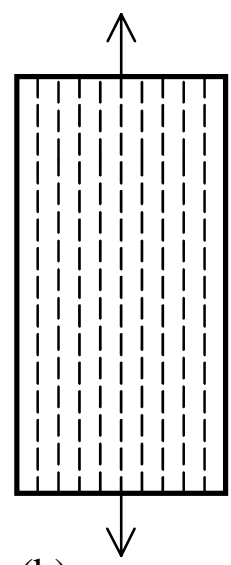

(b)

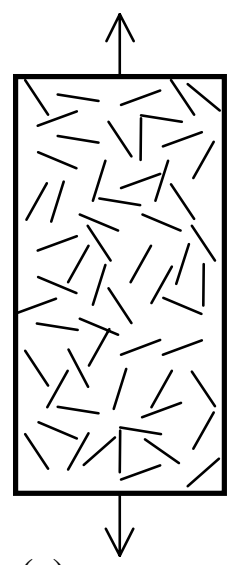

(c)

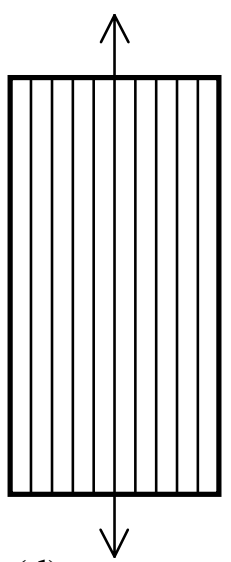

(d)

FIGURA 2.3 - Exemplos de compósitos reforçados: (a) por partículas aleatórias; (b) por fibras descontínuas unidirecionais; (c) por fibras descontínuas aleatórias; (d) por fibras contínuas unidirecionais (MATTHEWS \& RAWLINGS, 1994).

\subsubsection{Constituintes - Matrizes, Fibras, Resinas e Interface Fibra/Matriz}

Segundo (EDWARDS, 1998), além das considerações feitas normalmente quando se projeta com materiais de engenharia convencionais, o projetista que utiliza um compósito, tem que considerar também a seleção dos seus materiais constituintes, isto é, proporção, tipo, distribuição e orientação, dependendo das propriedades requeridas, seleção do processo, geometria do compósito e requisitos de produção. Deste modo, convém algum comentário relevante a respeito dos materiais constituintes e da interface entre eles. Porém, devido à grande variedade de matrizes e reforços, serão abordados especificamente, os compósitos de matrizes poliméricas reforçados por fibras contínuas. 


\section{a) Matrizes}

Segundo (FILHO, 2001), as matrizes podem ser materiais poliméricos, metálicos ou cerâmicos. O fator que determinará a escolha do material da matriz serão as propriedades físicas, mecânicas e térmicas exigidas do processo de fabricação e do custo estipulado do projeto.

(REINHART \& CLEMENTS, 1987) define que o papel da matriz é manter a integridade estrutural do compósito através da ligação simultânea com as fibras em virtude de suas características coesivas e adesivas. Além disso, tem a função de transferir o carregamento para as fibras e também protegê-las contra o ataque ambiental (como corrosão e abrasão) e danos devido ao manuseio. Por isso, segundo (CALLISTER, 1994), é essencial que as forças adesivas da interface fibramatriz sejam fortes. De fato, a resistência da adesão é uma importante consideração na escolha da combinação fibra - matriz.

De acordo com (FILHO, 2001) as matrizes mais utilizadas são as poliméricas devido ao baixo custo, fácil modelagem, boa resistência química e baixo peso específico, embora apresentem baixa resistência mecânica, baixo módulo de elasticidade e baixa temperatura de serviço comparadas às matrizes metálicas e cerâmicas. Outro fator negativo das matrizes poliméricas se dá através da degradação referente à exposição prolongada a luzes ultravioleta e alguns solventes. 


\section{b) Fibras}

Conforme a classificação de (MATTHEWS \& RAWLINGS, 1994) com relação aos reforços dos compósitos, as fibras apresentam - se em duas formas: fibras contínuas ou fibras descontínuas. Como componente estrutural, ambas têm a função de suportar os esforços provenientes da matriz, porém com características distintas que influenciam o desempenho mecânico dos compósitos.

Segundo (CALLISTER, 1994) as características mecânicas dos MCRF não dependem somente das propriedades das fibras, mas também da magnitude que o carregamento é transmitido para as fibras por meio da matriz. Este fenômeno de transferência de carregamento, mostrado nas FIGURAS (2.4a) e (2.4b), é função do comprimento da fibra e da adesão interfacial entre a fibra e matriz. Assim, para cada combinação fibra - matriz é necessário estabelecer um comprimento mínimo da fibra capaz de garantir efetivamente a rigidez e resistência do compósito.

Sobre esse contexto, (MATTHEWS \& RAWLINGS, 1994) definem o comprimento crítico da fibra $\left(l_{c}\right)$ como sendo o comprimento mínimo da fibra necessário para que um determinado diâmetro de fibra alcance a tensão de ruptura a tração da fibra em lugar de tensão de ruptura ao cisalhamento da interface, ou seja, o comprimento mínimo de fibra necessário para que a tensão transmitida alcance a tensão de ruptura a tração da fibra.

Então:

$$
l_{c}=\frac{\sigma_{c \cdot d}}{2 . \tau}
$$

na qual:

$l_{c}=$ comprimento crítico da fibra; 
$\sigma_{c}=$ resistência à tração na ruptura da fibra;

$\tau_{\text {I }}$ menor resistência ao cisalhamento da matriz ou da interface;

$d$ = diâmetro da fibra.

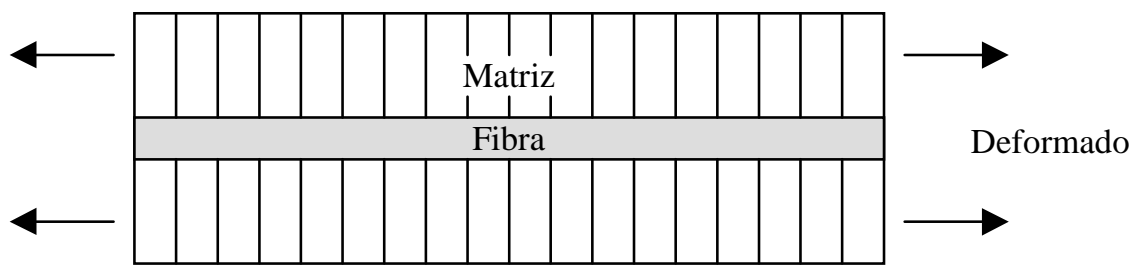

(a)

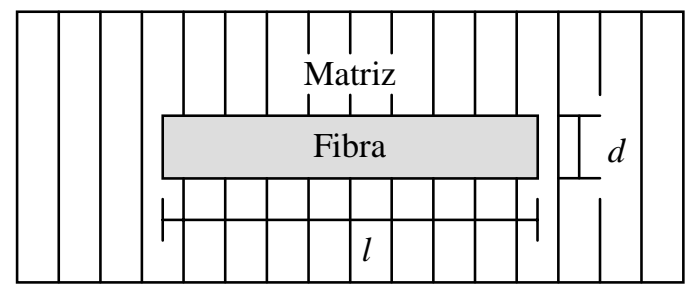

Não Deformado
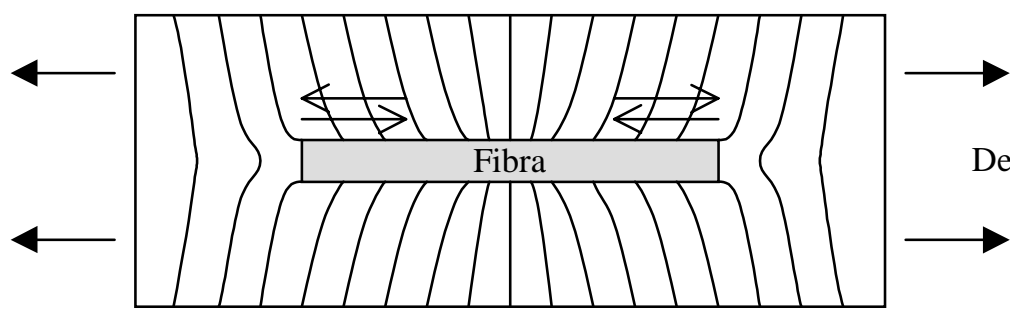

Deformado

(b)

FIGURA 2.4 - Efeito da deformação ao redor da fibra na matriz sob tensão: (a) fibra contínua; (b) Fibra descontínua. Fonte: (MATTHEWS \& RAWLINGS, 1994).

As fibras longas (contínuas) e de pequeno diâmetro são as mais adequadas para o reforço de estruturas em materiais compósitos pela ótima capacidade de transferência de carga e de aproveitamento de suas propriedades. 
Dois importantes fatores a ressaltar por (FILHO, 2001) além do comprimento das fibras são a orientação e a fração volumétrica. Estes fatores têm influência significativa sobre a resistência e outras propriedades dos MCRF. As propriedades mecânicas dos compósitos reforçados por fibras contínuas alinhadas são anisotrópicas. Na direção do alinhamento a eficiência do reforço e a resistência são máximas, enquanto que na direção perpendicular, são mínimos.

Para os compósitos reforçados por fibras descontínuas, as fibras podem ser orientadas preferencialmente ou aleatoriamente. Uma rigidez e resistência significativa são possíveis para os compósitos reforçados por fibras curtas alinhadas longitudinalmente. Apesar de algumas limitações com respeito à eficiência do reforço, as propriedades dos compósitos reforçados por fibras curtas orientadas aleatoriamente são isotrópicas (CALLISTER, 1994).

\section{c) Resinas}

Os polímeros segundo (FILHO, 2001) utilizados como materiais de matrizes são comumente chamados de resinas. A matriz é o "elo fraco" do compósito, especialmente, porque não existem atualmente resinas que permitam a utilização das tensões que as fibras são capazes de resistir.

De acordo com (FILHO, 2001) um ambiente químico agressivo, a umidade do ambiente, ou a exposição a outras condições adversas podem diminuir bastante o desempenho da matriz antes da fibra ser danificada. Entretanto, as resinas exercem muitas funções essenciais, além daquelas mencionadas no parágrafo acima, elas mantêm as fibras na posição e orientação adequada de modo que possam suportar as cargas desejadas, distribuem as cargas quase uniformemente entre as fibras, 
servem como uma barreira à propagação de trincas e garantem toda a resistência ao cisalhamento interlaminar do compósito. Um importante fator, observado por (HYER, 1998), é que a limitação de um compósito pode ser perfeitamente uma função das propriedades da matriz. Como exemplo, a estabilidade térmica e a temperatura máxima de serviço do compósito são amplamente determinadas pelas propriedades da matriz.

As matrizes poliméricas podem ser classificadas como resinas termoplásticas e termofixas. (SHACKELFORD, 1996) mostra que a principal diferença entre os polímeros termoplásticos e os termofixos está no comportamento quando aquecidos, ou seja, os termoplásticos se fundem e se transformam em um líquido viscoso capaz de sofrer processos de extrusão, enquanto os termofixos, ao invés de sofrerem processo de fusão, começam a se decompor termicamente.

Conforme (FILHO, 2001) as resinas termofixas passam por uma reação química irreversível durante a polimerização, conhecido como processo de cura. Durante o processo de cura são formadas ligações cruzadas covalentes entre as cadeias moleculares adjacentes, desenvolvendo uma estrutura tridimensional. Essas ligações cruzadas, à medida que se formam, causam diminuição da mobilidade das cadeias moleculares, provocando solidificação. Quando a reação química é exotérmica, a temperatura irá influenciar no tempo de cura. Portanto, o processo de cura pode ser acelerado pela aplicação de calor e pressão em condições controladas, por meio de autoclaves. Ou ainda, pela adição de um catalisador adequado, conhecido como agente de cura (hardener), na proporção certa para cada tipo de resina. Quando se solidificam, assim permanecem e mesmo reaquecidas, não se refundem. Sob aquecimento a temperaturas elevadas, haverá combustão do material. Deste modo, não podem ser reutilizadas. 
Segundo (TITA, 1999), as resinas termofixas são mais comuns para o uso estrutural em materiais compósitos, devido ao enorme número de aplicações e características finais mais desejáveis como menor custo comparado às resinas termoplásticas. (SMITH, 1993) descreve as vantagens dos polímeros termofixos para uso na engenharia como:

- Alta estabilidade térmica;

- Alta rigidez;

- Alta estabilidade dimensional;

- Resistência à fluência e a deformação sob carregamento;

- Baixo peso específico;

- Boas propriedades de isolamento térmico e elétrico.

Segundo (JUSTULIN, 2008) dentre as resinas mais utilizadas temos as resinas epóxi, devido à extensa gama de propriedades físicas e mecânicas do material. Para manipular esse tipo de resina é preciso respeitar alguns detalhes de processos tais como: o período em que a resina mantém suas características de aderência e pode ser manipulada sem dificuldade é conhecido como tempo de utilização (potlife). Quanto maior a temperatura e quantidade de material a ser preparado, menor o tempo de utilização. Isto ocorre em função da maior quantidade de calor e conseqüente aceleração das reações. Outro processo é o tempo de endurecimento, necessário para que a resina adquira o estado sólido. É o intervalo no qual o compósito deve ser colado para que suas propriedades se desenvolvam satisfatoriamente. Este tempo é influenciado pelas temperaturas do ambiente, do compósito e da superfície a ser reforçada. 
Para aumentar a resistência da matriz e facilitar a fabricação do compósito, vários tipos de aditivos podem ser usados. Os mais comuns são os inibidores da ação de raios ultravioleta, os antioxidantes, os catalisadores e os desmoldantes.

\section{d) Interface Fibra-Matriz}

Segundo (FILHO, 2001) a interface entre fibra e matriz é o "coração" dos materiais compósitos. A estrutura e as propriedades da interface fibra-matriz são igualmente responsáveis pelo desempenho mecânico e pela integridade estrutural dos compósitos reforçados por fibra, uma vez que as tensões atuantes na matriz são transmitidas para as fibras através da interface, (HULL, 1981). Algumas hipóteses normalmente aceitas, mas que nem sempre são verdadeiras na prática, são:

- A matriz e a fibra se comportam como materiais elásticos;

- A interface é infinitamente delgada;

- A interação fibra-matriz é perfeita de forma que não ocorra descontinuidade de deformação ao longo da interface;

- A interface que se forma ao redor da fibra tem as mesmas propriedades que um material no estado sólido.

\subsubsection{Vantagens, desvantagens e aplicações}

Conforme (NOTON, 1987) quando se comparam os compósitos com os materiais estruturais convencionais, na fase de seleção dos materiais no desenvolvimento do projeto, é essencial comparar as vantagens das tecnologias dos compósitos com as tecnologias dos materiais estruturais convencionais, isto é, 
processos de fabricação e configurações de projeto. Sob este ponto de vista, ao escolhermos um material para aplicação estrutural, diversas variáveis devem ser consideradas, porém, as mais importantes são o custo e a eficiência estrutural. Por outro lado, a eficiência estrutural do material é a relação entre sua rigidez ou sua resistência com seu peso específico, ou seja, $E / \rho$ e $\sigma / \rho$, respectivamente. Em geral, quanto menor o peso específico do material, maior é sua eficiência estrutural e seu custo e vice - versa. Assim, ao optar pelo uso de um material com custos ainda elevados, como por exemplo os compósitos, deve - se considerar que a eficiência estrutural necessária para uma determinada condição de serviço, compensa seus custos.

De acordo com (NOTON, 1987), as aplicações dos diferentes processos de manufatura e o alto desempenho dos compósitos estruturais reforçados por fibras são provas de suas vantagens sobre os materiais estruturais convencionais. Porém, em alguns casos, estas vantagens não são obtidas por um único tipo de fibra como reforço. Uma combinação com diferentes tipos de fibras (compósitos híbridos) é necessária para conseguir as propriedades de projeto exigidas.

De modo geral, as outras vantagens dos compósitos são:

- Em virtude do seu aspecto multifuncional, os compósitos são capazes de satisfazer diversas exigências de projeto;

- A economia de peso é significativa, freqüentemente, varia de 25 a $50 \% \mathrm{em}$ relação aos materiais metálicos convencionais;

- A alta rigidez à torção exigida em vários veículos, principalmente, em aviões, pode ser satisfeita;

- A resistência à corrosão é excelente;

- Numerosas qualidades de fadiga e fratura; 
- As características de tolerância ao impacto e ao dano são excelentes;

- Flexibilidade de seleção e mudança no estilo e considerações estéticas do produto são características importantes. As freqüentes modificações no estilo, em resposta à mudança de necessidade do cliente, podem ser feitas com baixos investimentos;

- Uma baixa expansão térmica pode ser obtida, mas varia significativamente com a escolha do material da matriz, com o tipo de fibra empregada e com sua orientação;

- A manufatura e montagem são simplificadas por causa da integração dos componentes, reduzindo as uniões e os dispositivos de união.

Embora as atuais aplicações dos compósitos reforçados por fibras de alto desempenho em produtos e sistemas de engenharia complexos chamem a atenção, alguns fatores podem retardar a aceitação destes materiais. Entre estes fatores podem ser incluídos:

- O custo do material é um inibidor para algumas aplicações de produção em grande escala;

- Alguns processos de manufatura são complexos e de alto custo;

- Conhecimento insuficiente sobre as reais condições do comportamento mecânico em serviço, principalmente, sobre a reposta às solicitações de impacto e fadiga, refletindo diretamente na confiabilidade dos componentes fabricados;

- Precauções especiais são muitas vezes necessárias para prevenir ocorrências que causam rejeição da peça. 
- Os regulamentos das agências de proteção ambiental e administração da saúde e segurança do trabalho, relacionados aos constituintes químicos, são fatores de preocupação por parte dos executivos industriais. Atualmente, o mercado exige certificações, como a ISO 14000. Consequentemente, a empresa que não seguir as determinações, eliminando os resíduos de forma ecologicamente correta, acabará sendo excluída desse mercado.

Com relação às desvantagens apresentadas pelos materiais compósitos reforçados em relação aos custos de produção e manufatura, estes tendem a diminuir com o avanço tecnológico. Além do mais, o desenvolvimento de modelos matemáticos mais precisos para o estudo da resposta do material quando solicitados em condições adversas, podem oferecer uma importante contribuição para ampliar as possibilidades de aplicações estruturais dos compósitos.

Segundo (REZENDE \& BOTELHO, 2000), após décadas de uso restrito em alguns setores da indústria, devido ao seu custo de obtenção, os compósitos poliméricos estruturais, também denominados avançados, têm ampliado a sua utilização em diferentes setores da indústria moderna. Atualmente, a utilização de estruturas de alto desempenho e com baixo peso tem sido feita nas indústrias automotiva, esportiva, biomédica e de construção civil.

\subsubsection{Cálculo das Propriedades Elásticas de um Laminado}

Segundo (AGARWAL \& BROUTMAN, 1990), uma característica marcante dos compósitos é que eles têm suas propriedades fortemente influenciadas pela distribuição, interação e propriedades dos seus constituintes. Muitas propriedades dos compósitos podem ser estimadas por meio da fração volumétrica $(v)$ de seus 
constituintes, ou por meio da fração em massa $(w)$, como demonstram (MATTHEWS \& RAWLINGS, 1994). Do ponto de vista experimental, uma medida das frações em massa é mais fácil obter do que as frações volumétricas correspondentes dos elementos constituintes. Existe porém, uma conexão analítica entre estes fatores de proporção que permitem a conversão da fração em massa para fração volumétrica e vice-versa. Considerando que a fração volumétrica é uma palavra - chave para cálculos de propriedades elásticas, esta conexão se torna importante. As expressões necessárias para este desenvolvimento são:

\begin{tabular}{cl}
\hline Fração Volumétrica & Fração em Massa \\
\hline$v_{f}=\frac{V_{f}}{V_{c}}$ & $w_{f}=\frac{W_{f}}{W_{c}}$ \\
$v_{m}=\frac{V_{m}}{V_{c}}$ & $w_{m}=\frac{W_{m}}{W_{c}}$
\end{tabular}

Nas quais os subscritos $m, f$ e $c$ referem-se à matriz, à fibra e ao compósito respectivamente, $V$ ao volume e $W$ à massa.

Nota - se que:

$v_{f}+v_{m}=1 \quad$ e $\quad w_{f}+w_{m}=1$

Relaciona-se a fração em massa com a fração volumétrica pela introdução da densidade, $\rho$, do compósito e dos seus constituintes. Agora

$W_{c}=W_{f}+W_{m}$ 
como, $W=\rho \cdot V$, torna-se

$\rho_{c} V_{c}=\rho_{f} V_{f}+\rho_{m} V_{m}$

a eq. (3) pode ser reescrita em termos da fração volumétrica dividindo os dois lados da equação por $V_{c}$. Então,

$\rho_{c}=\rho_{f} v_{f}+\rho_{m} v_{m}$

e também pode ser expressa em termos das massas dos constituintes. Então,

$\frac{W_{c}}{\rho_{c}}=\frac{W_{f}}{\rho_{f}}+\frac{W_{m}}{\rho_{m}}$

e dividindo seus termos por $W_{c}$, obtém-se

$\frac{1}{\rho_{c}}=\frac{w_{f}}{\rho_{f}}+\frac{w_{m}}{\rho_{m}}$

Agora, relacionando a massa, o volume e a densidade, tem-se

$w_{f}=\frac{W_{f}}{W_{c}}=\frac{\left(\rho_{f} V_{f}\right)}{\left(\rho_{c} V_{c}\right)}=\frac{\rho_{f}}{\rho_{c}} v_{f}$ 
e similarmente

$$
W_{m}=\frac{W_{m}}{W_{c}}=\frac{\left(\rho_{m} V_{m}\right)}{\left(\rho_{c} V_{c}\right)}=\frac{\rho_{m}}{\rho_{c}} v_{m}
$$

A relação para $v_{f}$ e $v_{m}$ em termos de $w_{f}$ e $w_{m}$ pode ser obtida facilmente pela inversão da eq.(6) e eq.(7), desde que a densidade do reforço $\left(\rho_{f}\right)$ e da matriz $\left(\rho_{m}\right)$ seja conhecida. Segundo (VINSON \& SIERAKOWSKI, 1987), a conversão entre a fração em massa e fração volumétrica da fibra ou matriz pode ser expressa analiticamente em termos das seguintes equações

$$
\begin{gathered}
w_{f}=\frac{\left(\rho_{f} / \rho_{m}\right)}{\left(\rho_{f} / \rho_{m}\right) \cdot v_{f}+v_{m}} \cdot v_{f} \\
w_{m}=\frac{v_{m}}{\rho_{f} / \rho_{m} \cdot\left(1-v_{m}\right)+v_{m}}
\end{gathered}
$$

Que são combinações das eqs. (4) e (6) e eqs. (4) e (7), respectivamente. A eq.(4) mostra que a densidade do compósito é dada pela soma das densidades dos constituintes, ponderadas pelas proporções que eles aparecem. Esta equação não é aplicável somente para a densidade, mas se aplica, em certas situações, para outras propriedades dos compósitos. A forma geral da equação é

$$
X_{c}=X_{m} v_{m}+X_{f} v_{f}
$$


Na qual $X_{c}$ representa uma certa propriedade do compósito, $v$ é a fração volumétrica e os subscritos $m$ e $f$ referem-se à matriz e à fibra respectivamente.

Uma aplicação bastante utilizada para a equação acima consiste na determinação do módulo de elasticidade e de cisalhamento para o compósito, utilizados assim para o cálculo de tensões e deformações no laminado. Para a análise de tensões, considera-se que a tração ou compressão aplicada paralelamente à fibra fornece as mesmas deformações para a matriz e para a fibra. Se a adesão entre as duas fases é perfeita então as tensões são dadas por:

$$
\begin{gathered}
\sigma_{\mathrm{f}}=\varepsilon_{1} \cdot \mathrm{E}_{\mathrm{f}} \\
\sigma_{\mathrm{m}}=\varepsilon_{1} \cdot \mathrm{E}_{\mathrm{m}}
\end{gathered}
$$

onde:

$\sigma_{\mathrm{m}}=$ Tensão aplicada na matriz

$\sigma_{\mathrm{f}}=$ Tensão aplicada na fibra

$\varepsilon_{1}=$ Deformação relativa na direção principal 1(longitudinal à fibra)

$\mathrm{E}_{\mathrm{f}}=$ Módulo de Elasticidade da fibra

$\mathrm{E}_{\mathrm{m}}=$ Módulo de Elasticidade da matriz

Considera-se que a direção 1 esta alinhada com a fibra, a direção 2 é perpendicular a fibra e pertence ao plano do laminado. E para finalizar, a direção 3 é perpendicular ao plano do laminado.

Sabe-se que $E_{f}>E_{m}$, então a tensão na fibra é maior que na matriz. $A$ tensão média é dada por: 


$$
\mathrm{P}=\sigma_{1} \cdot \mathrm{A}
$$

Na qual:

$\mathrm{P}=$ Força aplicada

$\sigma_{1}=$ Tensão aplicada na direção principal (1)

$A=$ Área da secção transversal

Tem-se que:

$$
\mathrm{P}=\mathrm{P}_{\mathrm{f}}+\mathrm{P}_{\mathrm{m}}
$$

Na qual:

$P_{f}=$ Força aplicada na fibra

$\mathrm{P}_{\mathrm{m}}=$ Força aplicada na matriz

Sendo assim:

$$
\begin{aligned}
& \mathrm{P}_{\mathrm{f}}=\sigma_{\mathrm{f}} \cdot \mathrm{A}_{\mathrm{f}} \\
& \mathrm{P}_{\mathrm{m}}=\sigma_{\mathrm{m}} \cdot \mathrm{A}_{\mathrm{m}}
\end{aligned}
$$

Então:

$$
\mathrm{P}=\sigma_{\mathrm{f}} \cdot \mathrm{A}_{\mathrm{f}}+\sigma_{\mathrm{m}} \cdot \mathrm{A}_{\mathrm{m}}
$$

onde:

$A_{f}=$ Área da seção transversal da fibra

$A_{m}=$ Área da seção transversal da matriz

Dada as relações:

$$
\begin{aligned}
& \sigma_{1}=\varepsilon_{1} \cdot \mathrm{E}_{1} \\
& \mathrm{~V}_{\mathrm{i}}=\frac{\mathrm{A}_{\mathrm{i}}}{\mathrm{A}}, \mathrm{i}=\mathrm{m} \text { ou } \mathrm{f}
\end{aligned}
$$

sendo:

$V_{i}=$ Fração volumétrica de fibra ou matriz 
Substituindo as equações (11 e 12) e as relações acima na equação (17) temse que:

$$
E_{11}=E_{f} \cdot V_{f}+E_{m} \cdot V_{m}
$$

Como,

$$
\mathrm{V}_{\mathrm{f}}+\mathrm{V}_{\mathrm{m}}=1
$$

Então,

$$
E_{11}=E_{f} \cdot V_{f}+E_{m} \cdot\left(1-V_{f}\right)
$$

sendo:

$$
E_{11}=\text { Módulo de Elasticidade do compósito na direção principal }
$$

Se o mesmo raciocínio for usado para solicitações perpendiculares à fibra, obtém-se de modo análogo a seguinte equação:

$$
E_{22}=\frac{E_{f} \cdot E_{m}}{E_{f} \cdot\left(1-V_{f}\right)+E_{m} \cdot V_{f}}
$$

sendo:

$$
\mathrm{E}_{22}=\text { Módulo de Elasticidade do compósito na direção principal } 2
$$
(perpendicular à fibra)

Para a determinação dos módulos de cisalhamento $\left(G_{12}\right.$ e $\left.G_{23}\right)$, VINSON \& SIERAKOWSKI (1987) apud HAHN (1980) estabelecendo uma relação similar às referenciadas acima. Sua relação constitui-se da seguinte forma: 


$$
\mathrm{P}=\frac{\left(\mathrm{P}_{\mathrm{f}} \mathrm{V}_{\mathrm{f}}+\eta \mathrm{P}_{\mathrm{m}} \mathrm{V}_{\mathrm{m}}\right)}{\left(\mathrm{V}_{\mathrm{f}}+\eta \mathrm{V}_{\mathrm{m}}\right)}
$$

Para o plano 1-2 tem-se:

$$
\eta=\frac{1+\frac{\mathrm{G}_{\mathrm{m}}}{\mathrm{G}_{12 \mathrm{f}}}}{2}
$$

$P=1 / G 12$ (inverso do módulo de cisalhamento do composto no plano 1-2)

$P f=1 / G 12 f$ (inverso do módulo de cisalhamento da fibra)

$\mathrm{Pm}=1 / \mathrm{Gm}$ (inverso do módulo de cisalhamento da matriz) dado por $\mathrm{G}_{\mathrm{m}}=\frac{\mathrm{E}_{\mathrm{m}}}{2 \cdot\left(1+v_{\mathrm{m}}\right)}$ caso a matriz seja isotrópica e $v_{\mathrm{m}}$ seja o coeficiente de Poisson da matriz.

Para o plano 2-3 tem-se:

$$
\eta=\frac{3-4 v_{m}+\frac{G_{m}}{G_{23 f}}}{4 .\left(1-v_{m}\right)}
$$

$P=1 / G_{23}$ (inverso do módulo de cisalhamento do composto no plano 2-3)

$P_{f}=1 / G_{23 f}$ (inverso do módulo de cisalhamento da fibra)

$P_{m}=1 / G_{m}$ (inverso do módulo de cisalhamento da matriz) dado por $\mathrm{G}_{\mathrm{m}}=\frac{\mathrm{E}_{\mathrm{m}}}{2 .\left(1+v_{\mathrm{m}}\right)}$ caso a matriz seja isotrópica e $v_{\mathrm{m}}$ seja o coeficiente de Poisson da matriz. 
Com base ainda na equação (2.1.3-14) é possível determinar o coeficiente de Poisson do compósito na direção paralela à fibra $\left(v_{12}\right)$, basta adotar:

$$
\begin{aligned}
& \eta=1 \\
& P=v_{12} \text { (coeficiente de Poisson determinado na direção paralela a fibra) } \\
& \mathrm{P}_{\mathrm{f}}=v_{12 \mathrm{f}} \text { (coeficiente de Poisson da fibra determinado ao longo da fibra) } \\
& \mathrm{P}_{\mathrm{m}}=v_{\mathrm{m}} \text { (coeficiente de Poisson da matriz) }
\end{aligned}
$$

Tais equações desenvolvidas anteriormente são chamadas de Regra das Misturas (Rule of Mixtures). Elas não são válidas para os casos em que a fibra e a matriz apresentam coeficientes de Poisson diferentes, entretanto esse erro não ultrapassa a faixa de $2 \%$. Portanto, torna-se viável determinar as propriedades elásticas de uma lâmina unidirecional através das propriedades da fibra e da matriz bem como das suas respectivas porcentagens na formação do compósito. Vale ressaltar aqui que essas propriedades sofrem variações

\subsubsection{Definição e Aplicação da Teoria Clássica dos Laminados (TCL)}

O modelo Macromecânico geralmente aceito para análise do laminado é a Teoria Clássica de Laminados (TCL). Visto que, um laminado é constituído de várias lâminas empilhadas, a descrição do comportamento mecânico de uma única lâmina forma a base com a qual o comportamento mecânico do laminado é descrito, podendo-se assim obter uma formulação matemática que quantifique a rigidez estrutural do laminado. 
Considerando uma lâmina de material compósito com as fibras alinhadas paralelamente à direção 1, como mostrado na FIGURA (2.5), é prática comum no estudo de compósitos utilizar uma notação reduzida para a tensão e a deformação.

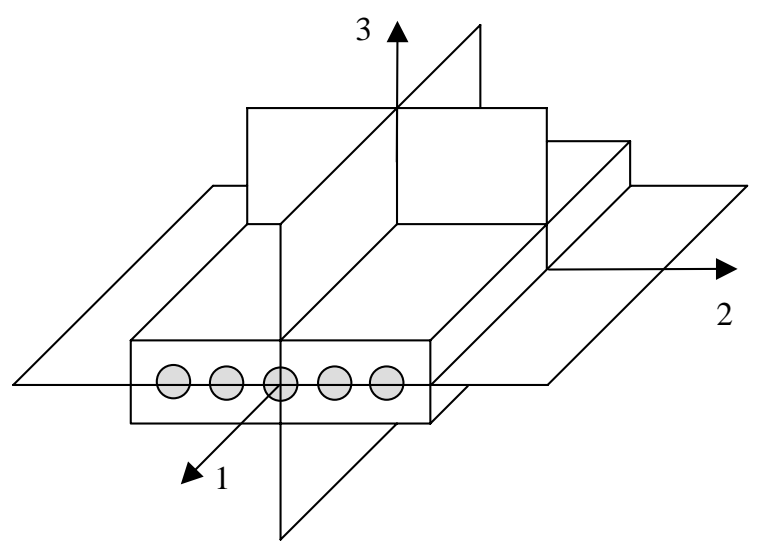

FIGURA 2.5 - Planos de simetria ortogonais de uma lâmina.

Assim, define - se as tensões e as deformações planas em termos das componentes do tensor das tensões e das deformações, respectivamente, como segue:

$\sigma=\left\{\begin{array}{l}\sigma_{1} \\ \sigma_{2} \\ \sigma_{6}\end{array}\right\}$

$\varepsilon=\left\{\begin{array}{l}\varepsilon_{1} \\ \varepsilon_{2} \\ \varepsilon_{6}\end{array}\right\}$

nas quais $\sigma_{1}$ e $\sigma_{2}$ são as tensões nas direções dos eixos principais e $\sigma_{6}$ é a tensão de cisalhamento, e $\varepsilon_{1}, \varepsilon_{2}$ e $\varepsilon_{6}$ são as deformações correspondentes. 
As camadas individuais (lâmina) de um laminado são consideradas meios contínuos, homogêneos, elásticos e ortotrópicos com a equação constitutiva do material no sistema de coordenadas principal da forma:

$$
\left\{\begin{array}{l}
\varepsilon_{1} \\
\varepsilon_{2} \\
\varepsilon_{6}
\end{array}\right\}=\left[\begin{array}{ccc}
S_{11} & S_{12} & 0 \\
S_{12} & S_{22} & 0 \\
0 & 0 & S_{66}
\end{array}\right]\left\{\begin{array}{c}
\sigma_{1} \\
\sigma_{2} \\
\sigma_{6}
\end{array}\right\}
$$

na qual [S] é a matriz de flexibilidade reduzida da lâmina. O termo reduzida é utilizado na relação da eq.(2) devido à hipótese do estado plano de tensões. A eq.(2) pode ser invertida e escrita como:

$$
\left\{\begin{array}{c}
\sigma_{1} \\
\sigma_{2} \\
\sigma_{6}
\end{array}\right\}=\left[\begin{array}{ccc}
Q_{11} & Q_{12} & 0 \\
Q_{12} & Q_{22} & 0 \\
0 & 0 & Q_{66}
\end{array}\right]\left\{\begin{array}{c}
\varepsilon_{1} \\
\varepsilon_{2} \\
\varepsilon_{6}
\end{array}\right\}
$$

na qual $[\mathrm{Q}]=[\mathrm{S}]^{-1}$ é a matriz de rigidez reduzida para o estado plano de tensões. Os termos individuais da matriz de flexibilidade reduzida [S] podem ser expressos em termos das constantes de engenharia $E_{1}, E_{2}, v_{12} e G_{12}$ como:

$$
S_{11}=\frac{1}{E_{1}} \quad S_{12}=S_{21}=\frac{-v_{12}}{E_{1}} \quad S_{22}=\frac{1}{E_{2}} \quad S_{66}=\frac{1}{G_{12}}
$$


na qual $E_{1}$ e $E_{2}$ são os módulos de elasticidade na direção da fibra e na direção transversal à mesma, respectivamente; $v_{12}$ é o coeficiente de Poisson associado ao carregamento na direção 1, isto é:

$$
v_{12}=-\frac{\varepsilon_{2}}{\varepsilon_{1}}
$$

e $G_{12}$ é o módulo de cisalhamento no plano 1-2. A simetria da matriz de flexibilidade reduzida requer que:

$$
E_{1} v_{21}=E_{2} v_{12}
$$

na qual $v_{21}$ é o coeficiente de Poisson associado ao carregamento na direção 2. As componentes de [Q] podem ser expressas em termos das constantes de engenharia por meio de substituições apropriadas.

As matrizes de flexibilidade [S] e rigidez [Q] reduzidas relacionam as tensões e as deformações nas direções dos eixos principais da lâmina $(1,2)$. Normalmente, os eixos principais da lâmina não coincidem com os eixos de referência do laminado (x, y). Quando isto ocorre, as relações constitutivas de cada lâmina individual devem ser transformadas para os eixos de referência do laminado para que determinem as relações constitutivas do laminado. Na FIGURA (2.6), dois sistemas de coordenadas são mostrados. 


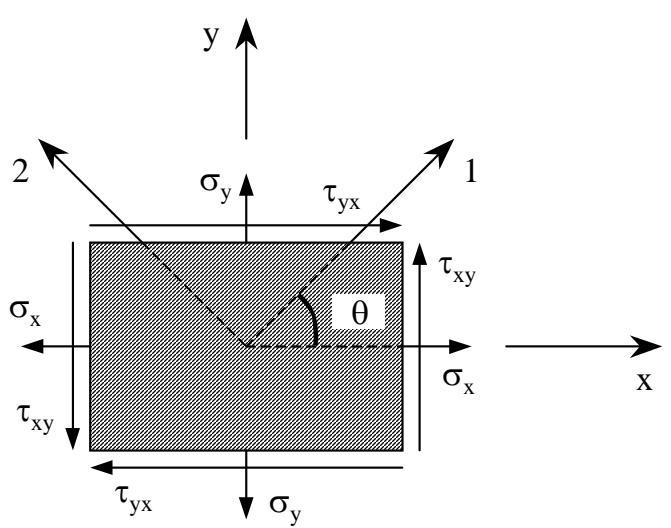

FIGURA 2.6 - O sistema de coordenadas 1-2 refere-se à lâmina e o sistema x-y ao laminado.

As coordenadas 1-2 correspondem aos eixos principais da lâmina, enquanto as coordenadas $x-y$ são arbitrárias e relacionam-se com as coordenadas 1-2 através da rotação em torno do eixo z. O ângulo $\theta$ é definido como a rotação do sistema arbitrário do laminado x-y para o sistema da lâmina 1-2 ( $\theta$ é positivo para uma rotação no sentido anti-horário).

A transformação das relações tensão-deformação do sistema 1-2 para o sistema $x$ y é:

$$
\left\{\begin{array}{c}
\sigma_{x} \\
\sigma_{y} \\
\tau_{x y}
\end{array}\right\}=\left[\begin{array}{lll}
\bar{Q}_{11} & \bar{Q}_{12} & \bar{Q}_{16} \\
\overline{Q_{12}} & \bar{Q}_{22} & \bar{Q}_{26} \\
\bar{Q}_{16} & \bar{Q}_{26} & \bar{Q}_{66}
\end{array}\right]\left\{\begin{array}{c}
\varepsilon_{x} \\
\varepsilon_{y} \\
\gamma_{x y}
\end{array}\right\}
$$

na qual a matriz $[\bar{Q}$ ] é denominada de matriz de rigidez reduzida transformada e é obtida por: 
$[\bar{Q}]=[T]^{-1}[Q][T]^{-T}$

[T] na eq.(8) é a matriz de transformação de coordenadas, ou seja:

$$
[T]=\left[\begin{array}{ccc}
\cos ^{2} \theta & \operatorname{sen}^{2} \theta & 2 \operatorname{sen} \theta \cos \theta \\
\operatorname{sen}^{2} \theta & \cos ^{2} \theta & -2 \operatorname{sen} \theta \cos \theta \\
-\operatorname{sen} \theta \cos \theta & \operatorname{sen} \theta \cos \theta & \cos ^{2} \theta-\operatorname{sen}^{2} \theta
\end{array}\right]
$$

nas quais $[\mathrm{T}]^{-1}$ e $[\mathrm{T}]^{-\mathrm{T}}$ são a inversa e a transposta da inversa da matriz de transformação de coordenadas, respectivamente. A relação inversa da eq.(7) em termos de $[\bar{S}]$ apresenta o mesmo aspecto geral. Observa-se que a orientação da fibra influencia nas propriedades elásticas e consequentemente na matriz de rigidez da lâmina, onde se obtém a mais alta rigidez quando o carregamento estiver na mesma direção de orientação da fibra. Caso contrário, com a defasagem angular entre o carregamento e a orientação da fibra, o valor da matriz de rigidez diminui, chegando a um valor mínimo quando o carregamento for perpendicular à orientação da mesma. Até agora, foram desenvolvidas as ferramentas necessárias para compreender a resposta elástica de uma lâmina individual. Sabendo-se que um compósito laminado é formado pelo empilhamento sistemático de várias lâminas, cada lâmina assume as hipóteses já discutidas e o laminado é analisado por meio da Teoria Clássica de Laminados.

Da mesma forma, algumas hipóteses associadas à TCL são consideradas: 
- Cada lâmina é considerada homogênea, ortotrópica e seus materiais constituintes têm comportamento elástico;

- Cada lâmina é analisada no estado plano de tensões;

- O deslocamento de cada lâmina segue uma regra restritiva de acordo com a hipótese de Kirchhoff;

- Cada lâmina está perfeitamente unida à lâmina adjacente, assegurando a continuidade de deslocamentos.

Das hipóteses da TCL segue-se que as distribuições das deformações nas direções $x$ e y variam linearmente através da espessura do laminado. Em termos das componentes de deformação no plano médio do laminado $\left\{\varepsilon^{\circ}\right\}$ e das componentes de rotação de corpo rígido medidas em relação ao plano médio do laminado $\left\{k^{\circ}\right\}$, as deformações podem ser expressas como:

$$
\left\{\begin{array}{c}
\varepsilon_{x} \\
\varepsilon_{y} \\
\gamma_{x y}
\end{array}\right\}=\left\{\begin{array}{c}
\varepsilon_{x}^{o} \\
\varepsilon_{y}^{o} \\
\gamma_{x y}^{o}
\end{array}\right\}+z \cdot\left\{\begin{array}{c}
k_{x}^{o} \\
k_{y}^{o} \\
k_{x y}^{o}
\end{array}\right\}
$$

As tensões para uma localização específica $z_{K}$, na qual o subscrito $K$ denota a $K$ - ésima lâmina do laminado são obtidas das equações constitutivas (eq.7) e a deformação provém da hipótese de Kirchhoff, obtendo-se: 


$$
\left\{\begin{array}{c}
\sigma_{x} \\
\sigma_{y} \\
\tau_{x y}
\end{array}\right\}_{K}=\left[\begin{array}{lll}
\bar{Q}_{11} & \bar{Q}_{12} & \bar{Q}_{16} \\
\overline{Q_{12}} & \bar{Q}_{22} & \bar{Q}_{26} \\
\overline{Q_{16}} & \bar{Q}_{26} & \bar{Q}_{66}
\end{array}\right]_{K}\left(\left\{\begin{array}{c}
\varepsilon_{x}^{o} \\
\varepsilon_{y}^{o} \\
\gamma_{x y}^{o}
\end{array}\right\}+z\left\{\begin{array}{c}
k_{x}^{o} \\
k_{y}^{o} \\
k_{x y}^{o}
\end{array}\right\}\right)_{K}
$$

De um modo geral, a distribuição da tensão ao longo da espessura do laminado não é linear e as tensões são descontínuas na interface entre as lâminas. Visto que as tensões no compósito laminado variam de lâmina para lâmina, é conveniente definir as forças (esforços) normais $\{N\}$ e os momentos fletores $\{M\}$ que atuam, por unidade de comprimento, através da espessura $H$ do laminado, como:

$$
\left\{\begin{array}{c}
N_{x} \\
N_{y} \\
N_{x y}
\end{array}\right\}=\int_{\frac{-H}{2}}^{\frac{H}{2}}\left\{\begin{array}{c}
\sigma_{x} \\
\sigma_{y} \\
\tau_{x y}
\end{array}\right\} d z \quad\left\{\begin{array}{l}
M_{x} \\
M_{y} \\
M_{x y}
\end{array}\right\}=\int_{\frac{-H}{2}}^{\frac{H}{2}}\left\{\begin{array}{l}
\sigma_{x} \\
\sigma_{y} \\
\tau_{x y}
\end{array}\right\}_{K} z d z
$$

Da integração das eqs. (12) provêem as equações fundamentais da Teoria Clássica de laminados:

$$
\left\{\begin{array}{l}
N_{x} \\
N_{y} \\
N_{x y}
\end{array}\right\}=\left[\begin{array}{ccc}
A_{11} & A_{12} & A_{16} \\
A_{12} & A_{22} & A_{26} \\
A_{16} & A_{26} & A_{66}
\end{array}\right]\left\{\begin{array}{c}
\varepsilon_{x}^{o} \\
\varepsilon_{y}^{o} \\
\gamma_{x y}^{o}
\end{array}\right\}+\left[\begin{array}{lll}
B_{11} & B_{12} & B_{16} \\
B_{12} & B_{22} & B_{26} \\
B_{16} & B_{26} & B_{66}
\end{array}\right]\left\{\begin{array}{c}
k_{x}^{o} \\
k_{y}^{o} \\
k_{x y}^{o}
\end{array}\right\}
$$

$$
\left\{\begin{array}{l}
M_{x} \\
M_{y} \\
M_{x y}
\end{array}\right\}=\left[\begin{array}{lll}
B_{11} & B_{12} & B_{16} \\
B_{12} & B_{22} & B_{26} \\
B_{16} & B_{26} & B_{66}
\end{array}\right]\left\{\begin{array}{c}
\varepsilon_{x}^{o} \\
\varepsilon_{y}^{o} \\
\gamma_{x y}^{o}
\end{array}\right\}+\left[\begin{array}{lll}
D_{11} & D_{12} & D_{16} \\
D_{12} & D_{22} & D_{26} \\
D_{16} & D_{26} & D_{66}
\end{array}\right]\left\{\begin{array}{c}
k_{x}^{o} \\
k_{y}^{o} \\
k_{x y}^{o}
\end{array}\right\}
$$


nas quais as matrizes $A_{i j}, B_{i j}$ e $D_{i j}$ são definidas para um laminado com $n$ lâminas, como:

$$
\begin{aligned}
& A_{i j}=\sum_{K=1}^{n}\left(\bar{Q}_{i j}\right)_{K}\left(z_{K}-z_{K-1}\right) \\
& B_{i j}=\frac{1}{2} \sum_{K=1}^{n}\left(\bar{Q}_{i j}\right)_{K}\left(z_{K}^{2}-z_{K-1}^{2}\right) \\
& D_{i j}=\frac{1}{3} \sum_{K=1}^{n}\left(\bar{Q}_{i j}\right)_{K}\left(z_{K}^{3}-z_{K-1}^{3}\right)
\end{aligned}
$$

sabendo, que para $A_{i j}, B_{i j}$ e $D_{i j}, \quad i=1,2,6$ e $j=1,2,6$ com $z_{K}$ iniciando na coordenada $z$ até a $K$ - ésima lâmina do laminado, como mostrado na FIGURA (2.7).
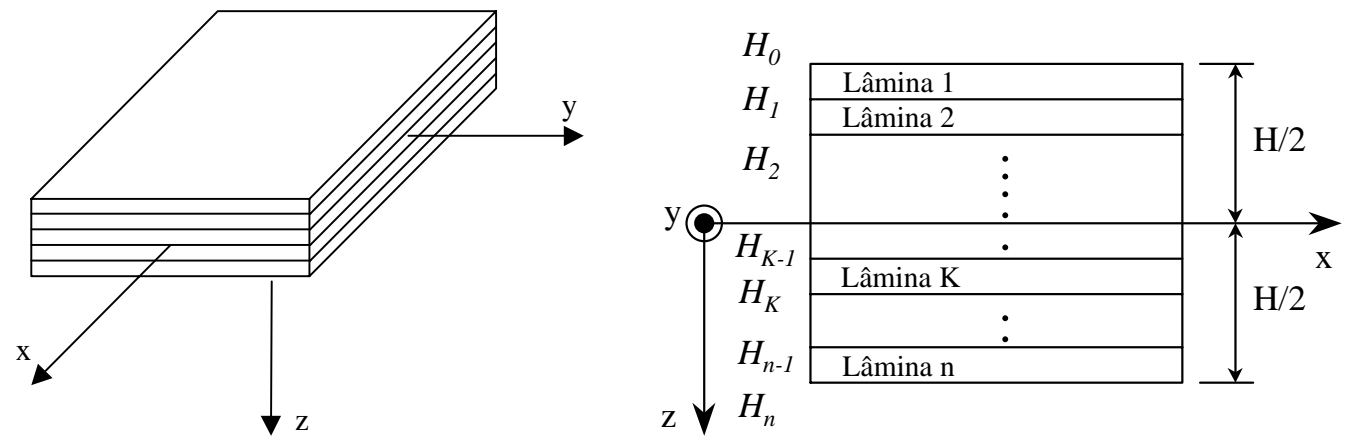

FIGURA 2.7 - Nomenclatura do laminado (HYER, 1998).

Combinando as eqs. (13), o total de equações constitutivo do laminado é escrito da seguinte forma: 


$$
\left\{\begin{array}{l}
N_{x} \\
N_{y} \\
N_{x y} \\
M_{x} \\
M_{y} \\
M_{x y}
\end{array}\right\}=\left[\begin{array}{llllll}
A_{11} & A_{12} & A_{16} & B_{11} & B_{12} & B_{16} \\
A_{12} & A_{22} & A_{26} & B_{12} & B_{22} & B_{26} \\
A_{16} & A_{26} & A_{66} & B_{16} & B_{26} & B_{66} \\
B_{11} & B_{12} & B_{16} & D_{11} & D_{12} & D_{16} \\
B_{12} & B_{22} & B_{26} & D_{12} & D_{22} & D_{26} \\
B_{16} & B_{26} & B_{66} & D_{16} & D_{26} & D_{66}
\end{array}\right]\left\{\begin{array}{c}
\varepsilon_{x}^{o} \\
\varepsilon_{y}^{o} \\
\gamma_{x y}^{o} \\
k_{x}^{o} \\
k_{y}^{o} \\
k_{x y}^{o}
\end{array}\right\}
$$

na qual a eq.(15) pode ser representada por uma notação simplificada, a saber:

$$
\left\{\begin{array}{l}
N \\
M
\end{array}\right\}=\left[\begin{array}{ll}
A & B \\
B & D
\end{array}\right] \cdot\left\{\begin{array}{l}
\varepsilon^{o} \\
k^{o}
\end{array}\right\}
$$

A equação da TCL pode ser invertida e expressa por:

$$
\left\{\begin{array}{l}
\varepsilon^{o} \\
k^{o}
\end{array}\right\}=\left[\begin{array}{ll}
A^{*} & B^{*} \\
C^{*} & D^{*}
\end{array}\right]\left\{\begin{array}{l}
N \\
M
\end{array}\right\}
$$

nas quais as quantidades $\left(^{*}\right)$ são apropriadamente definidas.

As equações fundamentais da TCL mostram que, em geral, existe um acoplamento entre a flexão e a tração através da matriz $B_{i j}$. A matriz da eq.(15) formada pelos componentes $A_{i j}, B_{i j}$ e $D_{i j}$ com $i=1,2,6$ e $j=1,2,6$, é denominada de matriz de rigidez do laminado, também conhecida como matriz $A B B D$. $A$ matriz $A$ representa a rigidez à tração e à compressão, a matriz $B$ é a matriz de acoplamento entre a rigidez planar e a rigidez à flexão e a matriz $D$ representa a rigidez à flexão. Esta matriz é fortemente influenciada pela seqüência de empilhamento (stacking sequence) das lâminas. Para representar a seqüência de empilhamento das 
lâminas, adota-se um sistema de convenção, utilizado na literatura, conhecido como "código do laminado" (laminate code) que simboliza a ordem dos ângulos de orientação das fibras de cada lâmina para especificar um laminado completo.

Os laminados apresentam uma gama de classificações conforme a seqüência de empilhamento utilizada e algumas destas classificações e seus efeitos sobre a matriz ABBD são encontradas em (TSAl \& HAHN, 1980), (TSAI, 1986), (HYER, 1998) entre outros. Quando um laminado é formado pelo empilhamento de várias lâminas ortotrópicas numa seqüência arbitrária de orientação, a matriz $A B D$ geralmente não possui termos nulos. Entretanto, é possível, e em muitos casos desejável, especificar a seqüência de empilhamento das lâminas para que vários termos da matriz $A B B D$ possam ser nulos, simplificando a análise do laminado.

Portanto, verifica-se a importância da disposição das fibras em cada lâmina do laminado. Esta característica exclusiva dos MCRF, concede a estes materiais um atrativo para o desenvolvimento de projetos. Principalmente em projetos que exijam uma estrutura de alta rigidez e alta resistência com baixo peso específico.

O Fluxograma apresentado por (KEUNINGS, 1992), ilustrado na FIGURA (2.8) reúne todas as etapas necessárias para análise de um laminado, discutidas neste trabalho até agora. Nota-se assim, que as propriedades elásticas $\left(E_{1}, E_{2}, G_{12} \mathrm{e}\right.$ $v_{12}$ ) de uma lâmina podem ser obtidas por meio de um modelo Micromecânico baseado nas propriedades dos constituintes da lâmina (fibra e matriz) ou por meio de ensaios experimentais. Com isto, pode-se obter a matriz de rigidez $[\mathrm{Q}]_{\mathrm{K}}$ para uma lâmina tomando como referência os eixos 1-2. Caso haja uma defasagem $\theta_{K}$ na orientação das fibras de uma dada lâmina em relação ao eixo 1, aplica-se a matriz de transformação de coordenadas [T] sobre a matriz de rigidez. Assim, com a rigidez de cada lâmina e com a coordenada $z$ em relação ao plano médio do laminado $z_{K}$, 
pode-se com auxílio da Teoria Clássica de Laminados determinar as matrizes $[A],[B]$ e $[D]$. Com os esforços atuantes e a matriz de rigidez do laminado, têm-se as deformações desenvolvidas sob o mesmo. Tal cálculo pode ser executado por meio da TCL ou por técnicas numéricas, tais como o método das diferenças finitas, o método dos elementos finitos ou o método dos elementos de contorno. Utilizando-se das relações constitutivas para materiais compósitos, calcula - se as tensões $\sigma_{K}$ presentes em cada lâmina. 
Fibra/Matriz

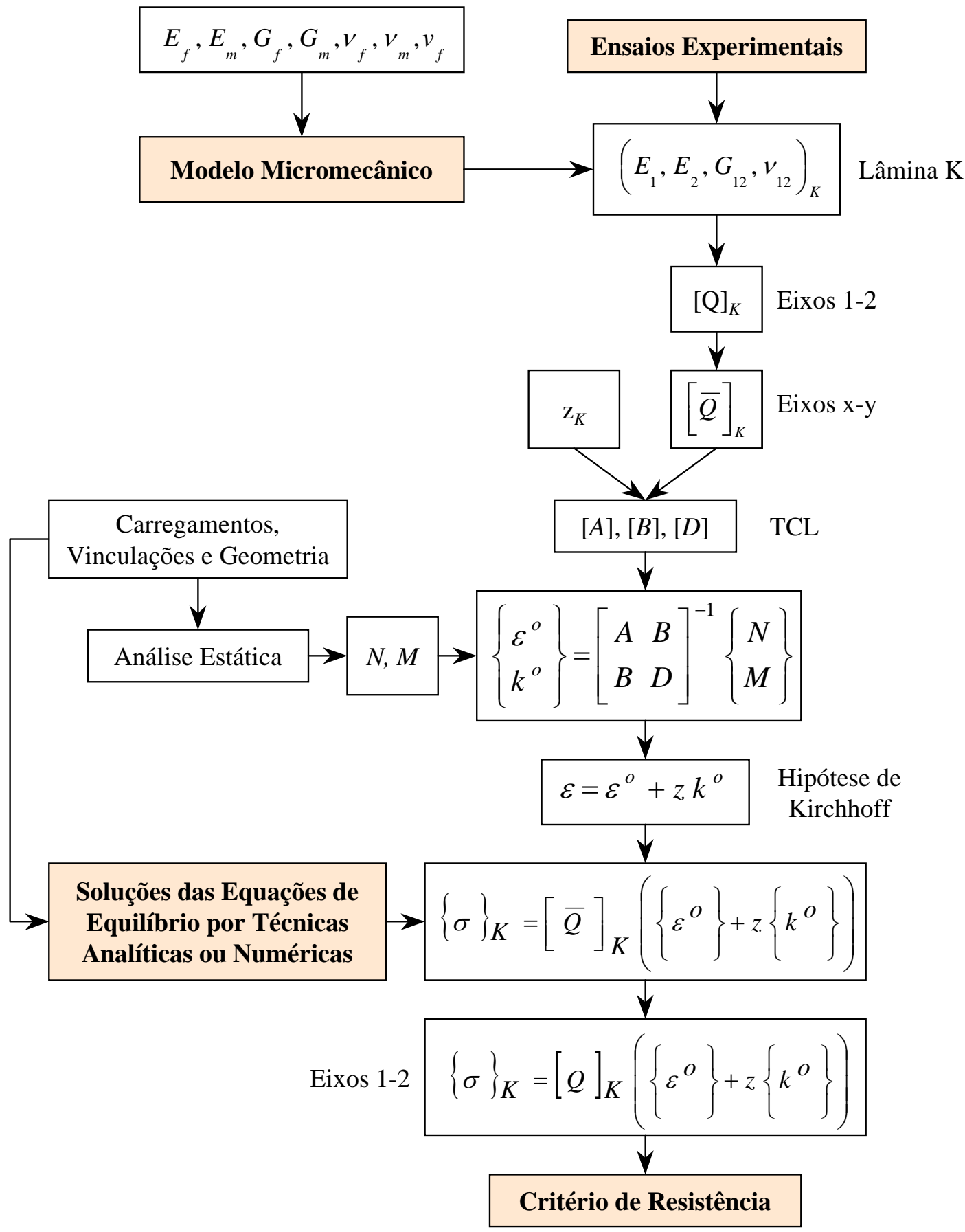

FIGURA 2.8 - Fluxograma para determinação da rigidez e tensões atuantes no laminado. Fonte: (KEUNINGS, 1992)

De acordo com (KEUNINGS, 1992), o uso de técnicas numéricas se faz necessário para uma melhor previsão das tensões nas regiões em que haja 
concentrações (regiões com mudança de seção), bem como a previsão das tensões interlaminares $\sigma_{x y}$. (AGARWAL \& BROUTMAN, 1990) confirmaram que as tensões de cisalhamento interlaminares são intensas porque há uma certa diferença entre os módulos de elasticidade das lâminas com diferentes orientações de fibras, segundo a seqüência de empilhamento. Diante disto, conclui-se que próximo às bordas do laminado ou em regiões em que haja mudança de seção, o comportamento do laminado não pode ser aproximado por um estado plano de tensões, mas sim por um estado triplo de tensões.

Por fim, nota-se que o fluxograma propõe o cálculo das tensões desenvolvidas em cada lâmina, isto ocorre porque os critérios de resistência para laminados estão na sua grande maioria baseados na falha de cada lâmina. Tal assunto será abordado em sessões posteriores.

Conclui-se que um componente mecânico fabricado a partir de MCRF possui uma gama de opções para se obter um desempenho desejado. Pode-se escolher desde as propriedades dos seus constituintes (fibra e matriz), até a orientação e a distribuição das fibras em cada lâmina. Consequentemente, modificar - se - á a rigidez do laminado final que depende da seqüência de empilhamento das lâminas (stacking sequence) e isto virá interferir diretamente na resistência do laminado bem como no seu comportamento dinâmico (freqüências naturais, modos de vibrar e fatores de amortecimento modal). Estas características únicas, presentes nos MCRF, fazem com que estes materiais, sejam atrativos no desenvolvimento de projetos, principalmente em projetos que requerem um menor peso específico sem comprometer a sua resistência, como por exemplo, as estruturas aeronáuticas e automobilísticas. 


\subsubsection{Caracterização Mecânica por Métodos Experimentais}

Segundo (AGARWAL \& BROUTMAN, 1990) a caracterização experimental refere - se à determinação das propriedades do material através de testes conduzidos por meio de corpos de prova preparados adequadamente.

Os dados obtidos a partir de testes são responsáveis pela avaliação das várias propriedades dos materiais que podem ser posteriormente utilizados no projeto e análise de componentes estruturais. O entendimento da resposta do material conforme a extensão total do carregamento é necessário, se procedimentos avançados de projeto são empregados para a utilização eficiente do material. No caso dos compósitos, pode ser desejável iniciar o projeto com as propriedades dos materiais constituintes e chegar às propriedades Macromecânicas do compósito por meio das análises Micromecânicas. Entretanto, a confiabilidade nas análises Micromecânicas é confirmada por meio de ensaios experimentais. Outros propósitos da caracterização experimental são: verificar a conformidade dos procedimentos de fabricação; assegurar a uniformidade do material e comparar os valores das propriedades de vários materiais candidatos à seleção para utilização em projetos de engenharia.

Para caracterizar uma lâmina unidirecional por meio de ensaios experimentais são determinadas quatro constantes elásticas independentes: módulos de elasticidade na direção longitudinal e transversal ( $E_{1}$ e $\left.E_{2}\right)$; módulo devido ao cisalhamento no plano da lâmina $\left(\mathrm{G}_{12}\right)$ e o maior coeficiente de Poisson $\left(v_{12}\right)$. Assim como são determinadas cinco resistências, a saber: resistência à tração e à compressão na direção longitudinal e transversal e resistência ao cisalhamento no plano da lâmina. No caso de um laminado, a resistência ao cisalhamento 
interlaminar é também uma propriedade importante. É necessário estabelecer estas propriedades para uma caracterização mínima de uma lâmina unidirecional. Elas são geralmente estabelecidas quando corpos de prova adequados são submetidos a carregamentos no plano. Entretanto, um laminado em serviço é muitas vezes submetido à ação de carregamentos combinados, deste modo é necessário caracterizar a lâmina em relação a carregamentos de flexão em adição àquelas propriedades já mencionadas. Com todas as propriedades estabelecidas para uma lâmina, a Teoria Clássica de Laminados pode ser utilizada para calcular as propriedades do laminado.

No entanto, muitas vezes, as considerações práticas impedem a construção de corpos de prova com uma única lâmina. Assim, torna-se necessário conduzir os testes por meio de corpos de prova com várias lâminas e utilizar apropriadamente a TCL para simplificar os resultados em termos das propriedades da lâmina. Se o laminado é unidirecional, certamente, seu comportamento simula o comportamento da lâmina.

Os procedimentos de testes normalmente empregados para determinar as várias propriedades dos compósitos, como a seleção mais conveniente de um tipo particular de corpo de prova para cada método de teste, os métodos de redução dos dados experimentais, os detalhes de instrumentação e as técnicas de medição são discutidos fartamente na literatura. Além disso, discussões detalhadas podem ser encontradas em normas técnicas, tais como as normas da American Society for Testing and Materials - ASTM que têm sido muito utilizadas para testes em compósitos. Contudo, (CARVALHO, 1996) descreve algumas particularidades relacionadas aos ensaios mecânicos em compósitos, tais como: 
- Os ensaios mecânicos que são executados para a determinação das propriedades mecânicas dos materiais estão fundamentados na aplicação da teoria básica da mecânica. Tal teoria é aplicada satisfatoriamente para materiais elásticos homogêneos e isotrópicos, o que não é o caso dos compósitos reforçados por fibras, cuja anisotropia, não homogeneidade e não elasticidade dificultam a aplicação de tais conceitos.

- As grandes dificuldades na execução dos ensaios são devido a:

- Influência de "efeitos de borda" (end - effects) que induzem as regiões de concentração de tensão próximas às arestas da amostra;

- Geração de níveis de carregamentos adequados sem causar danos ao material;

- Uso de dimensões apropriadas, principalmente a espessura, em relação à escala de heterogeneidade do material.

- A anisotropia conduz a problemas práticos, tais como:

- Intensifica os efeitos de borda, que dependem da geometria da amostra e do grau de anisotropia;

- Produz falha prematura em fixações ou em pontos de aplicação de carga;

- Favorece a delaminações prematuras em "arestas vivas" (free edges) ou aparecimento de outros mecanismos de falha;

- Aumenta a diferença entre as propriedades do material, como por exemplo, o módulo de elasticidade à tração, que é governado pelas propriedades da fibra e o módulo ao cisalhamento, governado basicamente pelas propriedades da matriz;

- Os testes em compósitos são geralmente de alto custo, pois:

- Os materiais, na sua maioria, têm alto custo; 
- A fabricação de amostras e corpos de prova demanda atenção meticulosa a detalhes.

- Em determinados casos, as normas técnicas ASTM, ISO e DIN. Podem ser muito adequadas, enquanto que em outros casos podem ser totalmente inadequadas.

\subsubsection{Critérios de Falhas}

A segurança na aplicação dos materiais compósitos para fins estruturais depende primordialmente da habilidade na estimativa da resistência desses materiais. Geralmente, as falhas em compósitos ocorrem devido a uma combinação de vários mecanismos ou modos descritos anteriormente, sendo portanto o evento final, ou seja, um processo complexo de acúmulo de danos no material. Apesar da importância do entendimento dos mecanismos de falha, em muitas aplicações tornase difícil, mesmo senão impossível, detalhar cada etapa do processo de falha. Assim, em um ciclo de projeto estrutural FIGURA (2.8), uma das características marcantes na fase de análise de desempenho é a seleção apropriada de um critério de falha, capaz de estimar se a estrutura está segura ou não sob um determinado estado de tensões ou deformações.

De um modo geral, a análise de falha ou de resistência visa: (1) analisar um laminado a fim de estimar o carregamento máximo ou o desempenho do mesmo; (2) projetar o laminado para uma determinada condição de carregamento.

Os critérios de falhas têm como objetivo, portanto, estimar os efeitos provocados pelos esforços na estrutura, indicando assim a ocorrência ou não da 
falha no material solicitado. Segundo (CARVALHO, 1996), esses critérios de falhas podem ser classificados em vários grupos, tais como:

- Limites: os que fornecem apenas limites, não considerando as interações entre as tensões ou deformações;

- Interativos: os que consideram as interações entre os componentes de tensões ou deformações;

- Híbridos: combinações de dois ou mais critérios diferentes;

- Micromecânicos: desenvolvidos com base nos micromecanismos de falha;

- Mecanismos de fratura: baseados na aplicação dos conceitos de mecânica da fratura em materiais compósitos;

- Mecanismos de dano: baseados em descrições matemáticas de vários tipos de danos observados em compósitos;

- Fenomenológicos: baseados na observação do comportamento dos compósitos.

Os autores (ECHAABI, et. al, 1996) classificam a gama de critérios existentes em dois grandes grupos:

- Critérios de falhas que não consideram os modos de falha: são aqueles escritos geralmente na forma polinomial, onde as relações entre as tensões ou deformações são apresentadas numa forma quadrática, e os coeficientes da expressão do critério dependem de parâmetros obtidos em testes uniaxiais, biaxiais ou ambos;

- Critérios de falhas que consideram os modos de falha: consideram os efeitos dos modos de falha no equacionamento do critério. 
Associado ao critério de falha tem - se dois métodos de abordagem de um problema de falha em compósitos laminados, descritos abaixo:

- O primeiro e mais simples de ser aplicado, cuja utilização é bastante usual, é conhecido como FPF (First Ply Failure), que considera a falha completa do laminado quando o carregamento proporcionar a falha da primeira lâmina. É evidente que a falha de uma simples lâmina, segundo um dado critério, não resulta na falha do laminado completo, caracterizando-se assim em um método bastante conservador em termos de segurança.

- O segundo método é chamado de LPF (Last Ply Failure), pois compara as tensões (ou deformações) em cada lâmina até o máximo carregamento permitido, e o laminado falha quando a última lâmina falhar. O LPF requer conhecimentos mais precisos sobre as condições de carregamento e distribuições de tensões, e são utilizados fatores de segurança mais elevados no projeto.

Nas análises FPF e LPF, o critério de falha selecionado é portanto aplicado ao estado de tensões ou deformações de cada lâmina individual. A seguir são apresentados alguns dos critérios de falhas para materiais compósitos, mais abordados na literatura, ressaltando que apesar de alguns deles serem originalmente formulados para o caso tri-dimensional, em muitos casos, os compósitos laminados são submetidos ao estado plano de tensões. Um estudo detalhado destes critérios é apresentado em Souza (2003). Dada a sua grande utilização, é feita abaixo uma descrição mais detalhada do critério interativo de Tsai Wu, com vistas a uma futura implementação no sistema em desenvolvimento. Outros critérios podem ser facilmente implementados no código fonte, uma vez que os dados de tensão deformação estão disponíveis no sistema. 


\subsubsection{Critério de Tsai Wu}

Alguns critérios de falha são formulados utilizando-se "tensores de resistência", que permitem transformações de sistemas de coordenadas. Entre estes a mais amplamente utilizada é a forma quadrática do critério de (TSAl \& Wu, 1971) para materiais anisotrópicos. A hipótese básica deste critério de resistência é a existência de uma superfície de falha no espaço de tensões, dada pela seguinte equação escalar:

$$
F_{i} \sigma_{i}+F_{i j} \sigma_{i} \sigma_{j}=1, \quad i, j=1,2, \ldots, 6
$$

onde, os termos lineares das tensões consideram as possíveis diferenças entre as resistências de tração e compressão. A expressão acima descreve um elipsóide no espaço de tensões. Além disso, $F_{i j}(i \neq j)$ são constantes de interação entre os componentes de tensões, e a magnitude de seus valores indica o grau dessa interação. Os termos de ordem superior $\left(F_{i j k} \sigma_{i} \sigma_{j} \sigma_{k}\right)$ foram ignorados no critério de resistência de Tsai Wu por não serem práticos do ponto de vista operacional, pois o número de componentes em um tensor de $6^{\underline{a}}$ ordem é muito elevado.

As magnitudes dos termos de interação devem, no entanto, satisfazer a seguinte condição:

$$
F_{i i} F_{j j}-F_{i j}^{2} \geq 0 \quad(\mathrm{i}, \mathrm{j}=1,2, \ldots, 6)
$$


Geometricamente, esta condição impõe que a superfície de falha intercepte cada eixo no espaço de tensões, e que a superfície de falha seja "fechada" (elipsóide) e não “aberta” (hiperbólica ou parabólica), (TSAI \& WU, 1986).

No caso de materiais compósitos ortotrópicos, sob estado plano de tensões, o critério de Tsai Wu em sua forma expandida, torna - se:

$$
\begin{aligned}
& F_{1} \sigma_{1}+F_{2} \sigma_{2}+F_{6} \sigma_{6}+F_{11} \sigma_{1}^{2}+F_{22} \sigma_{2}^{2}+F_{66} \sigma_{6}^{2}+2 F_{12} \sigma_{1} \sigma_{2} \\
& +2 F_{16} \sigma_{1} \sigma_{6}+2 F_{26} \sigma_{2} \sigma_{6}=1
\end{aligned}
$$

onde $\sigma_{6}=\sigma_{12}$, e o termo $F_{12}$ representa a interação entre as tensões normais $\sigma_{1}$ e $\sigma_{2}$. Segundo demonstrado por alguns autores, dentre os quais destaca - se (HYER,1998), a resistência de um material ortotrópico, submetido a tensões de cisalhamento puro com relação ao sistema de coordenadas principais, é independente do sinal da tensão de cisalhamento. Isso faz com que, na equação acima, todos os coeficientes dos termos lineares em $\sigma_{6}$ sejam nulos, ou seja, $F_{6}=$ $F_{16}=F_{26}=0$.

Os coeficientes remanescentes, exceto $F_{12}$, são obtidos aplicando-se condições de carregamento nas lâminas unidirecionais. Por exemplo, considere um elemento de material sujeito à tensão uniaxial, na direção das fibras, até a ocorrência da falha. Na situação de falha, tem-se que: $\sigma_{1}=X_{T}, \quad \sigma_{2}=\sigma_{6}=0$. Assim a equação anterior fica reduzida a:

$$
F_{1} X_{T}+F_{11} X_{T}^{2}=1
$$


Analogamente, sob compressão uniaxial na direção das fibras, a falha ocorre quando $\sigma_{1}=-X_{C}$, e $\sigma_{2}=\sigma_{6}=0$, ou seja:

$$
-F_{1} X_{C}+F_{11} X_{C}^{2}=1
$$

Resolvendo as equações acima simultaneamente, obtêm-se os coeficientes:

$$
F_{1}=\frac{1}{X_{T}}-\frac{1}{X_{C}}, \quad F_{11}=\frac{1}{X_{T} X_{C}}
$$

Considerando-se agora um elemento de material submetido a tensões de tração e compressão uniaxiais na direção transversal às fibras, obtêm-se de forma análoga:

$$
F_{2}=\frac{1}{Y_{T}}-\frac{1}{Y_{C}}, \quad F_{22}=\frac{1}{Y_{T} Y_{C}}
$$

Da mesma forma, a partir de um elemento de material sujeito à tensão de cisalhamento puro no plano 1-2, ou seja, $\sigma_{1}=\sigma_{2}=0, \sigma_{6} \neq 0$, e desconsiderando o sinal da tensão de cisalhamento, relativo ao sistema principal, chega-se às expressões:

$$
F_{6}=0, \quad F_{66}=\left(\frac{1}{S_{12}}\right)^{2}
$$


Dessa forma a expressão reduzida do critério de Tsai Wu para o caso do estado plano de tensões, quando aplicado no sistema principal de coordenadas do material, e desconsiderando-se todos os termos nulos fica:

$$
F_{1} \sigma_{1}+F_{2} \sigma_{2}+F_{11} \sigma_{1}^{2}+F_{22} \sigma_{2}^{2}+F_{66} \sigma_{6}^{2}+2 F_{12} \sigma_{1} \sigma_{2}=1
$$

Para a determinação do termo remanescente de interação entre as tensões normais $\sigma_{1}$ e $\sigma_{2}, F_{12}$, necessita-se de algum tipo de teste biaxial, ou seja, que a falha do material seja provocada pelas duas componentes de tensão normal. Esta forma de teste é mais complexa e envolve mais custos. Teoricamente, um único par de valores $\sigma_{1}$ e $\sigma_{2}$ seria suficiente para a determinação de $F_{12}$. Porém, na prática, uma série de valores de tensões normais combinadas devem ser estudados, incluindo tensões de tração e de compressão, e assim determina-se o coeficiente $F_{12}$ mais adequado para o caso em estudo.

Um método apresentado para a estimativa do coeficiente de interação $F_{12}$ consiste na utilização da expressão (HYER, 1998):

$$
\mathrm{F}_{12}=-\frac{1}{2} \sqrt{\mathrm{F}_{11} \mathrm{~F}_{22}}
$$

em muitos casos, a utilização desta expressão para estimar o valor de $F_{12}$ oferece bons resultados.

As vantagens apresentadas pelo critério de Tsai Wu são, segundo os próprios autores (TSAI \& WU, 1986): 
- No critério de Tsai Wu, as interações entre as componentes de tensão são independentes das propriedades do material. Já nos casos de alguns outros critérios quadráticos, como o de Hill, as interações são fixas (dependem das propriedades do material). Critérios como os da tensão ou deformação máxima, não consideram interações entre as tensões;

- Como as componentes de resistência são expressas na forma tensorial, valem todas as propriedades de tensores. Em particular, as transformações são similares às desenvolvidas para a flexibilidade elástica;

- Conhecendo as transformações, pode-se aplicá-las aos tensores de resistência, e assim encontrar a resposta do critério em qualquer direção, não valendo apenas para os eixos de ortotropia do material, ou seja, o critério de Tsai Wu é invariante ao sistema de coordenadas;

- A maioria dos critérios existentes são aplicáveis somente aos materiais ortotrópicos. Além disso, estes critérios somente podem ser utilizados transformando-se as tensões atuantes para os eixos do material. Nestes casos, não é possível a rotação dos eixos do material, pois as transformações nesses critérios de resistência não são conhecidas.

Dentre as desvantagens do critério de Tsai Wu, citam-se a impossibilidade de se prever diretamente o modo causador da falha, e a dificuldade na determinação experimental do coeficiente $F_{12}$, salientando-se que, em alguns casos, uma pequena diferença nos valores de $F_{12}$ utilizados pode trazer alterações drásticas no envelope de falha, indo desde uma mudança na orientação da elipse até uma alteração das amplitudes em relação aos eixos de tensão. 


\subsection{Recursos Computacionais}

\subsubsection{Processo de Desenvolvimento de um Software}

Dentre as principais áreas que constituem a Ciência da Computação, uma das que mais influenciam o mundo atual é a Engenharia de Software, envolvida nos aspectos tecnológicos e gerenciais do processo de desenvolvimento de um software. Software tornou-se a base de sustentação de inúmeras organizações dos mais diversos ramos espalhados pelo planeta, consistindo no elemento estratégico da diferenciação de produtos e serviços atuais. Atualmente, o software está embutido em sistemas de diferentes ciências e tecnologias.

Apesar dos inúmeros avanços tecnológicos, muito ainda é discutido acerca da baixa qualidade e produtividade da indústria mundial de softwares, refletindo na insatisfação dos seus usuários e em prejuízos financeiros de enormes proporções. Por outro lado, os computadores estão rapidamente tornando-se componentes indispensáveis no dia-a-dia das pessoas que, por sua vez, apontam necessidades com requisitos de complexidade cada vez maiores. O fenômeno descrito na literatura especializada como "Crise do Software" é um reflexo da incapacidade da indústria de software em atender plenamente às necessidades de um mercado consumidor cada vez mais exigente. A Crise do Software foi um termo utilizado nos anos 70 , quando a engenharia de software era praticamente inexistente. O termo expressava as dificuldades do desenvolvimento de software frente ao rápido crescimento da demanda por software, da complexidade dos problemas a serem resolvidos e da inexistência de técnicas estabelecidas para o desenvolvimento de sistemas que funcionassem adequadamente ou pudessem ser validados. 
As causas da crise do software estão ligadas à complexidade do processo e a software e a relativa imaturidade da Engenharia de Software como profissão. A referida crise se manifesta de várias formas:

- Projetos estourando o orçamento;

- Projetos estourando o prazo;

- Software de baixa qualidade;

- Software muitas vezes não atingiam os requisitos;

- Projetos ingerenciaveis e o código difícil de manter.

Atualmente segundo (PRESSMAN, 2001), cerca de 70\% dos investimentos da área são realizados com o objetivo de manter os produtos desenvolvidos anteriormente. Com o objetivo de solucionar esses problemas, várias tecnologias vêm sendo experimentadas no sentido de apoiar o ciclo de vida do software. Um dos esforços mais significativos corresponde a definição de metodologias voltadas a disciplinar o processo de desenvolvimento através do estabelecimento de etapas bem definidas, proporcionando, desta forma um mecanismo de controle para o processo.

\subsubsection{Considerações sobre Engenharia de Software}

Conforme (PRESSMAN, 2005), a Engenharia de Software (ES) é uma tecnologia em camadas. E a base de todas essas camadas é o foco na qualidade do software desenvolvido. Portanto, inclusive do ponto de vista didático, é interessante estudarmos a ES em suas camadas de Processo, Métodos e Ferramentas. 
A Engenharia de Software é uma área do conhecimento da informática voltada para a especificação, desenvolvimento e manutenção de sistemas de software aplicando tecnologias e práticas de ciência da computação, gerência de projetos e outras disciplinas, objetivando organização, produtividade e qualidade.

Atualmente, essas tecnologias e práticas englobam linguagens de programação, bases de dados, ferramentas, plataformas, bibliotecas, padrões, processos e a questão da qualidade do software.

Os fundamentos científicos para a Engenharia de Software envolvem o uso de modelos abstratos e precisos que permitem ao engenheiro especificar, projetar, implementar e manter sistemas de software, avaliando e garantindo suas qualidades. Além disso, a engenharia de software deve oferecer mecanismos para se planejar e gerenciar o processo de desenvolvimento de um Sistema de Informação.

Segundo (PRESSMAN, 1995), a preocupação com o estudo do software ultrapassou o hardware, uma vez que este possui uma evolução maior em função dos avanços tecnológicos. O software se tornou algo indispensável para os sistemas baseados em computador.

Algumas experiências realizadas mostram que conceber um software não resume somente em escrever seu código - fonte. Segundo o mesmo autor, mesmo não havendo uma metodologia definida para projetar um software, há várias técnicas, critérios de qualidade e notações específicas que podem ser aplicadas às várias atividades de seu desenvolvimento.

Um software pode ser definido como: (a) instruções/programas de computador que quando executados, produzem a função e desempenho desejados; (b) estruturas de dados que possibilitam que os programas manipulem 
adequadamente a informação; (c) documentos que descrevem a operação e a utilização de programas. Uma definição mais ampla define o software como: programa de computador, estruturas de dados e documentação correlata que servem para efetivar o método, processo ou controle lógico necessário.

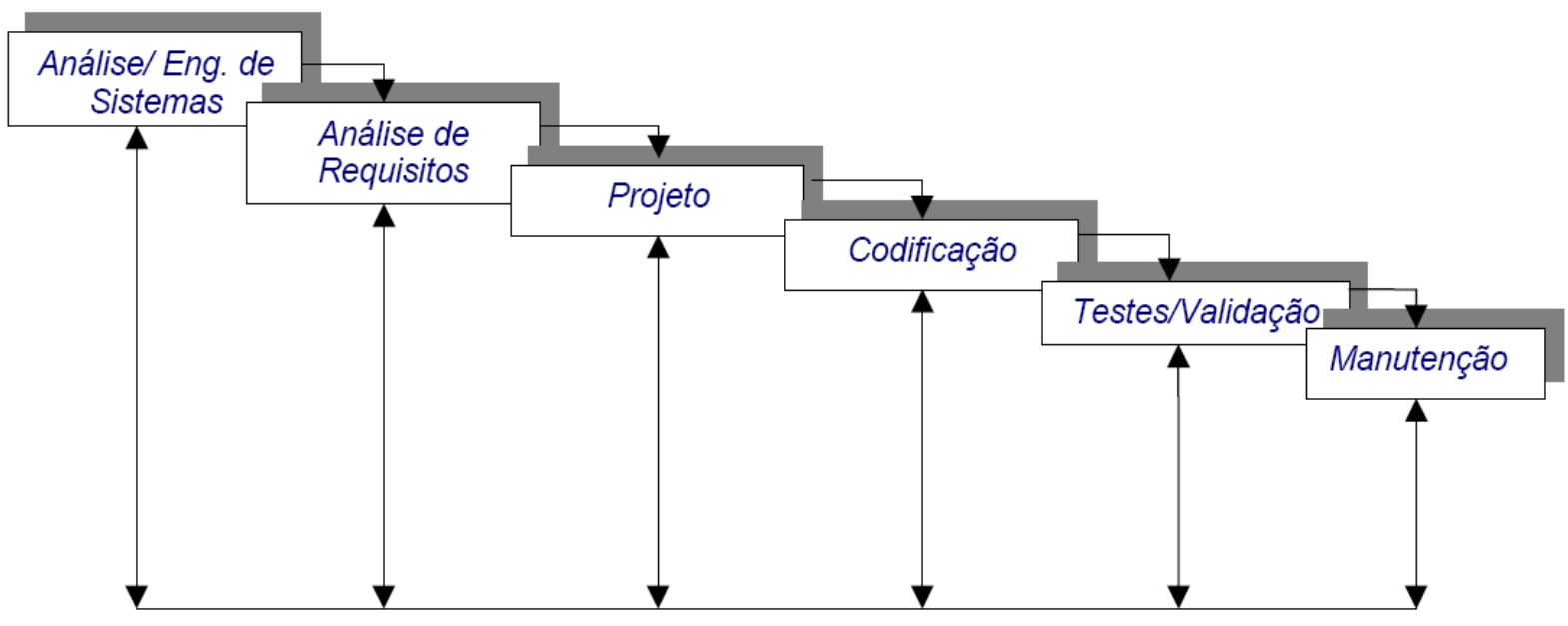

FIGURA 2.9 - Ciclo de vida de um software.

Fonte: (PRESSMAN, 1995).

O Ciclo de Vida Tradicional ou em Cascata é um modelo de desenvolvimento de software sequencial que se inicia na análise de sistemas e avança ao longo das fases de: Análise de Requisitos, Projeto, Codificação, Testes e Manutenção, descritas abaixo:

- Análise e engenharia de sistemas: O software irá compor um sistema computacional mais amplo. Nesta fase são estabelecidos e coletados os requisitos para todos os elementos do sistema e atribuições.

- Análise de Requisitos: o levantamento de requisitos é a primeira fase na criação de um software. É nesta fase que o analista faz reuniões com o cliente e/ou usuários do software para conhecer as funcionalidades do 
sistema que será desenvolvido. Embora o cliente acredite saber o que o software deve fazer, esta etapa requer muito conhecimento e experiência em Engenharia de Software para reconhecer ambigüidades ou contradição nos requisitos.

- Projeto: o projeto apresenta-se em quatro etapas distintas: estrutura de dados, arquitetura de software, detalhes procedimentais e caracterização da interface. O processo de construção do processo transmite as exigências numa representação do software que pode ser avaliada à qualidade, anteriormente à codificação. O projeto é então documentado.

- Codificação: nesta fase ocorre a tradução do projeto para a máquina. O projetado apresentando - se de forma detalhada, a codificação pode ser feita de maneira mecânica.

- Teste: é nessa fase que verificam - se todos os aspectos de funcionamento do software a fim de levantar possíveis erros;

- Manutenção: um software sempre sofre mudanças e adaptações quando entregue ao cliente e executado. A manutenção e melhoria do software lidam com a descoberta de novos problemas e requisitos, aplicadas para cada uma das etapas anteriores do ciclo de vida de um software existente.

Segundo (PRESSMAN, 1995) os aspectos fundamentais de projeto de software possui um núcleo técnico do processo de engenharia e é aplicado independentemente do paradigma de desenvolvimento adotado. Iniciada a análise de requisitos de software, o projeto é a primeira dentre as três atividades técnicas projeto, codificação e teste - que são etapas necessárias para a construção de um software. 


\subsubsection{Considerações sobre Interfaces Gráficas com o Usuário - (GUI’s)}

À medida que os microcomputadores foram evoluindo, surgiu a necessidade da criação de um sistema prático e de fácil acesso que facilitasse a vida do usuário. Assim os desenvolvedores de software passaram a se preocupar em satisfazer o usuário durante a criação de interfaces.

Uma das áreas da computação que tem se desenvolvido rapidamente é o projeto de interfaces com o usuário final ( $\mathrm{HCl}$ - Human - Computer Interface), decorrente do número de pessoas que utilizam os microcomputadores. Muitas pessoas sentem dificuldade em se relacionar com interfaces confusas e inflexíveis. A interface com o usuário é o mecanismo pelo qual, se estabelece a conexão entre a máquina e a pessoa. Se os fatores que contribuem para essa comunicação forem explícitos, é permitido um fluxo continuo de interação entre o usuário e a máquina. (PRESSMAN, 1995).

Conforme (PRESSMAN, 1995), muitos recursos contribuem para o desenvolvimento de uma boa interface com o usuário como, por exemplo, bibliotecas de componentes visuais. Esses componentes auxiliam a visão e fazem com que o cérebro possa captar e receber informações com referência a tamanho, forma, cor, orientação, movimento e outra características de identificação visual. Os

objetos gráficos assumem formas de botões, janelas, menus, ícones que são utilizados para apresentar os aplicativos em execução e seqüência de comandos. 


\subsubsection{Sistema Gerenciador de Banco de Dados (SGBD)}

\subsubsection{Introdução}

Durante muitos anos os sistemas de bancos de dados foram utilizados nas áreas comerciais, tais como: controle de estoque, sistema de vendas e controle de produção. Com o avanço tecnológico e o aumento das informações a serem armazenadas, a utilização dos Sistemas de Gerenciamento de Banco de Dados (SGBD), direcionaram-se para outras áreas de desenvolvimento como, por exemplo, engenharia, educação e medicina, dentre outras. Os elementos básicos que compõem os Sistemas de Gerenciamento de Banco de Dados segundo (Costa, 1996), são:

- Banco de Dados: é uma coleção de dados inter-relacionados e armazenados;

- Arquivos de Dados: são estruturas utilizadas para armazenar o próprio banco de dados. Um arquivo consiste em conjunto de registros;

- Registros: são estruturas de dados compostas por uma seqüência de campos.

O Sistema gerenciador de Banco de Dados é uma coleção de programas que permitem aos usuários criarem e manipularem uma base de dados. Um SGBD é um sistema de software de propósito geral que facilita o processo de definir, construir e manipular bases de dados de diversas aplicações.

- Definir - uma base de dados envolve a especificação de tipos de dados a serem armazenados na base de dados. 
- Construir - uma base de dados é o processo de armazenar os dados em algum meio que seja controlado pelo SGBD.

- Manipular - uma base de dados indica a utilização de funções como a de consulta, para recuperar dados específicos, geração de relatórios e modificação da base de dados para refletir mudanças no minimundo.

A base de dados e o software de gerenciamento da base de dados compõem o chamado Sistema de Base de Dados.

Exemplo de SGBD:

Usuários/Programadores

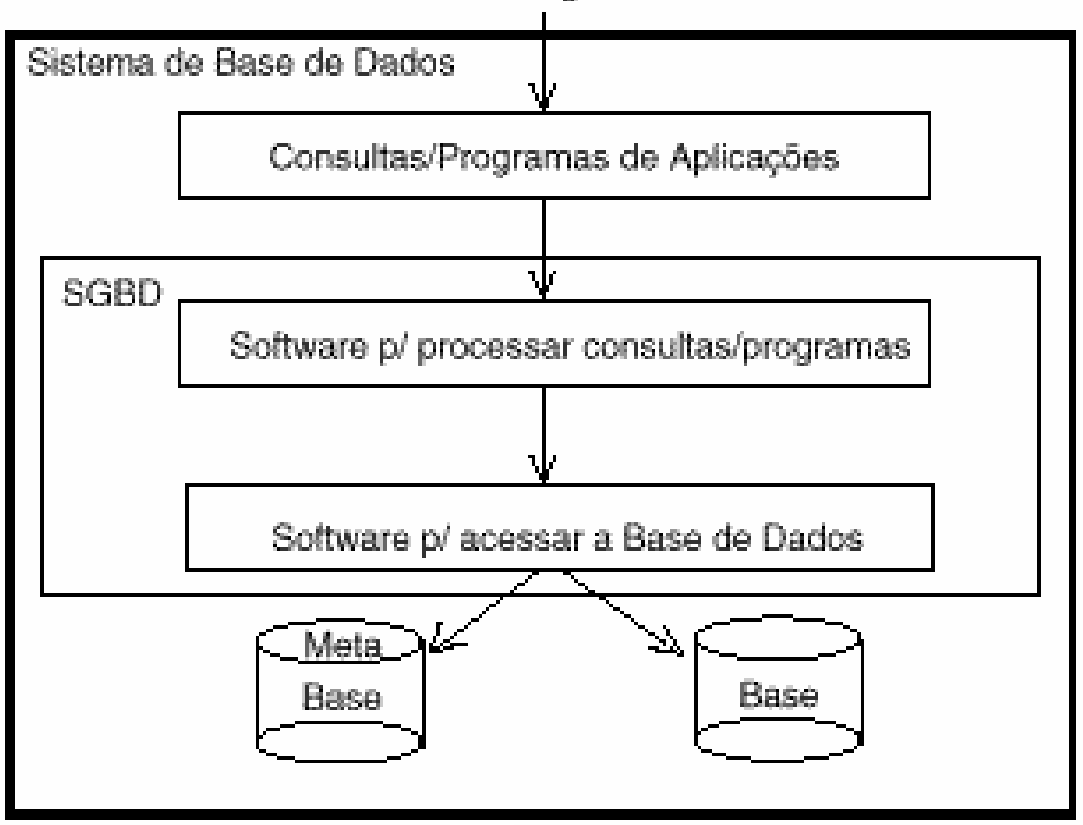

FIGURA 2.10 - Configuração de um Sistema de Banco de Dados.

Fonte: (MACHADO \& ABREU, 1996) 
Conforme (MACHADO \& ABREU, 2005) para registrarmos as necessidades de informação de uma realidade, precisamos fazer uso de um modelo, ou seja, algo que mostre como as informações estão relacionadas (fatos). E com base no modelo criado, os analistas podem interagir como os usuários validando seus objetivos e metas, permitindo a construção de um sistema de informações cada vez mais próximo da realidade do usuário.

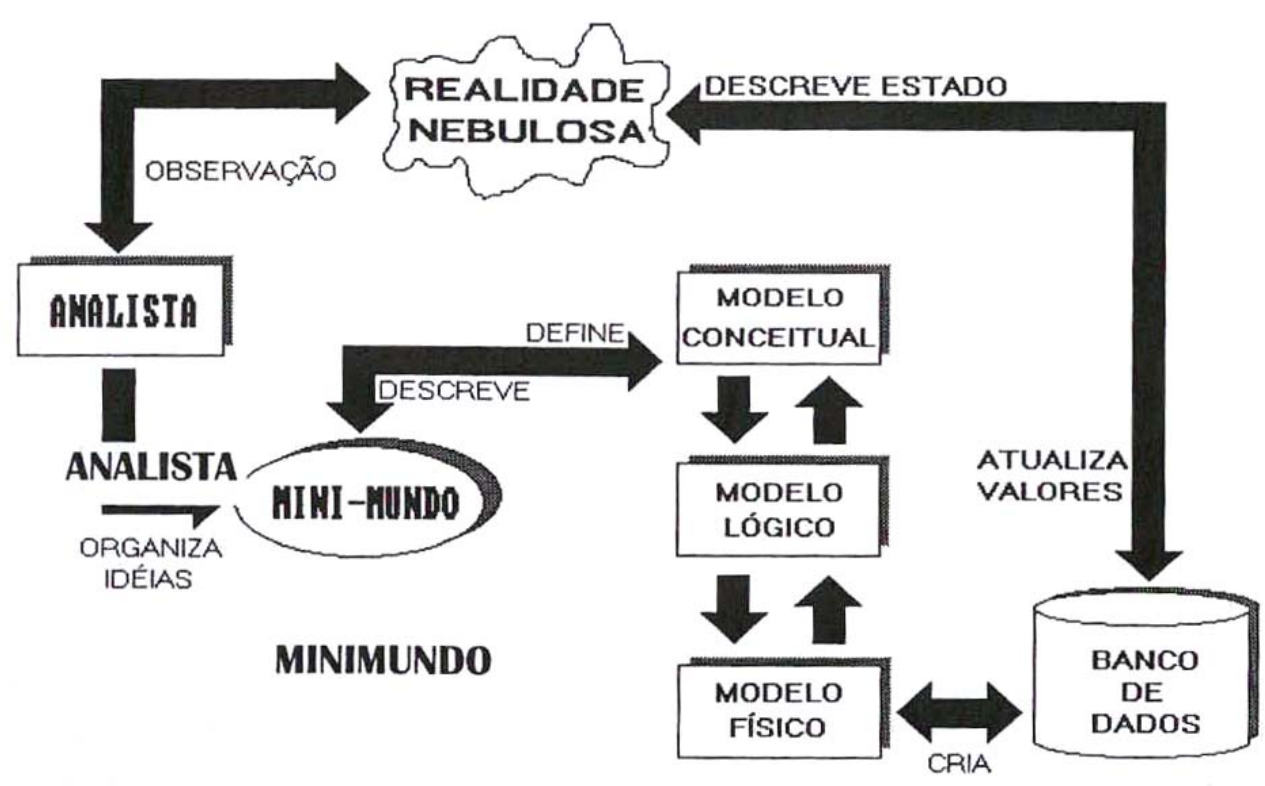

FIGURA 2.11 - Níveis de Abstração de uma Base de Dados.

Fonte: (MACHADO \& ABREU, 2005)

Descrição dos elementos de abstração:

- Minimundo: Porção da realidade, captada pelo analista, a qual a função gerencial tem forte interesse em observar. A complexidade de se analisar até mesmo um MiniMundo, pode levar o analista a subdividi-lo em partes menores, as quais damos o nome de visão. 
- Banco de Dados: É uma coleção de fatos registrados que refletem o estado de certos aspectos de interesse do mundo real. A todo o momento o conteúdo do banco de dados representa uma visão instantânea do estado do mundo real. Cada mudança em algum item do banco de dados reflete uma mudança ocorrida na realidade.

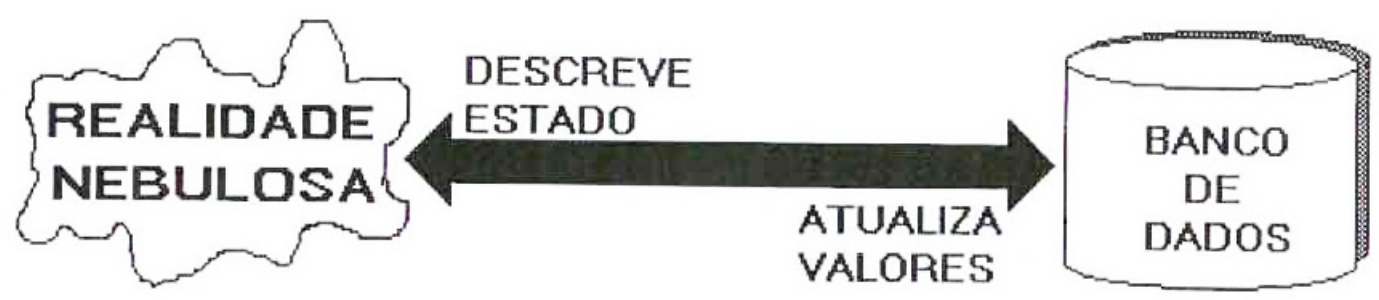

FIGURA 2.12 - Modelo mostra Mudanças na Base de Dados e na Realidade. Fonte: (MACHADO \& ABREU, 2005).

A tecnologia de banco de dados tem como fundamento básico possibilitar que os dados sejam definidos e mantidos, independentes dos sistemas de aplicação que venham a utilizá-los (independência DADO X PROCESSO).

\subsubsection{Vantagens de um Sistema Gerenciador de Banco de Dados}

As principais vantagens do Sistema Gerenciador de Banco de Dados são:

- Potencial para obrigar a Padronização: permite a comunicação e a cooperação entre vários departamentos, projetos e usuários. Padrões podem 
ser definidos para formatos de nomes, elementos de dados, telas, relatórios e terminologias;

- Flexibilidade: mudanças na estrutura de uma base de dados podem ser necessárias devido a mudanças nos requisitos;

- Redução do Tempo de Desenvolvimento de Aplicações: uma vez que a base de dados esteja em uso, o tempo para se criar novas aplicações, usando-se os recursos de um SGBD, é bastante reduzido;

- Disponibilidade de Informações Atualizadas: tão logo um usuário modifique uma base de dados, todos os outros usuários "sentem" imediatamente esta modificação;

- Economia de Escala: a abordagem de sistema gerenciador de banco de dados permite a consolidação de dados e de aplicações reduzindo -se, desse modo, o desperdício em atividades redundantes de processamento em diferentes projetos ou departamentos. Isto possibilita à organização como um todo investir em processadores mais poderosos, e periféricos de armazenamento e de comunicação mais eficientes.

\subsubsection{Capacidades de um Sistema Gerenciador de Banco de Dados}

As principais capacidades de um sistema gerenciador de banco de dados são:

- Controle de Redundância: no processamento tradicional de arquivos, muitos grupos de usuários mantêm seus próprios arquivos para manipular suas aplicações de processamento. Isso pode provocar o armazenamento de 
informações redundantes. Problemas: duplicação de esforços e desperdício de espaço;

- Inconsistência: alteração em alguns arquivos e em outros não, ou em todos os arquivos, porém de maneira independente.

- Compartilhamento de Dados: sistema gerenciador de banco de dados multiusuários devem fornecer controle de concorrência para assegurar que atualizações simultâneas resultem em modificações corretas. Um outro mecanismo que suporta a noção de compartilhamento de dados em um SGBD multiusuários é a facilidade de definir visões de usuário, que é usada para especificar a porção da base de dados que é de interesse para um grupo particular de usuários.

- Restrições de Acesso Multiusuário: quando múltiplos usuários compartilham uma base de dados, é comum que alguns usuários não autorizados não tenham acesso a todas as informações da base de dados.

- Fornecimento de Múltiplas Interfaces: devido a muitos tipos de usuários, com variados níveis de conhecimento técnico, um SGBD deve fornecer uma variedade de interfaces para usuários. Os tipos de interfaces incluem linguagens de consulta para usuários ocasionais, interfaces de linguagem de programação para programadores de aplicações, formulários e interfaces dirigidas por menus para usuários comuns.

- Representação de Relacionamento Complexo entre Dados: uma base de dados pode possuir uma variedade de dados que estão inter-relacionados de muitas maneiras. Um SGBD deve ter a capacidade de representar uma variedade de relacionamentos complexos entre dados, bem como recuperar e modificar dados relacionados de maneira fácil e eficiente. 
- Reforçar Restrições de Integridade: muitas aplicações de base de dados terão certas restrições de integridade de dados. A forma mais elementar de restrição de integridade é a especificação do tipo de dado de cada item. Existem tipos de restrições mais complexas. Um tipo de restrição que ocorre freqüentemente é a especificação de que um registro de um arquivo deve estar relacionado a registros de outros arquivos. Algumas restrições podem ser especificadas ao SGBD e automaticamente executadas.

- Fornecer Backup e Restauração: um sistema gerenciador de banco de dados deve fornecer recursos para restauração caso ocorra falhas de hardware ou software. O subsistema de backup e restauração do SGBD é o responsável pela restauração.

\subsubsection{Conceitos e Arquiteturas de um Sistema Gerenciador de Banco de Dados (SGBD)}

Entende-se por Modelos de Dados um conjunto de conceitos que podem ser usados para descrever a estrutura de uma base de dados. Muitos modelos de dados têm sido propostos. Pode - se classificar os modelos de dados baseando-se nos tipos de conceitos que fornecem para descrever a estrutura da base de dados:

- Modelos de Dados Conceituais ou de Alto-Nível: fornecem conceitos próximos à percepção dos usuários. Utilizam conceitos tais como Entidades, Atributos e Relacionamentos e algumas vezes são chamados de Modelos Baseados em objeto devido, principalmente, à sua característica de descreverem objetos e seus relacionamentos. 
- Modelos de Dados de Baixo - Nível: descreve como os dados são armazenados no computador, representando informações em formato de registros, ordem dos registros e caminho de acesso. Um Caminho de Acesso é uma estrutura de que facilita a busca de um registro particular na base de dados.

Entende-se por estrutura de uma base de dados os tipos de dados, relacionamentos e restrições pertinentes aos dados. Muitos modelos de dados também definem um conjunto de operações para especificar como recuperar e modificar a base de dados.

Em qualquer modelo de dados é importante distinguir entre descrição da base de dados da própria base de dados.

a) Esquema da Base de Dados (ou Base-Intencional): é a descrição de uma base de dados. Um esquema de base de dados é especificado durante o projeto da base de dados, sendo que a expectativa de mudanças não é grande. A forma de visualização de um esquema é chamada Diagrama do Esquema. Muitos modelos de dados têm certas convenções para, diagramaticamente, mostrar esquemas especificados no modelo.

b) Instâncias da Base de Dados (ou Ocorrências ou Estados): são dados atualmente existentes em uma base de dados que podem mudar com relativa frequência. Uma instância também é chamada de Base - Extensional do esquema. 


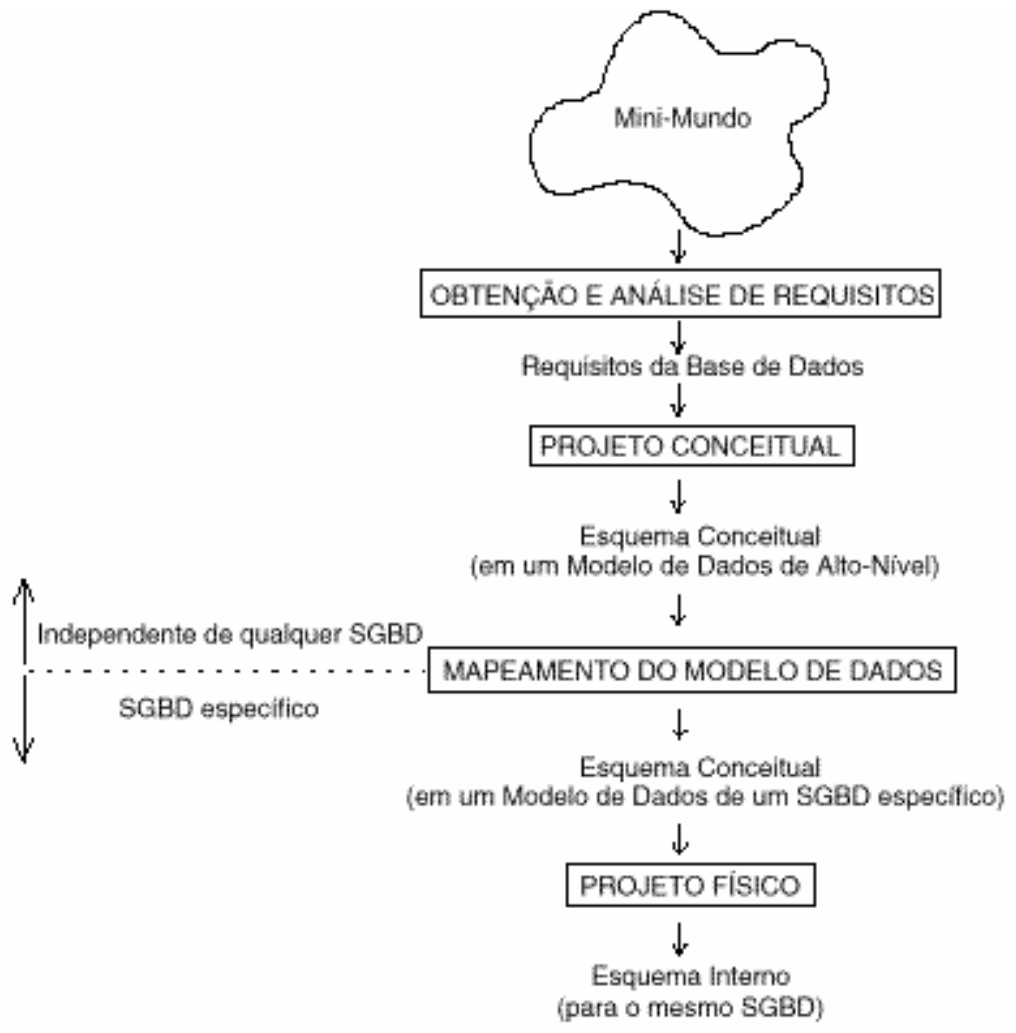

FIGURA 2.13 - Projeto da Base de Dados.

Fonte: (MACHADO \& ABREU, 1996)

\subsubsection{Modelagem Conceitual}

Segundo (MACHADO \& ABREU, 2005) quando se fala em Modelo Conceitual, estamos nos referindo a primeira etapa do projeto de um sistema de aplicação em banco de dados.

O objetivo do modelo conceitual é descrever as informações contidas em uma realidade, as quais estarão armazenadas em um banco de dados. É uma descrição de alto nível, mas que tem a preocupação de captar e retratar a realidade de uma organização, setor, repartição e departamento. 
- Modelo Conceitual: modelo de dados abstrato, que descreve a estrutura de um banco de dados de forma independente de um SGBD particular.

Nesta fase é construído o Modelo Conceitual, na forma de um Diagrama Entidade - Relacionamento (DER). Este modelo captura as necessidades da organização em termos de armazenamento de dados, independente das restrições de implementação.
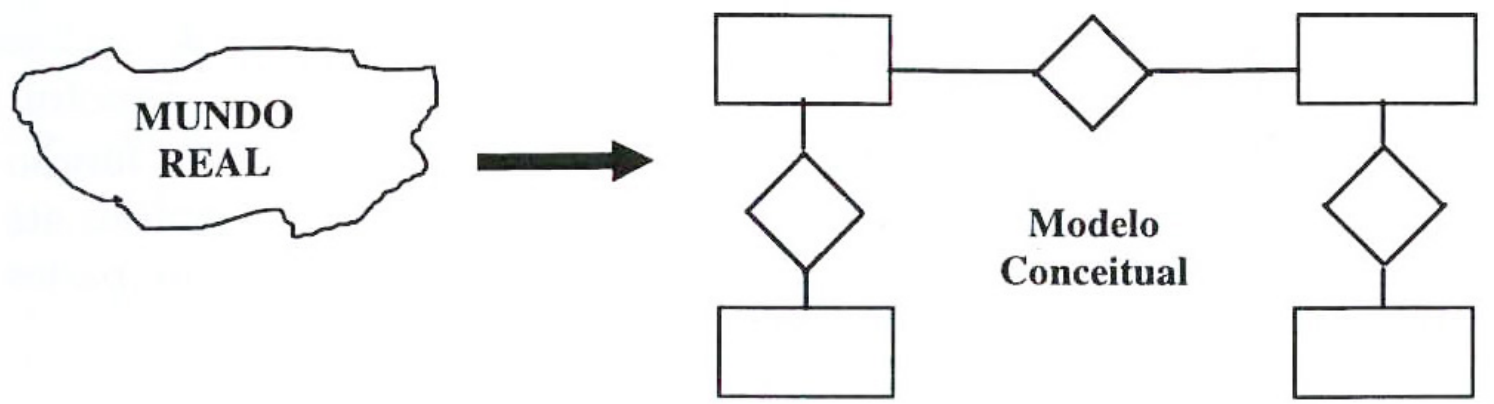

FIGURA 2.14 - Diagrama de Entidade - Relacionamento (DER).

Fonte: (MACHADO \& ABREU, 2005).

O Modelo Conceitual não é construído com considerações procedurais, não existindo preocupação com as operações de manipulação e manutenção dos dados. É na fase de modelagem que iremos desenvolver um modelo de dados.

- Modelo Lógico: modelo que representa a estrutura de dados de um banco de dados conforme vista pelo usuário do SGBD e tem como objetivo transformar o modelo conceitual em um modelo lógico, que define como a base de dados será implementada em um SGBD específico. 


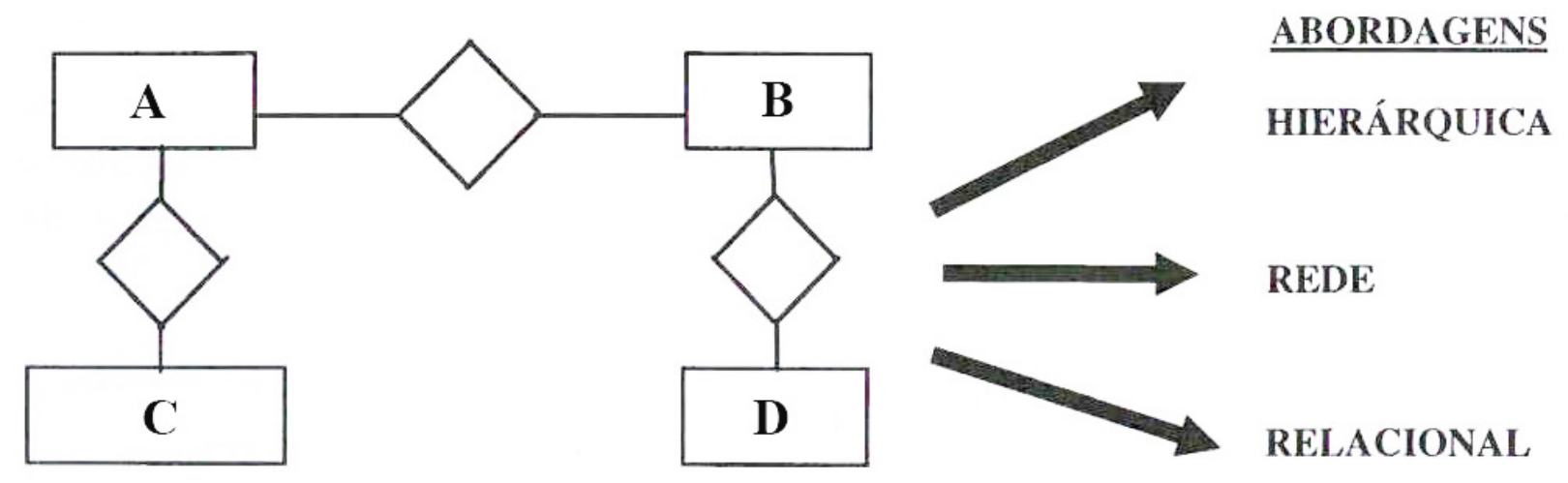

FIGURA 2.15 - Esquema Lógico de Dados com as Abordagens citadas.

Fonte: (MACHADO \& ABREU, 2005).

- Modelo Físico: o modelo físico é a etapa final do projeto de Banco de Dados e irá partir do Modelo Lógico fazendo a descrição das estruturas físicas de armazenamento de dados, tais como: tamanho de campo, índices, tipo de preenchimento destes campos e nomenclaturas, projetadas de acordo com os requisitos de processamento e economizando nos recursos computacionais. Este modelo faz o detalhamento do estudo dos métodos de acesso do SGBD, para elaboração dos índices de cada informação colocada nos Modelos Conceitual e Lógico.

\subsubsection{O Projeto de Banco de Dados}

Todo o projeto de um sistema de aplicação para banco de dados necessita de um coração, um centro nervoso do mesmo. A modelagem de um sistema partindo da abordagem Entidade - Relacionamento mostra este ponto central no Projeto Conceitual. 
O objetivo da Modelagem de Dados é apresentar uma representação única, não redundante e resumida, dos dados de uma aplicação. Em projetos conceituais de aplicações em banco de dados o modelo Entidade - Relacionamento é o mais utilizado para a representação e entendimento dos dados que compõem a essência de um sistema. Segundo (MACHADO \& ABREU, 2005) o projeto de um sistema de informações é uma atividade complexa que inclui planejamento, especificações e desenvolvimento de vários componentes. A aplicação de uma abordagem correta de metodologia orientada a banco de dados envolve a estruturação nos três níveis de visão de dados apresentados anteriormente, ou seja, três etapas na execução de um projeto: Conceitual, Lógico e Físico.

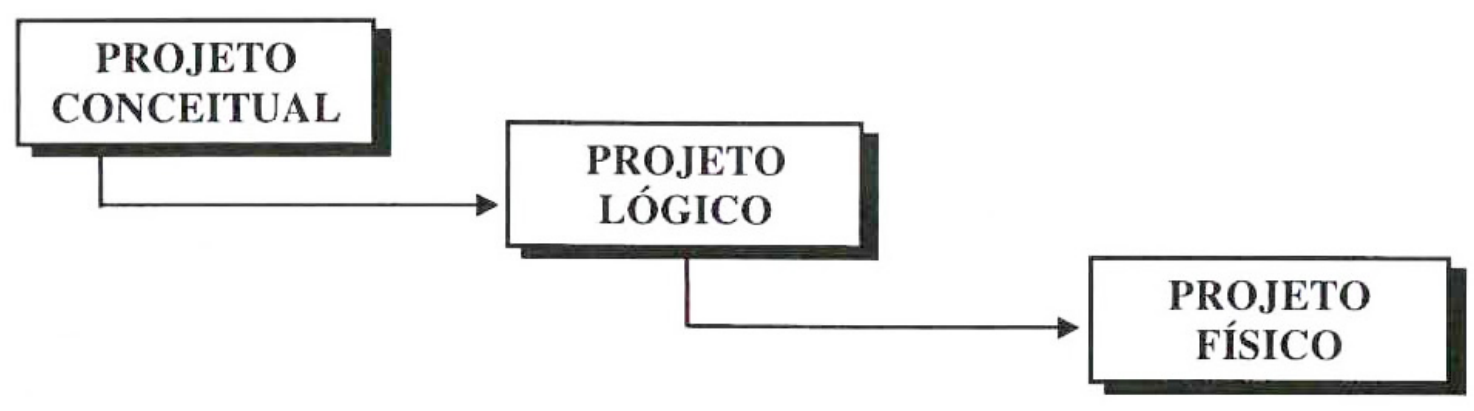

FIGURA 2.16 - Modelo com os Níveis de Visão de Dados.

Fonte: (MACHADO \& ABREU, 2005).

\subsubsection{Modelo Entidade - Relacionamento (MER)}

O MER é um modelo de dados conceitual de alto - nível. Assim, os conceitos do MER foram projetados para serem compreensíveis a usuários, descartando detalhes de como os dados são armazenados. 
Atualmente, o MER é usado principalmente durante o processo de projeto da base de dados.

Os objetos conceituais utilizados para modelagem do MER são:

- Entidade: conjunto de objetos da realidade modelada sobre os quais deseja - se manter informações na base de dados.

- Atributo: dado que é associado a cada ocorrência de uma entidade ou de um relacionamento.

- Relacionamento: conjunto de associações entre entidades. Os tipos de relacionamentos mais comuns são: 1:1 (Um para Um), 1:N (Um para Muitos) ou $\mathrm{N}: 1$ (Muitos para Um) e N:N ( Muitos para Muitos).

As principais propriedades do Modelo de Entidade - Relacionamento são:

- Um Modelo E-R é um modelo formal, preciso, não ambíguo, portanto diferentes "leitores" do modelo devem sempre entender exatamente o mesmo.

- A abordagem E-R tem poder de expressão limitada: há muitas restrições de integridade que não se deixam expressar através de um Modelo E-R.

- Equivalência de modelos: diferentes modelos podem ser equivalentes, ou seja, geram o mesmo modelo de BD relacional através das regras de transformação. Por mesmo modelo de BD relacional entende-se BDS que tenham a mesma estrutura (Tabelas, Colunas) sem levar em conta possíveis diferenças nos nomes que foram atribuídos.

A determinação de que construção do Modelo E-R (Entidade, Relacionamento e Atributo) são utilizados para modelar um objeto, não pode ser feita através da observação do objeto isoladamente: deve-se conhecer o contexto geral. Portanto, recomenda - se que as decisões tomadas na modelagem sejam consideradas sujeitas as alterações: são feitos vários esboços. 


\subsubsection{Modelo Relacional}

Criado por Edgar F. Codd, nos anos 70, começou realmente a ser utilizado nas empresas a partir de 1987. A abordagem relacional está baseada no princípio e que as informações em uma base de dados podem ser consideradas como relações matemáticas e que estão representadas de maneira uniforme, através do uso de tabelas bidimensionais. Este princípio coloca os dados (Entidades e Relacionamentos) dirigidos para estruturas mais simples de armazenar dados, que são as tabelas, e nas quais a visão do usuário é privilegiada. (MACHADO \& ABREU, 2005).

As tabelas são um conjunto não ordenado de linhas ou tuplas (terminologia acadêmica) e as colunas representam os atributos, e seus relacionamentos compõem as tabelas. Para cada atributo há um conjunto de valores permitidos, que são chamados de domínio desse atributo.

\subsubsection{Principais Vantagens da Abordagem Relacional}

As principais vantagens da abordagem relacional são as seguintes:

- Independência total dos dados;

- Visão múltipla dos dados;

- Melhor comunicação entre CPD e usuários;

- Redução acentuada na atividade de desenvolvimento de aplicações e o tempo gasto em manutenção. 


\subsubsection{As 12 Regras de Codd}

Segundo (MACHADO \& ABREU, 2005) Codd, ao definir o modelo relacional estabeleceu - se um conjunto de 12 regras para a determinação de um banco de dados ser realmente relacional. Segundo estas regras, discute - se fidelidade de um SGBD ao modelo relacional. Raros são os bancos de dados que se enquadrem em mais do que 10 destas regras. Conforme (MACHADO \& ABREU, 2005) as regras de Codd são:

1. Toda informação num banco de dados relacional é apresentada a nível lógico por valores em tabelas;

2. Todo dado em um banco de dados relacional tem a garantia de ser logicamente acessível, recorrendo - se a uma combinação do nome da tabela, um valor de chave e o nome da coluna;

3. Tratamento sistemático de valores nulos (ausência de dados);

4. O dicionário de dados (catálogo) relacional ativo é baseado no modelo relacional;

5. O SGBD relacional deve ter uma linguagem para definição, detalhamento e manipulação de dados;

6. Tratamento das atualizações de visões de dados;

7. Tratamento de alto-nível para inserção, atualização e eliminação de dados;

8. Independência dos dados físicos (mudança na memória e no método de acesso);

9. Independência de dados lógicos (mudanças de qualquer tipo nas tabelas básicas, ex: divisão de uma tabela por linha ou coluna);

10. Independência das restrições de integridade; 
11. Independência de distribuições;

12. Não subversão das regras de integridade ou restrições quando se utiliza uma linguagem de baixo nível.

\subsubsection{O Conceito de Chave no Modelo Relacional}

O conceito básico de chaves é para identificar linhas, buscar um dado que será empregado nas consultas à base de dados. É um conceito lógico da aplicação e podem ser classificados como:

\section{a) Chave Primária}

A Chave Primária é uma coluna ou uma combinação de colunas cujos valores distinguem uma linha das demais dentro de uma tabela.

- A chave primária deve ser mínima;

- Quando se estabelece uma chave primária, está se definindo uma restrição de integridade.

\section{b) Chave Estrangeira}

A Chave Estrangeira ou Secundária é uma coluna ou uma combinação de colunas cujos valores aparecem necessariamente na chave primária de uma tabela. É um mecanismo que permite a implementação de relacionamentos em um BD relacional.

A existência de uma chave estrangeira impõe restrições que devem ser garantidas ao executar diversas operações de alteração do banco de dados:

- Quando da inclusão de uma linha na tabela que contém a chave estrangeira; 
- Quando da alteração do valor da chave estrangeira;

- Quando da exclusão de uma linha na tabela que contém a chave primária referenciada pela chave estrangeira;

- Quando da alteração de uma linha na tabela que contém a chave primária referenciada pela chave estrangeira.

\subsubsection{Regras de Integridade do Modelo Relacional}

Um dos objetivos primordiais de um SGBD é manter a integridade dos dados. Dados íntegros significam que eles refletem corretamente a realidade apresentada e são consistentes entre si. A Restrição de Integridade é uma regra de consistência de dados garantida pelo próprio SGBD, dividindo - se em quatro categorias:

- Integridade de Domínio: restrições deste tipo especificam que o valor de um campo deve obedecer à definição de valores admitidos para a coluna (o domínio da coluna);

- Integridade de Vazio: através deste tipo de restrição são especificados se os campos de uma coluna podem ou não ser deixados vazios;

- Integridade de Chave: é a restrição que define se os valores das chaves primárias e alternativas devem ser únicos;

- Integridade Referencial: é a restrição que define que os valores dos campos que aparecem em uma chave estrangeira devem aparecer na chave primária da tabela referenciada. 
O banco de dados relacional deve conter no mínimo as definições de tabelas que formam $\mathrm{O} B \mathrm{~B}$, as colunas que as tabelas possuem e as restrições de integridade.

\subsubsection{Características do Modelo Relacional}

Segundo (MACHADO e ABREU, 2005) as principais características de um Modelo Relacional são:

- Uma tabela é acessível por qualquer campo (atributo) independente se este é declarado como chave ou não;

- O relacionamento entre conjunto de dados (tabelas) não existe fisicamente, pois este é apenas lógico e representado através das chaves estrangeiras;

- Utilização de linguagens autocontidas e não procedurais;

- Os ambientes relacionais possuem um otimizador estratégico para escolher o melhor caminho para recuperação dos dados.

\subsubsection{A Importância da Linguagem SQL}

Quando os Bancos de Dados Relacionais estavam sendo desenvolvidos, foram criadas linguagens destinadas à sua manipulação. O Departamento de Pesquisas da IBM desenvolveu a SQL (Linguagem Estruturada de Pesquisa) como forma de interface para o sistema de BD relacional denominado SYSTEM R, no início dos anos 70. Em 1982, o American National Standard Institute (ANSI), publicou um padrão SQL. A SQL estabeleceu - se como linguagem padrão de Banco de Dados Relacional. 
A linguagem SQL foi desenvolvida propriamente para o ambiente relacional, podendo ser adaptada a qualquer ambiente não relacional.

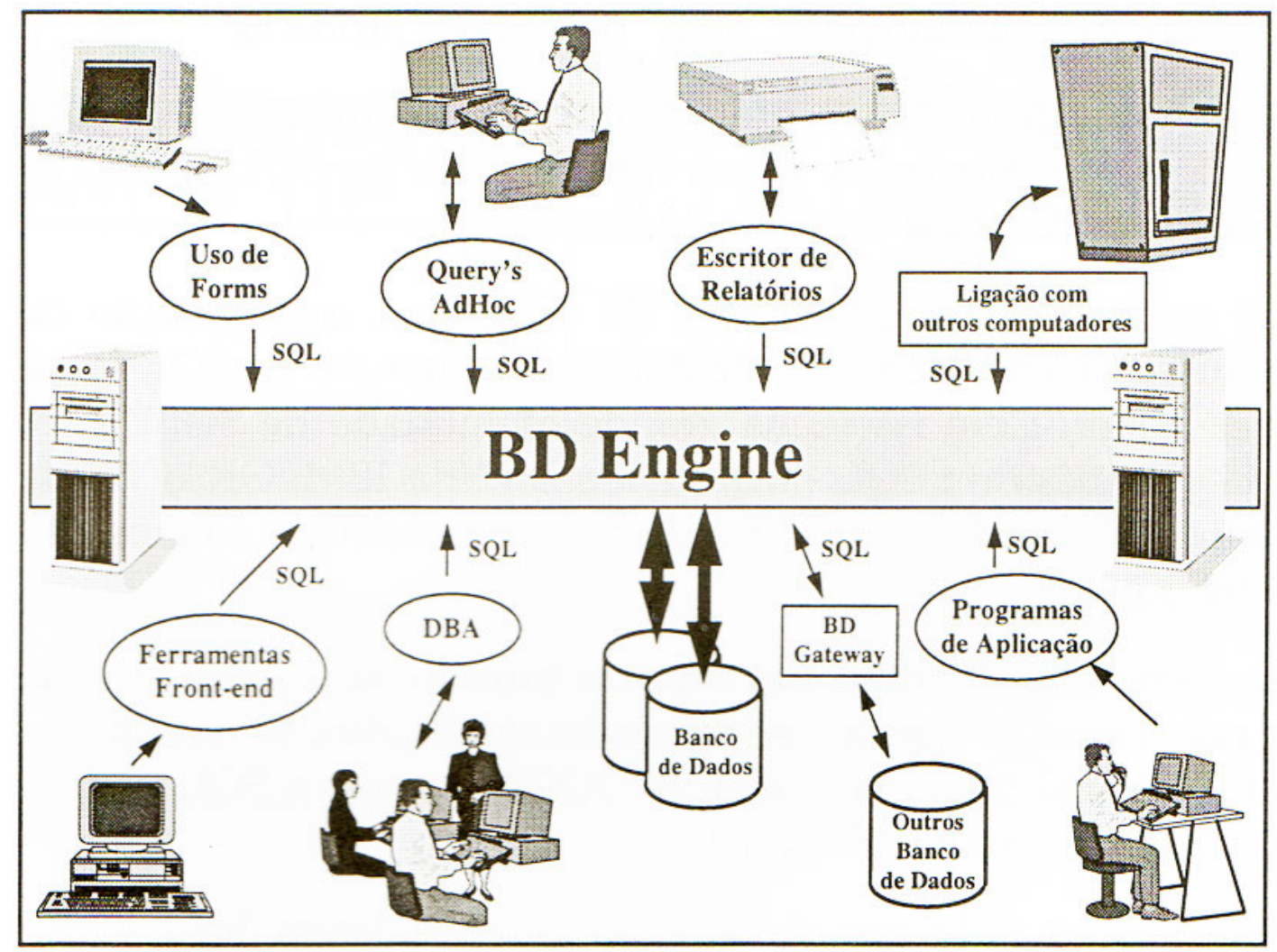

FIGURA 2.17 - Modelo ilustra os diversos enfoques da Linguagem SQL.

Fonte: (MACHADO e ABREU, 2005)

Atualmente segundo (MACHADO \& ABREU, 2005), a linguagem SQL, assume um papel muito importante nos sistemas de gerenciamento de banco de dados, podendo ter muitos enfoques, como apresenta a Figura (2.15):

- Linguagem Interativa de Consulta: a partir de comandos SQL, os usuários podem montar consultas sem a necessidade de criação de um programa, podendo utilizar Forms ou ferramentas de montagem de relatório; 
- Linguagem de Programação para Acesso a Banco de Dados: por meio de comandos SQL embutidos em programas de aplicação que acessam os dados armazenados;

- Linguagem de Administração de Banco de Dados: o responsável pela administração do banco de dados é o Administrador da Base de Dados (DBA), este pode utilizar comandos SQL para realizar suas tarefas;

- Linguagem Cliente/Servidor: os programas (cliente) dos computadores pessoais usam comandos SQL para se comunicarem por meio de uma rede local, compartilhando os dados armazenados em único local (servidor), essa arquitetura minimiza o tráfego de dados pela rede;

- Linguagem para Banco de Dados Distribuído: a linguagem SQL auxilia na distribuição dos dados por meio de nós, conectados ao sistema de computação e também na comunicação de dados com outros sistemas;

- Caminho de Acesso a outros Bancos de Dados em Diferentes Máquinas: a SQL auxilia na conversão entre diferentes produtos de banco de dados colocados em diferentes máquinas (de micro até mainframe).

Por ser uma linguagem de inúmeras aplicações, a SQL pode manipular objetos de diferentes classes FIGURA (2.18) entre as funções de um SGBD: 


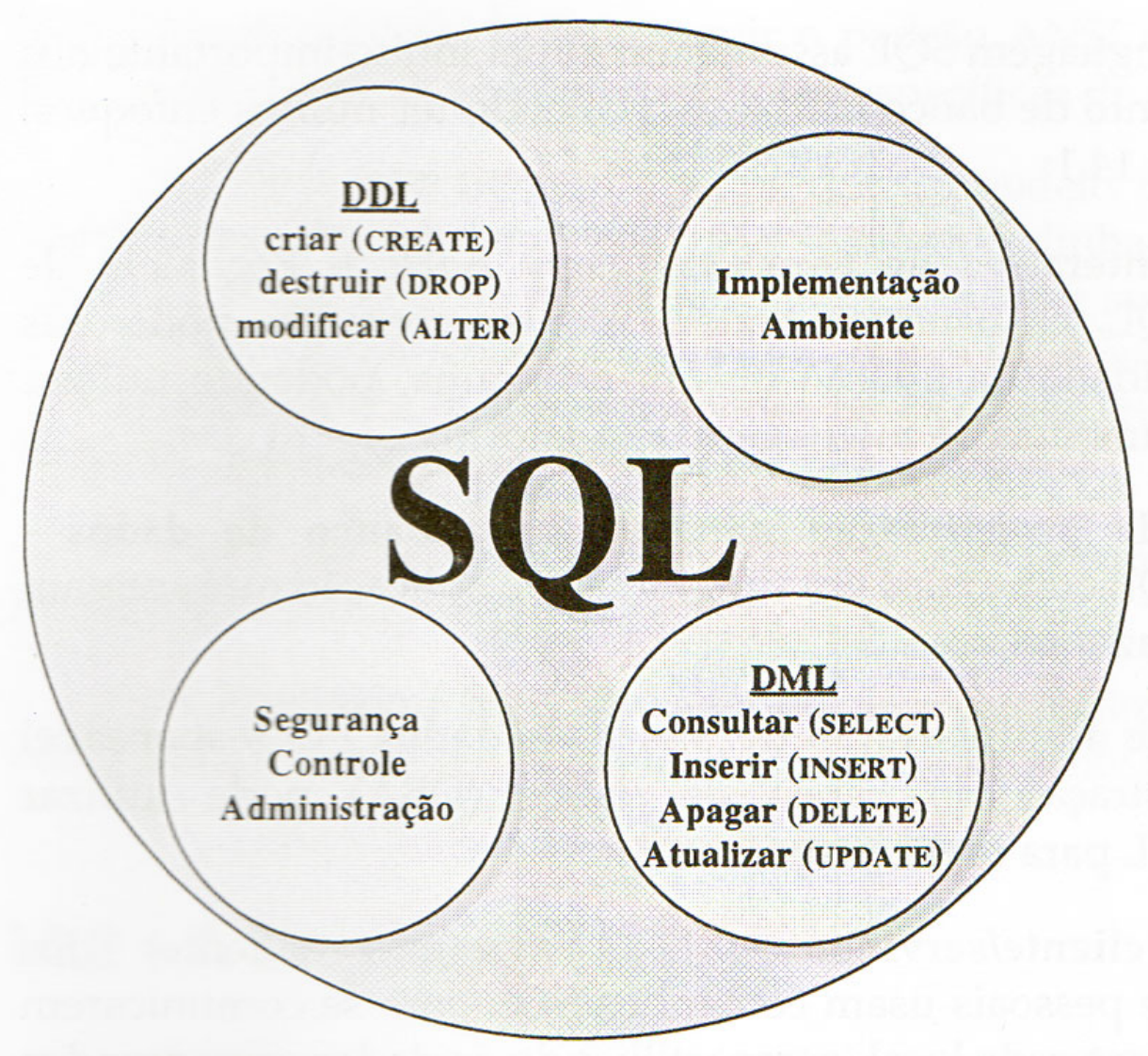

FIGURA 2.18 - Diagrama ilustra a manipulação de objetos na linguagem SQL.

Fonte: (MACHADO \& ABREU, 2005)

- Definição de Dados (DDL - Linguagem de Definição de Dados): permite ao usuário, definir a estrutura e organização dos dados armazenados, e as relações que existem entre eles;

- Manipulação de Dados (DML - Linguagem de Manipulação de Dados): permiti ao usuário ou a um programa de aplicação, a inclusão, remoção, seleção ou atualização de dados armazenados no banco;

- Controle de Acesso: protege os dados de manipulações não autorizadas; 
- Compartilhamento de Dados: coordena o compartilhamento dos dados por usuários concorrentes, sem interferir na ação de cada um deles;

- Integridade dos Dados: auxilia no processo de definição da integridade dos dados, protegendo contra corrupções, inconsistências e falhas do sistema de computação.

As principais vantagens da linguagem SQL, com o uso da padronização são:

- Independência de Fabricante;

- Portabilidade entre Computadores;

- Redução dos Custos de Treinamento;

- Inglês Estruturado de Alto Nível;

- Consulta Interativa;

- Múltiplas Visões dos Dados;

- Definição Dinâmica dos Dados.

Apesar de possuir todas essas vantagens, algumas desvantagens são dirigidas à SQL:

- A padronização inibe a criatividade dos desenvolvedores das aplicações, ou seja, fica preso a soluções padronizadas, não podendo sofrer melhorias ou alterações;

- Definição formal da linguagem após sua criação;

- Discordância com as linguagens hospedeiras (COBOL, FORTRAN e C);

- Falta de algumas funções;

- Não dá suporte a alguns aspectos do modelo relacional como, por exemplo, atribuição de relação e domínios. 
A linguagem SQL mesmo enfrentando alguns problemas e críticas, veio para ficar, auxiliando de forma bastante profunda a vida dos usuários e analistas no trabalho de manipulação dos dados armazenados em um banco de dados relacional.

\subsubsection{Projeto Orientado a Objetos - Objetivos, Princípios e Padrões}

Segundo (GOODRICH \& TAMASSIA, 2007) os "autores" principais do paradigma de projetos orientados a objetos são chamados de objetos. Um objeto se origina de uma classe, que é uma especificação tanto dos campos de dados, também chamados de variáveis de instância que um objeto contém, como métodos (operações) que pode executar. Cada classe apresenta para o mundo exterior uma visão concisa e consistente dos objetos que são instâncias dessa classe sem detalhes desnecessários ou acesso às estruturas internas dos objetos. Essa abordagem de computação visa atingir diversos objetivos e incorporar vários princípios de projeto.

\subsubsection{Objetivos do Projeto Orientado a Objetos}

As implementações do Software devem buscar robustez, adaptabilidade e reusabilidade como mostra a FIGURA (2.19): 


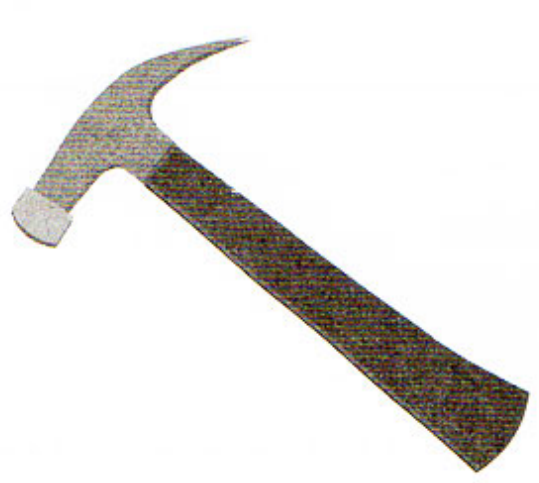

Robustez

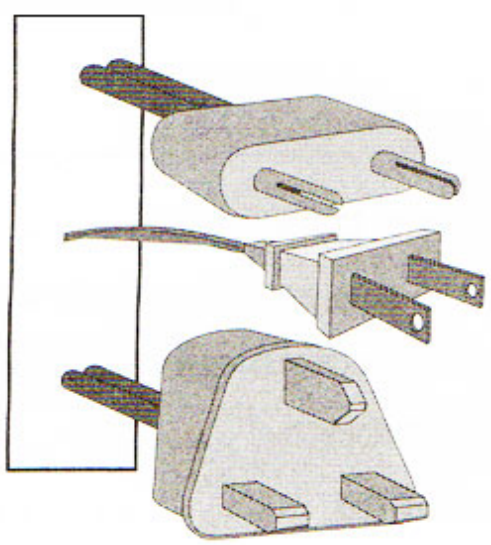

Adaptabilidade

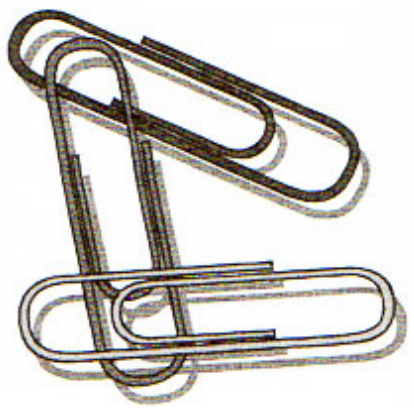

Reusabilidade

FIGURA 2.19 - Objetivos de um projeto orientado a objetos.

Fonte: (GOODRICH \& TAMASSIA, 2007).

- Robustez: todo programador tem o objetivo de produzir software que seja correto, o que significa um programa que produz as saídas certas para todas as entradas previstas pela aplicação do programa. Além disso, é desejável que um software seja robusto, ou seja, capaz de lidar com entradas inesperadas que não estão explicitamente definidas em sua aplicação.

- Adaptabilidade: o software deve ser capaz de evoluir ao longo do tempo em resposta a alterações nas condições de seu ambiente, portanto, a adaptabilidade também conhecida como capacidade de evolução é outro objetivo importante a ser atingido em qualidade de software. Portanto, outro conceito relacionado é portabilidade, que consiste na habilidade que um software tem de ser executado, com alterações mínimas, em diferentes plataformas de hardware ou sistemas operacionais. Uma das vantagens de se escrever programas em Java é a portabilidade oferecida naturalmente pela linguagem. 
- Reusabilidade: da mesma forma que se busca a capacidade de adaptação, é desejável que um software possa ser reutilizável, ou seja, que seu código possa ser usado como componente de diferentes sistemas em várias aplicações. Desenvolver um software de qualidade pode ser um empreendimento caro, porém, se for projetado de forma reutilizável em aplicações futuras, seu custo pode ser reduzido.

\subsubsection{Princípios de Projeto Orientado a Objetos}

Os principais princípios da abordagem orientada a objetos FIGURA (2.20) que visam facilitar os objetivos anteriormente descritos são os seguintes:

- Abstração;

- Encapsulamento;

- Modularidade.

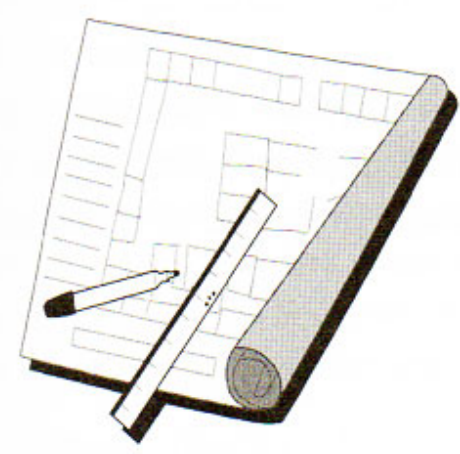

Abstração

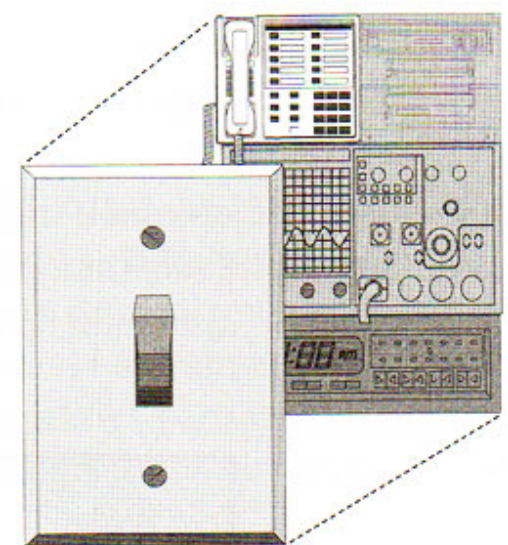

Encapsulamento

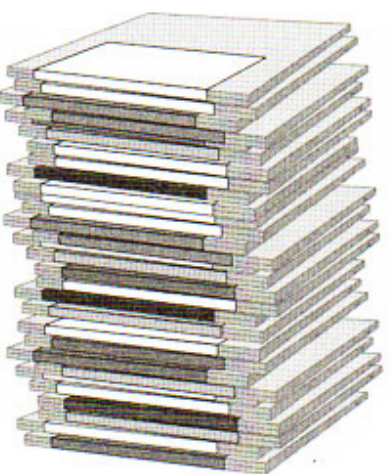

Modularidade

FIGURA 2.20 - Princípios de projeto orientado a objetos.

Fonte: (GOODRICH \& TAMASSIA, 2007) 
- Abstração: a noção de abstração significa decompor um sistema complicado em suas partes fundamentais e descrevê-las em uma linguagem simples e precisa. A descrição das partes de um sistema implica atribuir - Ihes um nome e descrever suas funcionalidades.

- Encapsulamento: o conceito de encapsulamento estabelece que os diferentes componentes de um sistema de software não devem revelar detalhes de suas respectivas implementações. A principal vantagem do enacapsulamento é que ele oferece ao programador liberdade na implementação dos detalhes do sistema. A única restrição ao programador é manter a interface abstrata que é percebida pelos de fora.

- Modularidade: outro princípio fundamental de projeto orientado a objetos é a modularidade Sistemas modernos de software normalmente são compostos por vários componentes diferentes que devem interagir corretamente, fazendo com que o sistema como um todo funcione de forma adequada. A modularidade se refere a uma estrutura de organização na qual os diferentes componentes de um sistema de software são divididos em unidades funcionais separadas.

\subsubsection{Herança e Polimorfismo}

Para tirar proveito de relacionamentos hierárquicos comuns em projetos de software, a abordagem de projeto orientado a objetos oferece maneiras de reutilizar o código. 
Conforme (GOODRICH \& TAMASSIA, 2007) a estrutura imposta pela modularidade auxilia a tornar o software reutilizável. Se os módulos do software forem escritos de uma forma abstrata para resolver problemas genéricos, então os módulos podem ser reutilizados quando instâncias do mesmo problema surgirem em outros contextos. Uma forma natural de organizar vários componentes estruturais de um pacote é de uma forma hierárquica, que agrupa definições abstratas similares juntas nível a nível, partindo do mais específico para o mais genérico, à medida que se percorre a hierarquia. Um uso normal de tais hierarquias ocorre em um gráfico organizacional, no qual cada arco que sobe pode ser lido como "é um", como em "um rancho é uma casa é um prédio". Esse tipo de hierarquia também é útil no projeto de software quando agrupa funcionalidades comuns no nível mais geral e vê comportamentos especializados como uma extensão do comportamento geral. (GOODRICH \& TAMASSIA, 2007).

\subsubsection{Herança}

O paradigma de orientação a objetos por (GOODRICH \& TAMASSIA, 2007) oferece uma estrutura hierárquica modular para reutilização de código através de uma técnica conhecida como herança. Essa técnica permite projetar classes genéricas que podem ser especializadas em classes mais particulares, em que as classes especializadas reutilizam o código das mais genéricas. A classe genérica também conhecida como classe base ou superclasse, define variáveis de instâncias "genéricas" e métodos que se aplicam em uma variada gama de situações. A classe que especializa, estende ou herda de uma superclasse não necessita fornecer uma nova implementação para os métodos genéricos, uma vez que os herda. Deve 
apenas definir aqueles métodos que são especializados para a subclasse em particular. Um outro conceito, bastante utilizado aqui é o de Polimorfismo. Conforme (GOODRICH \& TAMASSIA, 2007) literalmente, "polimorfismo" significa "muitas formas". No contexto de projeto orientado a objetos, entretanto refere - se à habilidade de uma variável de objeto de assumir várias formas diferentes. Linguagens orientadas a objetos, tais como Java, referenciam objetos usando variáveis referência.

A herança, polimorfismo e a sobrecarga de métodos, segundo (GOODRICH \& TAMASSIA, 2007) suportam o desenvolvimento de software reutilizável. Podem - se estabelecer classes que herdam as variáveis e os métodos de instância genéricos e que, a seguir, definem novas variáveis e métodos de instância mais específicos que lidam com os aspectos particulares dos objetos da nova classe.

\subsubsection{A Linguagem JAVA}

A linguagem de programação Java é uma linguagem de alto nível cuja principal característica é ser orientada a objetos. Além disso, a linguagem de programação Java tem característica de ser compilada para uma linguagem intermediária denominada Java bytecode, que é constituída por instruções que podem ser executadas pela plataforma Java. Foi desenvolvida na década de 90 por uma equipe de programadores chefiada pelo engenheiro James Gosling, na empresa Sun Microsystems. Diferentemente das linguagens convencionais, que são compiladas para código nativo, a linguagem Java é compilada para um "bytecode" que é executado por uma máquina virtual. 
Os bytecodes segundo (THOMPSON, 2003) Java possibilitam escrever programas uma única vez, que podem ser executados em qualquer lugar. Uma vez que um computador tenha uma Máquina Virtual Java instalada, ele pode executar bytecodes Java que foram gerados em outro computador, de hardware e/ou sistema operacional diferente.

O processo utilizado na programação em Java por (THOMPSON, 2003) é praticamente o mesmo das outras linguagens: digitar código, compilar, executar e depurar quando necessário. A FIGURA (2.21) seguinte ilustra o processo:

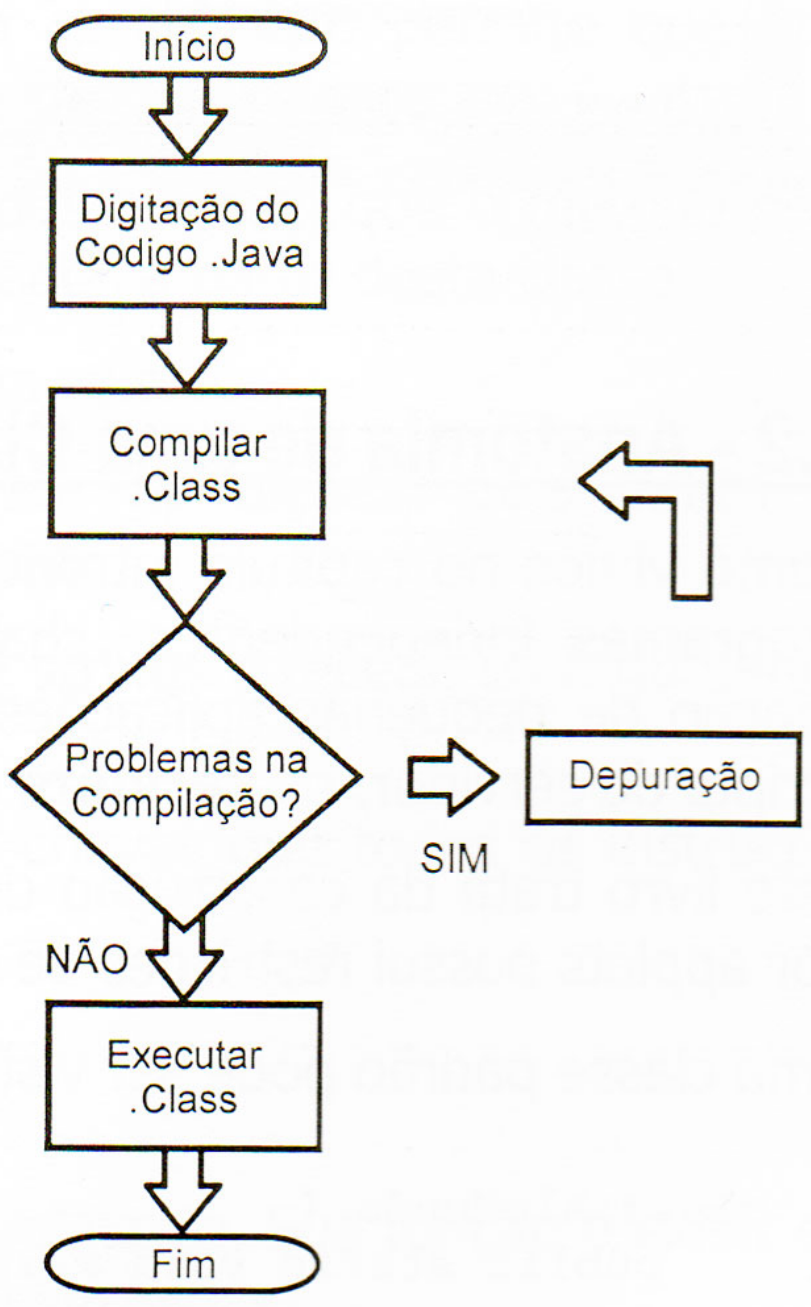

FIGURA 2.21 - Processo de compilação e execução de um programa em Java.

Fonte: (THOMPSON, 2003). 
As principais características da linguagem Java se referem a objetos, portabilidade, suporte à comunicação em rede e acesso remoto a banco de dados:

- Orientação a objetos;

- Portabilidade e Independência de plataforma;

- Multithreading (linhas de execução);

- Suporte a comunicação em rede;

- Acesso remoto a banco de dados.

A linguagem Java é indicada para o desenvolvimento de grandes aplicações como sistemas bancários, industriais e outros que tenham os fatores de segurança, compatibilidade e multiplataforma como fundamentais. Utilizada à criação de aplicações embutidas de aparelhos eletrodomésticos e eletroeletrônicos, como por exemplo, fornos de microondas, celulares e câmeras digitais.

\subsubsection{A Plataforma Java}

A Plataforma segundo (FURGERI, 2003) é um ambiente de software ou hardware no qual um programa roda. A maioria das plataformas é formada pelo conjunto hardware e software que atuam juntos. A Java difere da maioria das outras plataformas porque é composta apenas de um software operando sobre uma outra plataforma qualquer.

Conforme (FURGERI, 2003) a plataforma Java é uma nova plataforma de software que possibilita que um mesmo programa seja executado em diversas plataformas, talvez a característica mais importante da linguagem Java. Os bytecodes gerados pelo processo de compilação, que não são específicos a qualquer máquina física, são instruções de máquinas para uma máquina virtual. Um 
programa escrito na linguagem Java é compilado e gera um arquivo de bytecodes (com extensão .class), que pode ser executado onde quer que a plataforma Java esteja presente, em qualquer sistema operacional subjacente. Em outras palavras, o mesmo programa pode ser executado em qualquer sistema operacional que esteja executando a plataforma Java. A plataforma Java foi desenvolvida para ser segura, possibilitar manipulação de exceções e coleta de lixo, que libera, automaticamente, a memória alocada dinamicamente.

A Máquina Virtual Java (JVM) tem como objetivo executar os bytecodes Java, traduzindo - se para o código - nativo. Quando um programa é executado, a máquina virtual é quem controla as instruções da CPU, registradores, o controle de pilhas, controle de coletor de lixo e área de memória. A máquina virtual tem algumas vantagens como: portabilidade e otimização do bytecode sempre que possível.

\subsubsection{Ambientes de Desenvolvimento na Linguagem Java}

É possível desenvolver aplicações em Java através de vários ambientes integrados de desenvolvimento (IDES). Dentre as opções mais utilizadas podem - se destacar: Jedit, Jccreator, Eclipse, Netbeans, Jbuilder e Jdeveloper. 


\section{CAPÍTULO III}

\section{IMPLEMENTAÇÃO DO SOFTWARE SISLAM}

A seguir são detalhados os materiais que serão utilizados para o desenvolvimento deste trabalho. Em seguida é apresentada a metodologia utilizada visando se atingir os objetivos iniciais.

\subsection{Materiais e Métodos}

A partir do modelo criado, foi desenvolvido o protótipo do software na linguagem Java. Foi escolhida a linguagem Java, por ser simples, porém completa, robusta, portável, compacta, atual e flexível. Possui interface gráfica amigável, independente de plataforma e manutenibilidade para a incorporação de novas rotinas.

O Sistema além dos cálculos permite que grande parte do programa seja dedicado à manipulação dos dados, como cadastro de Resinas, Fibras, Compósitos, Laminados, Carregamentos e Análises.

A tela principal exibe um menu suspenso com os tipos de Materiais (Fibras, Resinas e Compósitos), Laminados, Carregamentos e Análises. 
As telas para cadastrar os dados são todas baseadas numa mesma estrutura.

Cada tela inicialmente exibe um grid com os itens cadastrados, um botão para inserção de um novo dado e o botão de fechar.

\subsection{Definição e Características do Ambiente de Desenvolvimento Netbeans}

O ambiente de programação escolhido para escrever o código fonte do protótipo foi Netbeans IDE 6.0.1, como mostra a FIGURA (3.1).

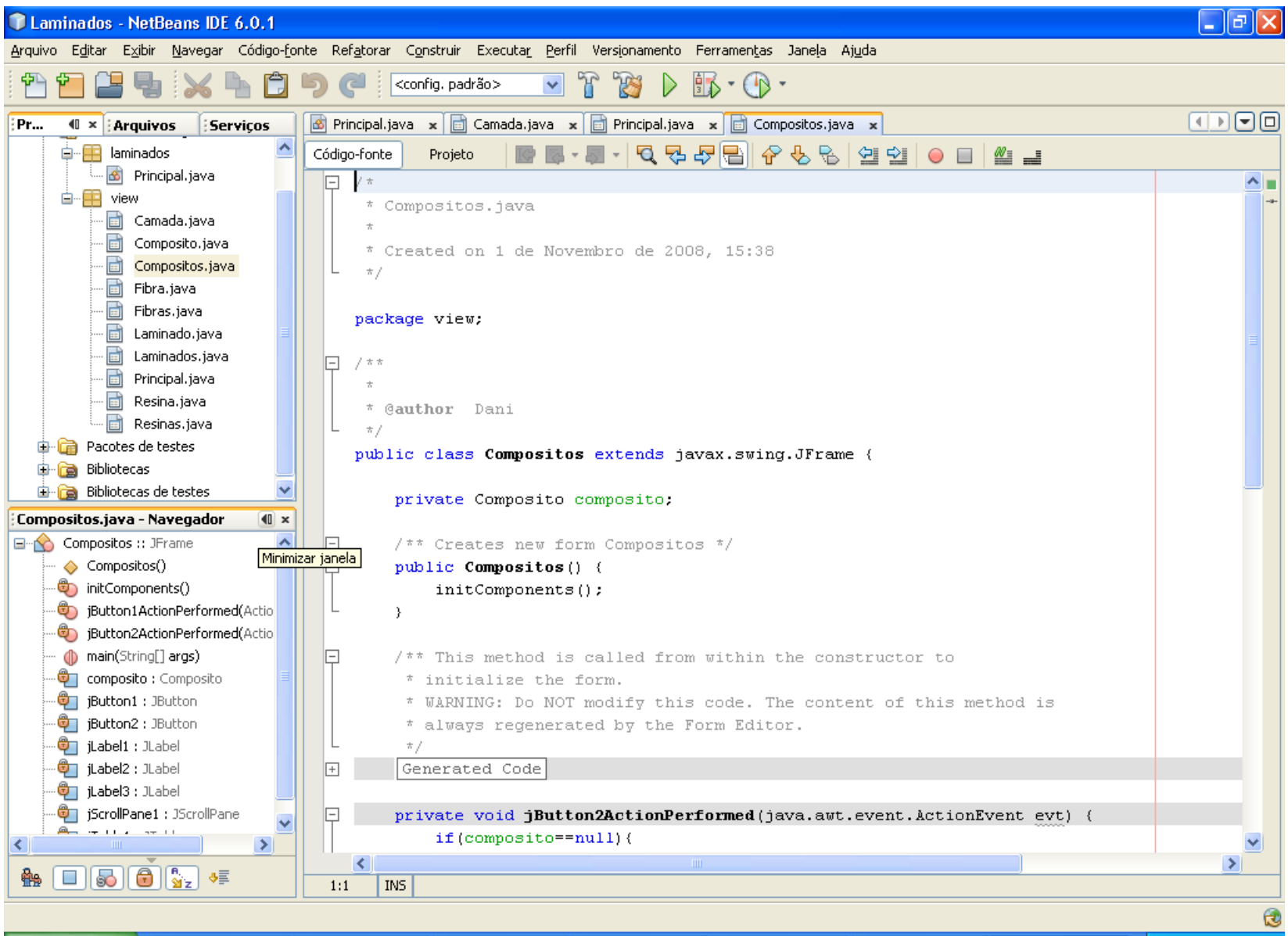

FIGURA 3.1 - Ambiente de Programação Netbeans IDE 6.0.1 
O Netbeans é um ambiente de desenvolvimento integrado (IDE), gratuito e de código aberto para desenvolvedores de software na linguagem Java. O IDE é executado em muitas plataformas, como Windows, Linux, Solaris e Macintosh. O Netbeans IDE oferece aos programadores uma ferramenta que auxilia a escrever, compilar, debugar e instalar aplicações e a criação de aplicativos profissionais de desktop, empresariais, web e móveis multiplataformas.

A IDE Netbeans foi arquitetada em forma de uma estrutura reutilizável que visa simplificar o desenvolvimento e aumentar a produtividade, pois disponibiliza em uma única aplicação todas estas funcionalidades. Totalmente escrita em Java, mas que pode suportar qualquer outra linguagem de programação.

O Netbeans fornece uma base sólida para a criação de projetos e módulos, possui um grande conjunto de bibliotecas, módulos e interface de programação de aplicativos (API's). As API's são um conjunto de instruções e padrões de programação para acesso a um aplicativo de software baseado na Web, ou ferramenta de web. Uma empresa de software lança seu API para o público, de modo, que outros criadores de software possam desenvolver produtos acionados por esse serviço. A distribuição da ferramenta é realizada sob as condições da SPL (Sun Public License), uma variação da MPL (Mozilla Public License), esta licença tem como objetivo garantir a redistribuição de conhecimento à comunidade de desenvolvedores quando novas funcionalidades forem incorporadas à ferramenta.

O ambiente Netbeans atualmente está distribuído em diversos idiomas tornando - o cada vez mais popular, facilitando o acesso a iniciantes em programação e possibilitado o desenvolvimento de aplicativos multilíngüe. 


\subsection{Sistema Gerenciador de Banco de Dados HSQLDB}

Como apresentado na FIGURA (3.1), definimos o Netbeans como o ambiente de desenvolvimento integrado de aplicações da linguagem Java, o próximo passo foi a escolha de um sistema gerenciador de banco de dados (SGBD) e que apresentasse flexibilidade em relação a outros Sistemas de Banco de Dados, uma vez que que um dos objetivos do trabalho é promover um ambiente amigável e de fácil manipulação para o usuário. As tecnologias de banco de dados tiveram um avanço significativo em áreas não convencionais, tais como: engenharia, medicina e educação. Essa denominação "não convencional " deve - se ao fato de que essas áreas envolvem processamento complexo de um garnde volume de dados, que pode incuir informações sobre um determinado projeto, imagens e multimídia.

Um sistema gerenciador de banco de dados (SGBD) é a união entre um conjunto de tabelas de programas que manipulem as informações sobre os seus dados (COSTA, 1996), objetivando manter um único depósito de dados.

Segundo (COSTA, 1996) as vantagens em se utilizar um Sistema de Banco de Dados são:

- Forçar Padronização;

- Flexibilidade;

- Redução do tempo de desnvolvimento de aplicações;

- Disponibilidades de informações atualizadas e consistentes;

- Economia com pessoal e equipamentos. 
O servidor selecionado foi o HSQLDB do inglês (Hyperthreaded Structured Query Language Data Base) é um Sistema Gerenciador de Banco de Dados (SGBD) de código aberto escrito na linguagem Java. Entretanto, o HSQLDB é uma solução simples, que utiliza poucos recursos e que possui bom desempenho. Devido a essas características, ele é bastante utilizado em aplicações que são executadas em desktops que necessitam interagir com uma camada de persistência através da linguagem SQL. A suíte office OpenOffice, na versão 2.0, destaca o HSQLDB como engine de armazenamento de dados com o principal objetivo de fornecer uma alternativa de baixo custo e de alta qualidade.

As principais características do Sistema Gerenciador de Banco de Dados HSQLDB são:

- Ocupa pouco espaço em disco;

- Dispensa configurações para operar;

- Criação de bancos de dados em arquivo texto e em memória;

- Portabilidade em virtude de sua implementação ser feita em Java;

- Suporte à linguagem SQL básica.

\subsection{Diagrama de Tabelas do Sistema}

Como ilustra a FIGURA (3.2) o Diagrama de Tabelas do Modelo Relacional do protótipo do sistema, foi construído em um dos ambientes integrados de desenvolvimento (IDE) da linguagem Java, o Eclipse. 


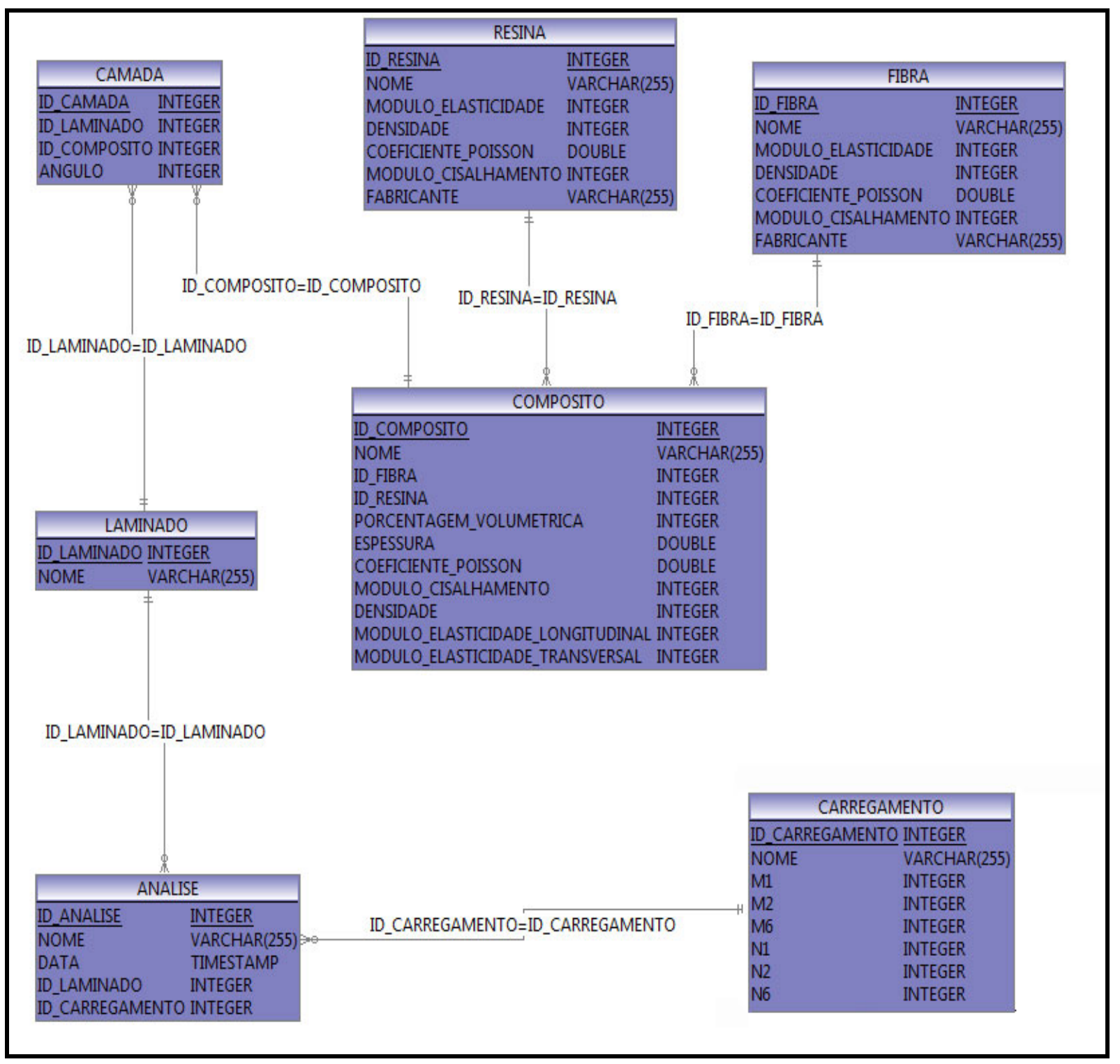

FIGURA 3.2 - Diagrama de Tabelas do Modelo Relacional do Sistema

\subsection{Construção das Interfaces Gráficas dos Módulos do Sistema}

A interação entre o usuário e o sistema de aplicação é muito importante, para a utilização mais eficiente dos recursos proporcionados pelo computador. Interfaces gráficas implementadas através de ícones, caixas de diálogos, figuras e gráficos facilitam o aprendizado e possibilitam uma maior interação entre o homem e a máquina. 


\subsubsection{Entrada de Dados}

Ao abrir o sistema, a tela principal oferece quatro menus. A partir dele temos acesso às funções e manipulação do sistema, como mostra a FIGURA (3.3):

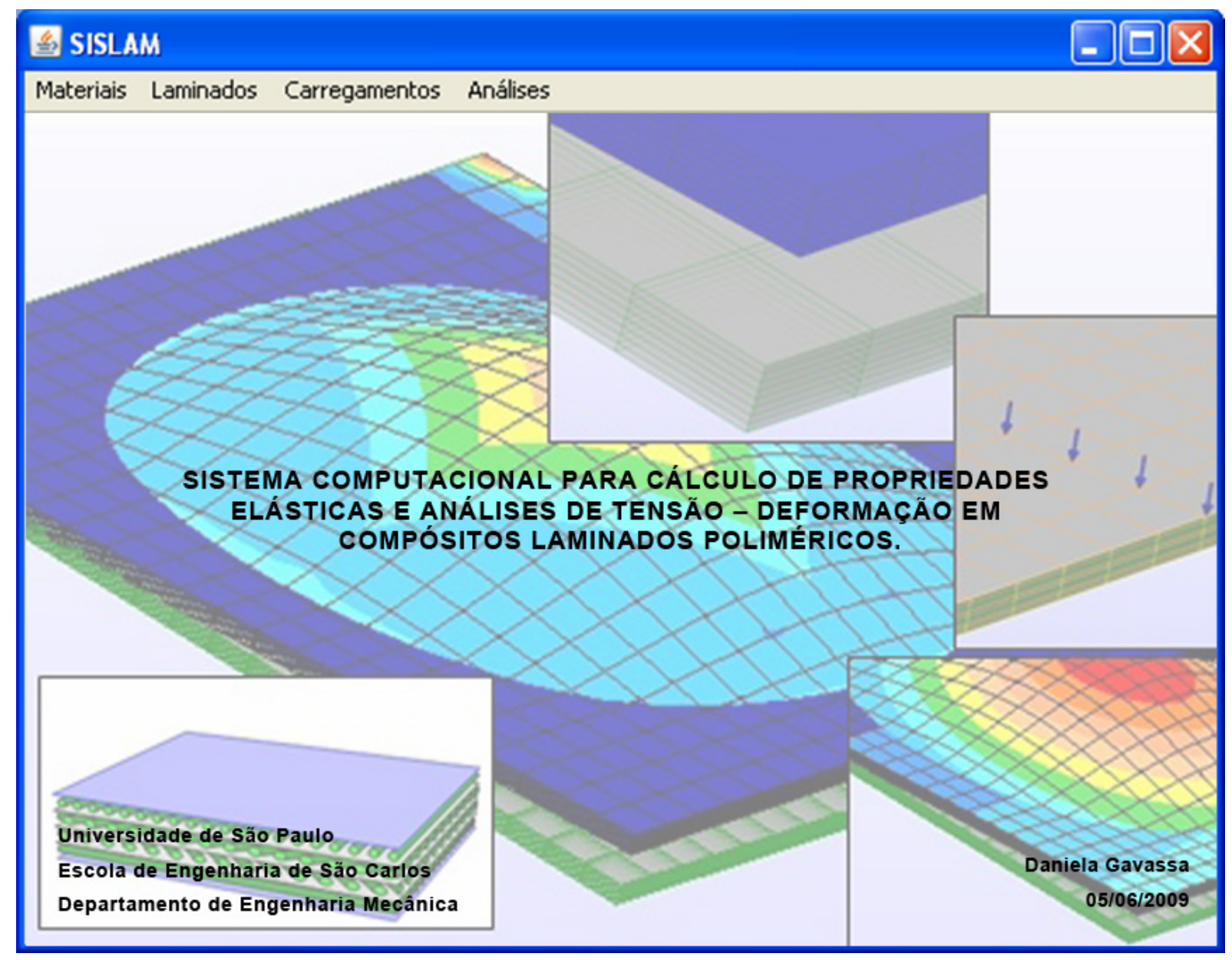

FIGURA 3.3 - Tela Principal do Software SISLAM

- Materiais: gerenciamento do cadastro de Fibras, Resinas e Compósitos;

- Laminados: gerenciamento do cadastro de Laminados e inserção de $n$ camadas a partir da escolha do material compósito;

- Carregamentos: gerenciamento do cadastro de Carregamentos; 
- Análises: gerenciamento das análises, onde é possível visualizar análises já existentes ou realizar novas análises.

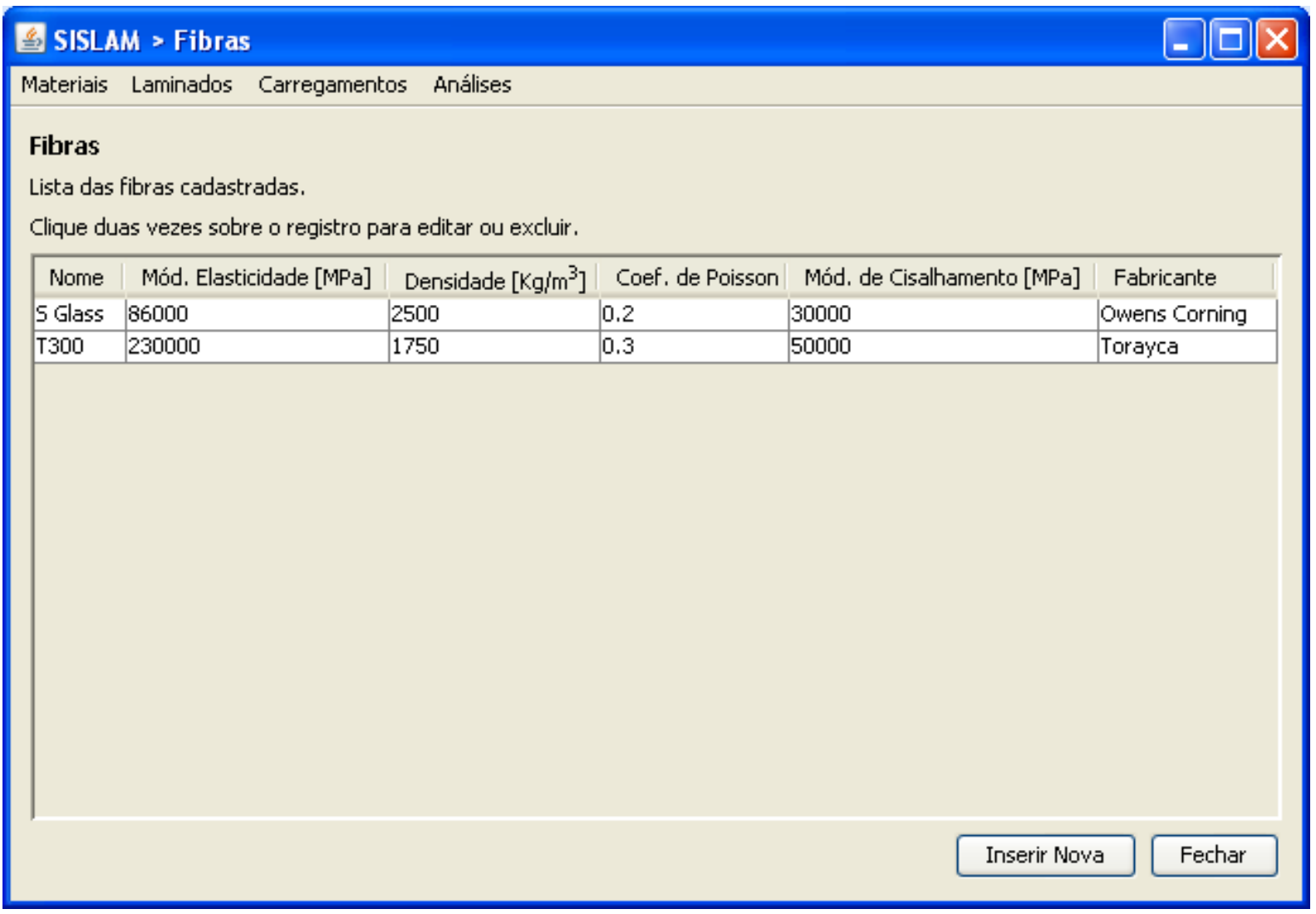

FIGURA 3.4 - Tela de Cadastro das Fibras do Sistema

\begin{tabular}{l} 
Detalhes da Fibra \\
\hline Fibra \\
Nome: \\
Densidade: \\
Mód. Elasticidade: \\
Coef. de Poisson: \\
Mód. de Cisalhamento: \\
Fabricante: \\
$\quad 36000 \mathrm{MPa}$ \\
\hline
\end{tabular}

FIGURA 3.5 - Tela Detalhes da Fibra do Sistema 


\section{SISLAM > Resinas}

Materiais Laminados Carregamentos Análises

\section{Resinas}

Lista das resinas cadastradas.

Clique duas vezes sobre o registro para editar ou excluir.

\begin{tabular}{|l|l|l|l|l|l|}
\hline Nome & Mód. Elasticidade [MPa] & Densidade $\left[\mathrm{Kg}^{\prime} \mathrm{m}^{3}\right.$ ] & Coef. de Poisson & Mód. de Cisalhamento [MPa] & Fabricante \\
\hline Epoxy & 4500 & 1200 & 0.4 & 1600 & DuPont \\
\hline Poliéster & 4000 & 1200 & 0.4 & 1600 & DuPont \\
\hline
\end{tabular}

FIGURA 3.6 - Tela de Cadastro das Resinas do Sistema

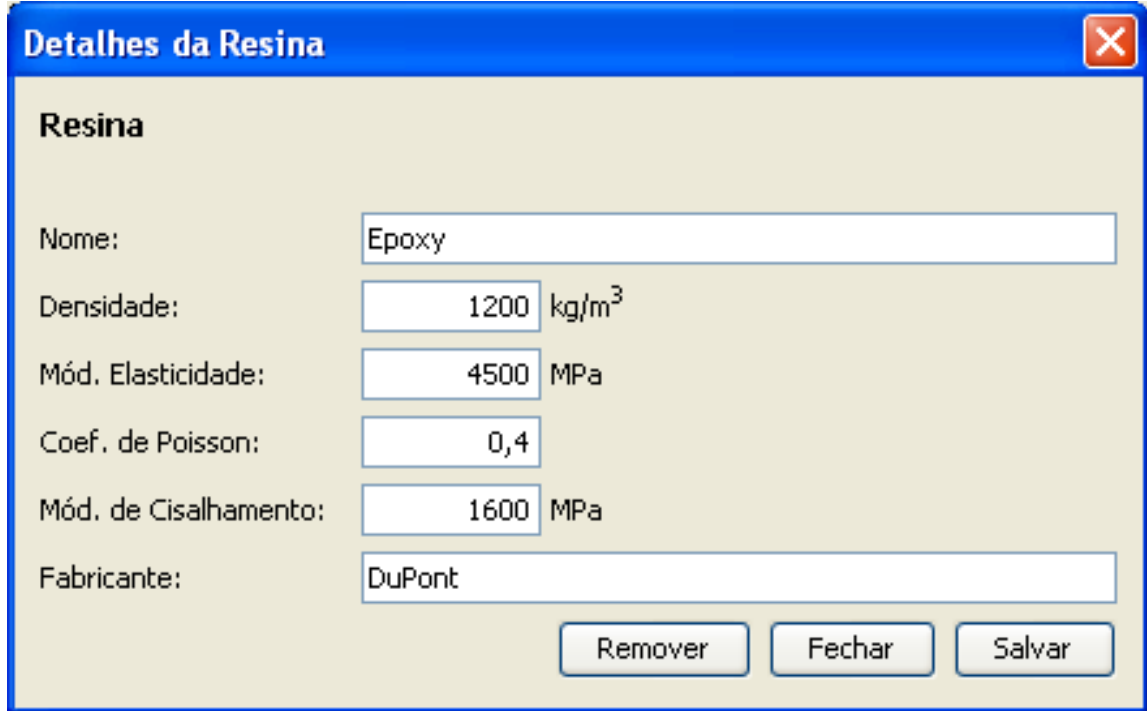

FIGURA 3.7 - Tela Detalhes da Resina do Sistema 
SISLAM > Compósitos

Compósitos

Lista dos compósitos cadastrados.

Clique duas vezes sobre o registro para editar ou excluir.

\begin{tabular}{|c|c|c|c|c|c|c|c|c|}
\hline Nome & Fibra Resina $\%$ Volumétrica & Espessura [mm] & Coef. Poisson & Mód. Cisalhamento [MPa] Densidade [Kg/m³ & Mód. Elast. Long. [MPa] Mód. Elast. Trans. [MPa] \\
\hline
\end{tabular}

\begin{tabular}{l|l|l|l|l|l|l|l|} 
Filament Winding 5 Glass & Epoxy & 60 & 0.125 & 0.2 & 1600 & 2500 & 4500
\end{tabular}

FIGURA 3.8 - Tela de Cadastro dos Compósitos do Sistema

\begin{tabular}{|c|c|c|c|c|c|c|}
\hline Detalhes do Compósito & & & & & & $\mathrm{X}$ \\
\hline Compósito & & & & & & \\
\hline Nome: & ilament Windi & & & & & \\
\hline Fibra: & Glass & & & & & $\checkmark$ \\
\hline Resina: & Epoxy & & & & & $\checkmark$ \\
\hline \% Volumétrica de Fibra: & $60 \hat{\vee}$ & $\%$ & & & & \\
\hline Espessura: & 0,125 & $\mathrm{~mm}$ & & & & \\
\hline Coef, de Poisson: & & 0,20 & & & & \\
\hline Mód. de Cisalhamento: & & 1600 & $\mathrm{MPa}$ & & & \\
\hline Densidade: & & 2500 & $\mathrm{~kg} / \mathrm{m}^{3}$ & & & \\
\hline Mód. de Elasticidade Longitudinal: & & 4500 & $\mathrm{MPa}$ & & & \\
\hline Mód. de Elasticidade Transversal: & & 4500 & $\mathrm{MPa}$ & & Calcular & \\
\hline & & Remo & & Fechar & Salvar & \\
\hline
\end{tabular}

FIGURA 3.9 - Tela Detalhes do Compósito do Sistema 


\section{SISLAM > Laminados}

Materiais Laminados Carregamentos Análises

\section{Laminados}

Lista dos laminados cadastrados.

Clique duas vezes sobre o registro para editar ou excluir.

\begin{tabular}{|l|l|}
\hline Nome & Núm. de Camadas \\
\hline Laminado 1 & 6 \\
\hline
\end{tabular}

FIGURA 3.10 - Tela de Cadastro dos Laminados do Sistema 
Detalhes do Laminado

\section{Laminado}

Nome:

Laminado 1

Camadas:

Inserir Nova Camada

Remover Camada

\section{Compósito}

Filament Winding

Ângulo [Graus]

Filament Winding

Filament Winding

Filament Winding

Filament Winding

Filament Winding

\begin{tabular}{|l|}
\hline 30 \\
\hline 60 \\
\hline 45 \\
\hline-35 \\
\hline-55 \\
\hline-65 \\
\hline
\end{tabular}

FIGURA 3.11 - Tela Detalhes dos Laminados do Sistema

\section{Nova Camada}

Nova Camada

Compósito: Filament Winding

Ângulo: $\quad 45$ Graus

FIGURA 3.12 - Tela de Inserção de Novas Camadas dos Laminados do Sistema 


\section{SISLAM > Carregamentos}

Materiais Laminados Carregamentos Análises

\section{Carregamentos}

Lista dos carregamentos cadastrados.

Clique duas vezes sobre o registro para editar ou excluir.

\begin{tabular}{|l|l|l|l|l|l|l|}
\hline Nome & N1 $[\mathrm{N}]$ & $\mathrm{N} 2[\mathrm{~N}]$ & $\mathrm{N} 6[\mathrm{~N}]$ & $\mathrm{M} 1[\mathrm{Nm}]$ & $\mathrm{M} 2[\mathrm{Nm}]$ & $\mathrm{M} 6[\mathrm{Nm}]$ \\
\hline Carregamento 1 & 100 & 100 & 100 & 100 & 100 & 100 \\
\hline
\end{tabular}

FIGURA 3.13 - Tela de Cadastro dos Carregamentos Sistema

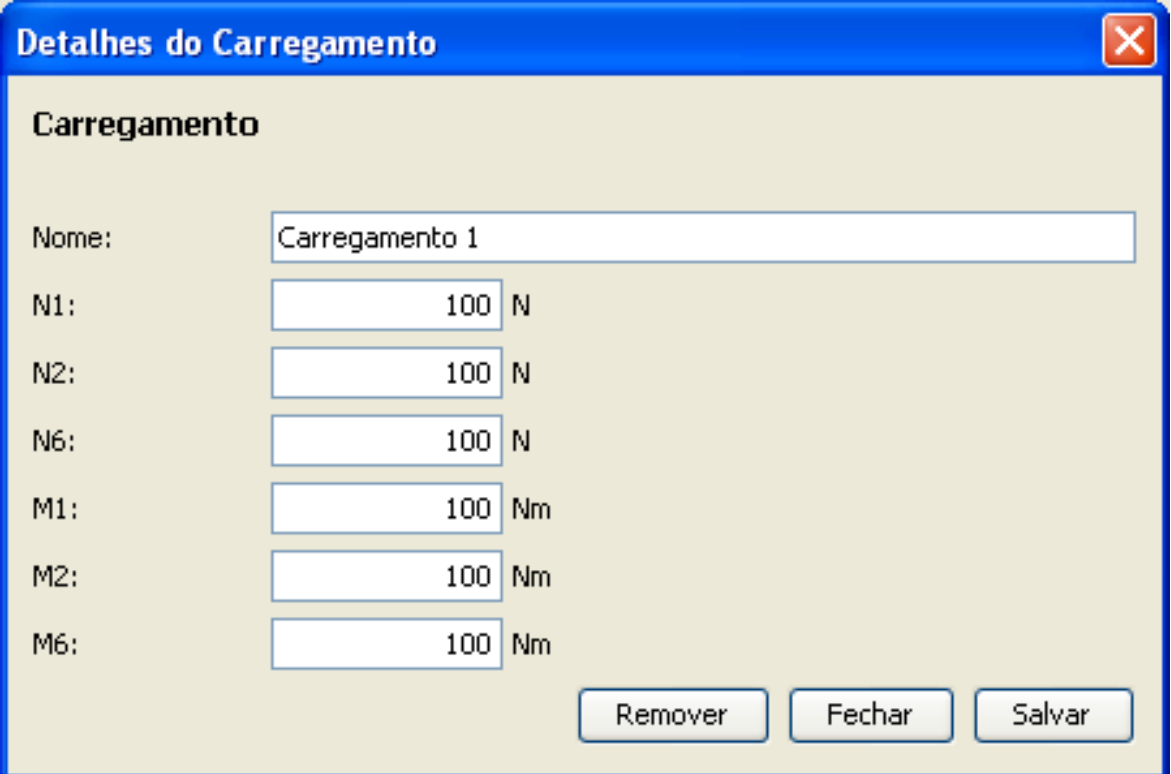

FIGURA 3.14 - Tela Detalhes dos Carregamentos Sistema 


\subsubsection{Saída de Dados}

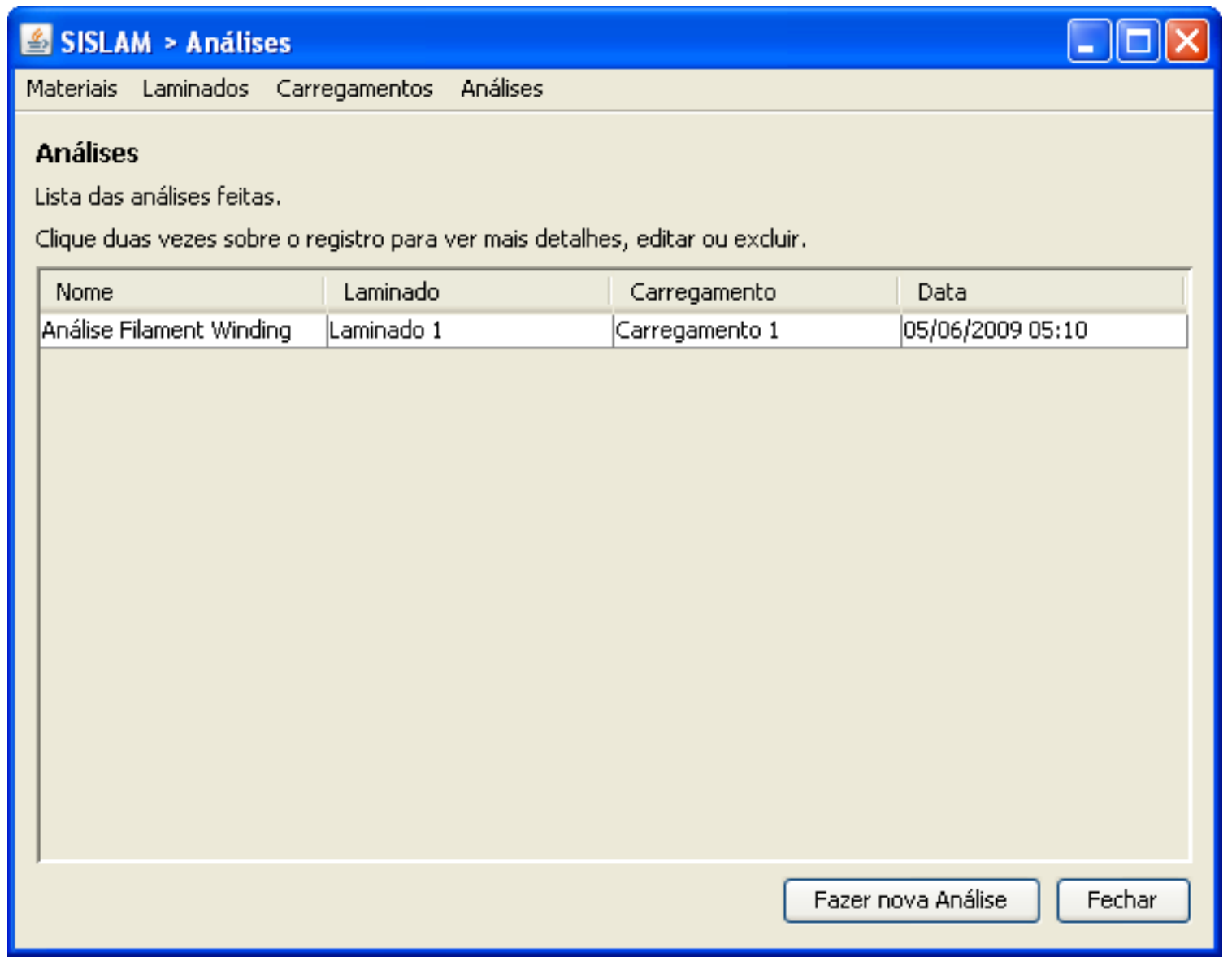

FIGURA 3.15 - Tela de Cadastro das Novas Análises Geradas no Sistema 
Detalhes da Análise

Análise

Nome: $\quad$ Anălise Filament Winding

Laminado: Laminado 1

Carregamento: Carregamento 1

Resultado da Análise:

Iniciando análise...

Camada 1: Compósito "Filament winding" à 30 graus

E11: $4500.0 \mathrm{Gpa}$

E22: $4500.0 \mathrm{Gpa}$

G12: $1600.0 \mathrm{Gpa}$

Ni12: 0.2

Ni21: 0.2

Q11: 4687.5

Q22: 4687.5

$\mathrm{Q} 12=\mathrm{Q} 21: 937.5$

Q66: 1600.0

$\mathrm{m}: \quad 0.15425144988758405$

Q11t: 4661.9498834474025

Q12t: 963.050116552598

Q22t: $4.827976226808589 \mathrm{E} 14$

Q16t: 79.83403782919333

Q26t: -1008.8119325688962

Q66t: 1625.5501165525982

FIGURA 3.16 - Tela Detalhes dos Resultados das Análises Geradas no Sistema

As telas de saída correspondentes às análises das propriedades elásticas, tensões e deformações serão mostradas e validadas no capítulo a seguir. 


\section{CAPÍTULO IV}

\section{ESTUDOS DE CASOS}

Neste capítulo são desenvolvidas aplicações do sistema desenvolvido para laminados típicos utilizados em projetos mecânicos, para validação dos procedimentos e rotinas implementadas. Para facilidade de representação gráfica, bem como objetividade nas análises dos resultados, serão considerados laminados formados por oito laminas (camadas) com diferentes orientações, considerando casos de laminados simétricos e não simétricos. Para facilidade de comparação entre as várias análises será considerado a mesma composição do compósito, ou seja, resina epóxi reforçada por fibra de vidro contínua ( S-glass) considerando a mesma fração volumétrica e diferentes orientações nas camadas. Os valores obtidos são validados com resultados de (HYER, 1998).

\subsection{Dados de Materiais}

Os valores utilizados para as propriedades dos materiais constituintes são mostrados na Tabela (4.1): 


\begin{tabular}{|c|c|c|c|c|}
\hline Material & $\begin{array}{c}\text { Módulo de } \\
\text { Elasticidade (E) } \\
\text { longitudinal } \\
{[\mathrm{GPa}]}\end{array}$ & $\begin{array}{c}\text { Módulo de } \\
\text { Cisalhamento } \\
\text { (G) } \\
{[\mathrm{GPa}]}\end{array}$ & $\begin{array}{c}\text { Coeficiente } \\
\text { de Poisson }\end{array}$ & $\begin{array}{c}\text { Densidade } \\
{\left[\mathrm{Kg} / \mathrm{m}^{3}\right]}\end{array}$ \\
\hline $\begin{array}{c}\text { Fibra de vidro } \\
\text { ( S-glass })\end{array}$ & 86 & 30 & 0,20 & 2500 \\
\hline Epóxi & 4,5 & 1,6 & 0,4 & 1200 \\
\hline
\end{tabular}

Tabela 4.1 - Propriedades da fibra e resina utilizadas.

Foi considerado um compósito contendo $60 \%$ de fração volumétrica de fibra de vidro, que conjuntamente com as relações desenvolvidas na Regra das Misturas (visto na seção 2.1.4) conduz às seguintes propriedades da lamina (calculadas no próprio sistema):

$$
\begin{aligned}
& \mathrm{E}_{11}=53,4 \mathrm{GPa} \quad \mathrm{E}_{22}=\mathrm{E}_{33}=10,4 \mathrm{GPa} \quad v_{12}=v_{13}=0,28 \\
& \mathrm{G}_{12}=\mathrm{G}_{13}=5,34 \mathrm{Gpa}
\end{aligned}
$$

A partir destes valores é possível calcular a Matriz de Rigidez Reduzida extensional, conforme ilustrado na Figura (4.1), dados retirado do sistema

\begin{tabular}{|c|c|c|c|c|}
\hline \multicolumn{5}{|c|}{ Matriz de Rigidez Reduzida Extensional } \\
\hline Entrada & & & Saída & \\
\hline E11 & 53,400 & $\mathrm{GPa}$ & $\mathrm{Ni} 21$ & 0,055 \\
\hline E22 & 10,400 & $\mathrm{GPa}$ & Q11 & 54,228 \\
\hline G12 & 5,340 & GPa & Q22 & 10,561 \\
\hline $\mathrm{Ni} 12$ & 0,280 & & $\mathrm{Q} 12=\mathrm{Q} 21$ & 2,957 \\
\hline & & & Q66 & 5,340 \\
\hline
\end{tabular}
desenvolvido.

FIGURA 4.1 - Matriz de Rigidez Reduzida Extensional, calculada no sistema. 
Conforme citado, estes dados de materiais serão utilizados em todos os estudos de casos selecionados, sendo os resultados verificados com a literatura (HYER, 1998) e (TSAI, 1984). Para todos os casos serão considerados laminados formados por oito camadas (layers) com $0,125 \mathrm{~mm}$ cada, totalizando $1,0 \mathrm{~mm}$ no laminado total

\subsection{Caso 1: Laminado simétrico com cargas normais e de flexão}

Para este primeiro caso foi considerado o laminado $\left[0,90^{\circ}, 45^{\circ},-45^{\circ}\right]_{s}$ sujeito a carregamentos combinados normais e de flexão. Os passos seguintes ilustram as etapas para o cálculo da matriz ABBD. Uma vez que o laminado é simétrico são ilustrados os cálculos apenas para as quatro diferentes camadas (layers).

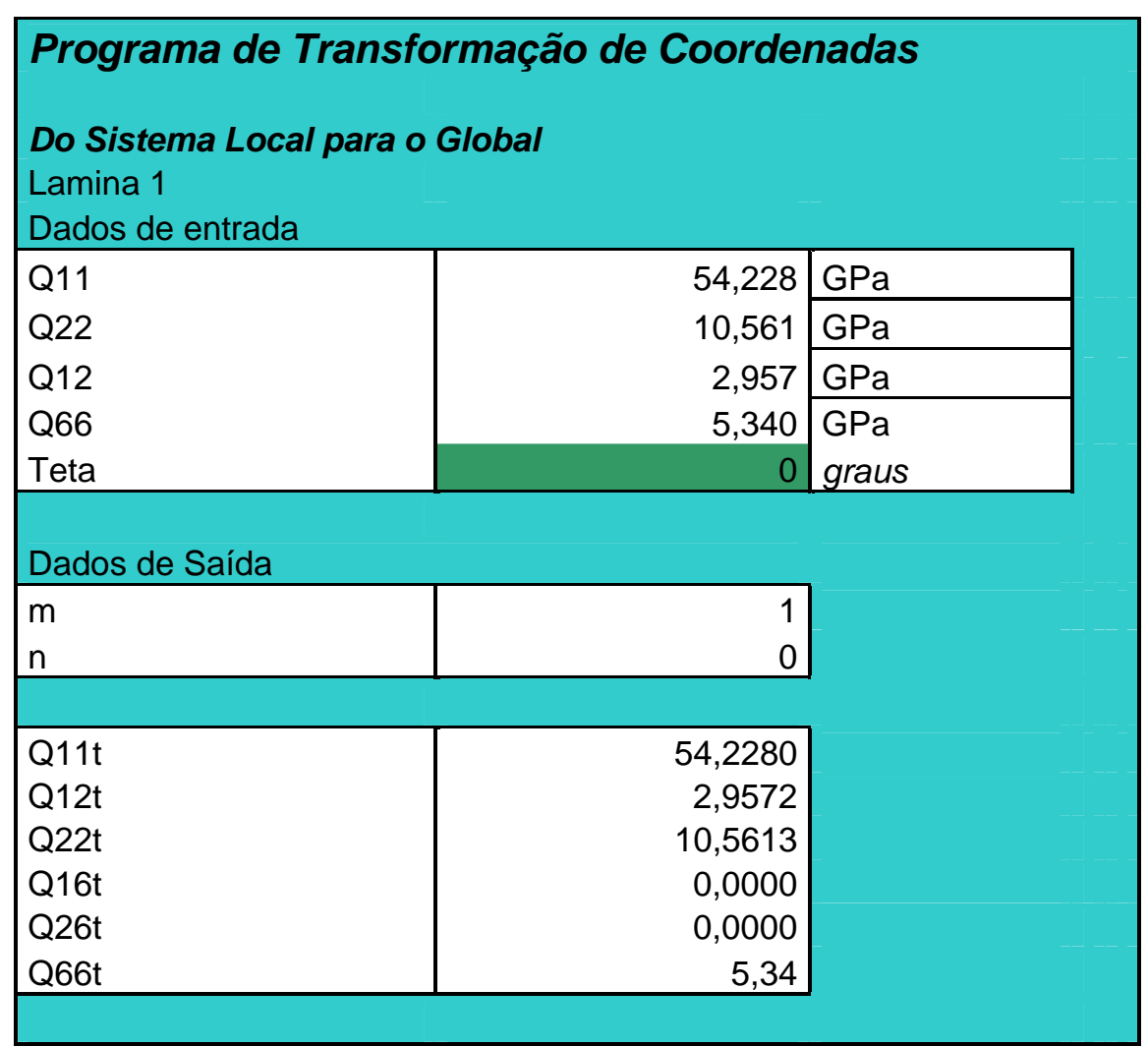

FIGURA 4.2 - Dados para lâmina $1\left(0^{\circ}\right)$ no plano de simetria. 


\begin{tabular}{|c|c|c|}
\hline \multicolumn{3}{|c|}{ Proarama de Transformacão de Coordenadas } \\
\hline \multirow{2}{*}{\multicolumn{3}{|c|}{ Do Sistema Local para o Global }} \\
\hline & & \\
\hline \multicolumn{3}{|c|}{ Dados de entrada } \\
\hline Q11 & 54,228 & GPa \\
\hline Q22 & 10,561 & $\mathrm{GPa}$ \\
\hline Q12 & 2,957 & $\mathrm{GPa}$ \\
\hline Q66 & 5,340 & $\mathrm{GPa}$ \\
\hline Teta & 90 & graus \\
\hline \multicolumn{3}{|c|}{ Dados de Saída } \\
\hline $\mathrm{m}$ & 0 & \\
\hline $\mathrm{n}$ & 1 & \\
\hline Q11t & 10,5613 & \\
\hline Q12t & 2,9572 & \\
\hline Q22t & 54,2280 & \\
\hline Q16t & 0,0000 & \\
\hline Q26t & 0,0000 & \\
\hline Q66t & 5,34 & \\
\hline
\end{tabular}

FIGURA 4.3 - Dados para lâmina $2\left(90^{\circ}\right)$ no plano de simetria.

\begin{tabular}{|c|c|c|}
\hline \multicolumn{3}{|c|}{$\begin{array}{l}\text { Do Sistema Local para o Global } \\
\text { Lamina } 3 \\
\text { Dados de entrada }\end{array}$} \\
\hline Q11 & 54,228 & GPa \\
\hline Q22 & 10,561 & GPa \\
\hline Q12 & 2,957 & GPa \\
\hline Q66 & 5,340 & GPa \\
\hline Teta & 45 & graus \\
\hline \multicolumn{3}{|c|}{ Dados de Saída } \\
\hline $\begin{array}{l}\mathrm{m} \\
\mathrm{n} \\
\end{array}$ & $\begin{array}{l}0,70710678 \\
0,70710678 \\
\end{array}$ & \\
\hline $\begin{array}{l}\text { Q11t } \\
\text { Q12t } \\
\text { Q22t } \\
\text { Q16t } \\
\text { Q26t } \\
\text { Q66t }\end{array}$ & $\begin{array}{r}23,0159 \\
12,3359 \\
23,0159 \\
10,9167 \\
10,9167 \\
14,7187392\end{array}$ & \\
\hline
\end{tabular}

FIGURA 4.4 - Dados para lâmina 3 ( 45º). 


\begin{tabular}{|c|c|c|}
\hline $\begin{array}{l}\text { Prog } \\
\text { Do Sis } \\
\text { Lamin }\end{array}$ & e Coordena & las \\
\hline \multicolumn{3}{|c|}{ Dados de entrada } \\
\hline Q11 & 54,228 & $\mathrm{GPa}$ \\
\hline Q22 & 10,561 & $\mathrm{GPa}$ \\
\hline Q12 & 2,957 & $\mathrm{GPa}$ \\
\hline Q66 & 5,340 & $\mathrm{GPa}$ \\
\hline Teta & -45 & graus \\
\hline \multicolumn{3}{|c|}{ Dados de Saída } \\
\hline$M$ & 0,707106781 & \\
\hline $\mathrm{N}$ & $-0,707106781$ & \\
\hline Q11t & 23,0159 & \\
\hline Q12t & 12,3359 & \\
\hline Q22t & 23,0159 & \\
\hline Q16t & $-10,9167$ & \\
\hline Q26t & $-10,9167$ & \\
\hline Q66t & 14,71873916 & \\
\hline
\end{tabular}

FIGURA 4.5 - Dados para lâmina 4 ( $\left.-45^{\circ}\right)$ no plano de simetria.

Considerando estes dados, é agora possível calcular a matriz ABBD e a sua inversa ( necessária para o cálculo das tensões e deformações ).

\begin{tabular}{|c|c|c|c|c|c|c|}
\hline \multirow[t]{6}{*}{ [ABBD] } & 27,71 & 7,65 & 0,00 & 0 & 0 & $0^{-}$ \\
\hline & 7,65 & 27,71 & 0,00 & 0 & 0 & 0 \\
\hline & 0,00 & 0,00 & 10,03 & 0 & 0 & 0 \\
\hline & 0 & 0 & 0 & 0,072 & 0,020 & 0,000 \\
\hline & 0 & 0 & 0 & 0,020 & 0,072 & 0,000 \\
\hline & 0 & 0 & 0 & 0,000 & 0,000 & 0,026 \\
\hline
\end{tabular}

FIGURA 4.6 - Matriz ABBD

\begin{tabular}{|c|c|c|c|c|c|c|}
\hline$\left[A^{\prime} B^{\prime} B^{\prime} D^{\prime}\right]$ & $\begin{array}{c}0,039 \\
-0,011 \\
0,000 \\
0 \\
0 \\
0\end{array}$ & $\begin{array}{c}-0,011 \\
0,039 \\
0,000 \\
0 \\
0 \\
0\end{array}$ & $\begin{array}{c}0,000 \\
0,000 \\
0,100 \\
0 \\
0 \\
0\end{array}$ & $\begin{array}{c}0 \\
0 \\
0 \\
0,0000003 \\
-0,0000001 \\
0,0000000\end{array}$ & $\begin{array}{c}0 \\
0 \\
0 \\
-0,0000001 \\
0,0000003 \\
0,0000000\end{array}$ & $\begin{array}{c}0 \\
0 \\
0 \\
0,0000000 \\
0,0000000 \\
0,0000007\end{array}$ \\
\hline
\end{tabular}

FIGURA 4.7 - Inversa da Matriz ABBD 
Neste caso serão considerados os carregamentos $N x=N y=N x y=10 N / m$ e $M x=M y=M x y=1000 N . m / m$. Os resultados em termos de deformações são: $\varepsilon_{\mathrm{x}}=0,2828, \varepsilon_{\mathrm{x}}=0,2828$ e $\varepsilon_{\mathrm{x}}=0,9970$. Para as curvaturas são encontrados $\mathrm{Kx}=$ $0,000192, K y=0,000192$ e $K x y=0,000676$. Os valores de tensões obtidos nas diferentes camadas são mostrados na Tabela (4.2), e graficamente nas FIGURAS (4.8), (4.9) e (4.10).

\begin{tabular}{|c|c|c|c|c|c|}
\hline Camada & Ângulo & $\begin{array}{c}\text { Espessura } \\
{[\mathrm{mm}]}\end{array}$ & $\begin{array}{c}\text { Tensão } \\
\text { normal x-x } \\
\text { [GPa] }\end{array}$ & $\begin{array}{c}\text { Tensão } \\
\text { normal y-y } \\
{[\mathrm{GPa}]}\end{array}$ & $\begin{array}{c}\text { Tensão } \\
\text { cisal. x-y } \\
\text { [GPa] }\end{array}$ \\
\hline 1 & $0^{\circ}$ & 0,125 & 16,1760 & 3,8239 & 5,3243 \\
\hline 2 & $90^{\circ}$ & 0,125 & 3,8239 & 16,1760 & 5,3243 \\
\hline 3 & $45^{\circ}$ & 0,125 & 20,8847 & 20,8847 & 20,8516 \\
\hline 4 & $-45^{\circ}$ & 0,125 & 7,3470 & 16,1760 & 14,6756 \\
\hline 5 & $-45^{\circ}$ & 0,125 & 7,3470 & 16,1760 & 14,6756 \\
\hline 6 & $45^{\circ}$ & 0,125 & 20,8847 & 20,8847 & 20,8516 \\
\hline 7 & $90^{\circ}$ & 0,125 & 3,8239 & 16,1760 & 5,3243 \\
\hline 8 & $0^{\circ}$ & 0,125 & 16,1760 & 3,8239 & 5,3243 \\
\hline
\end{tabular}

Tabela 4.2 - Tensões calculadas nas diferentes lâminas (camadas) do laminado para $1^{\circ}$ caso de estudo. 


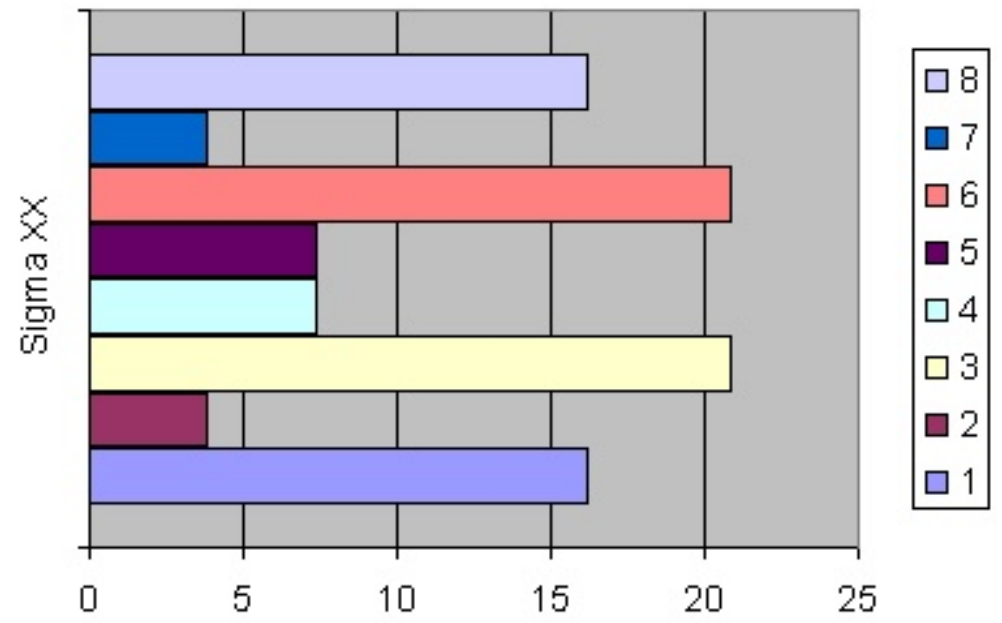

FIGURA 4.8 - Distribuição de tensões normais na direção x-x.

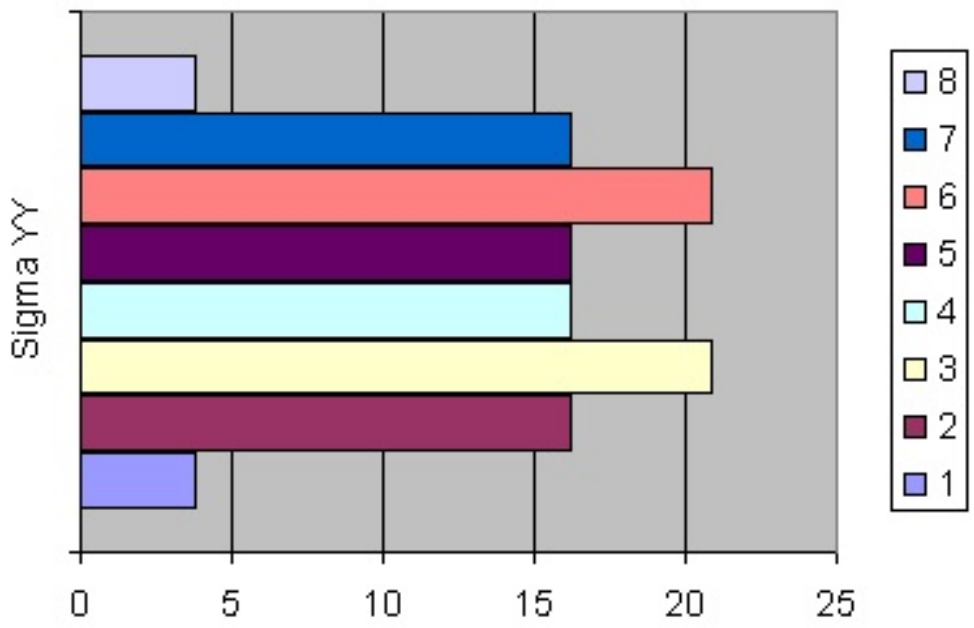

FIGURA 4.9 - Distribuição de tensões normais na direção y-y. 


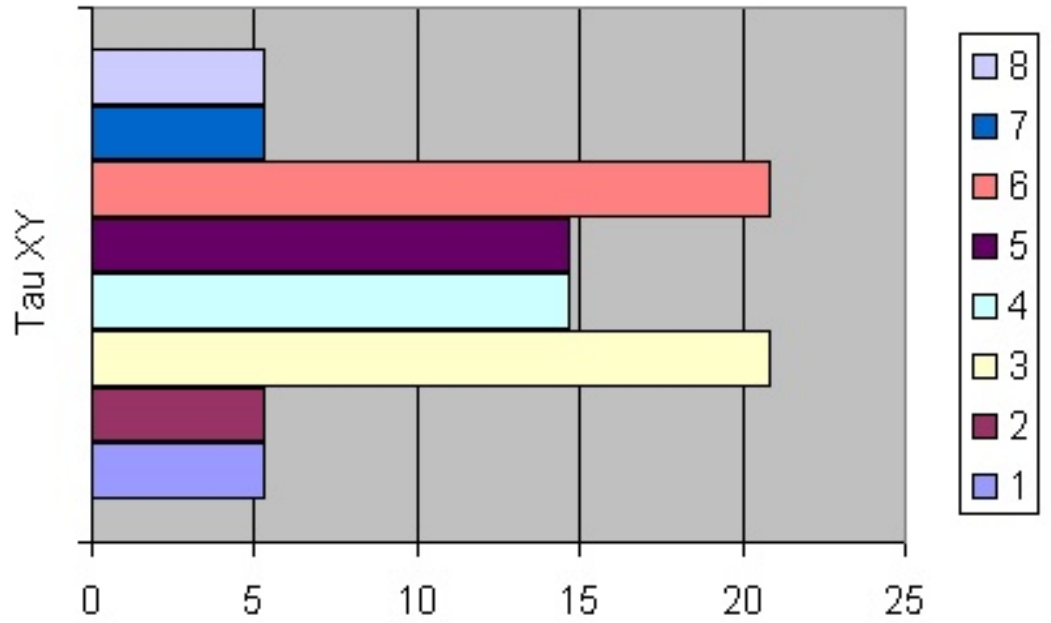

FIGURA 4.10 - Distribuição de tensões de cisalhamento na direção x-y.

\subsection{Caso 2: Laminado não simétrico com cargas normais}

Para este caso foi considerado o laminado $\left[0^{\circ}, 90^{\circ}, 45^{\circ},-45^{\circ}\right]_{T}$ sujeito a carregamentos combinados normais e de flexão. Pretende-se neste caso, verificar o acoplamento entre deformações normais e curvaturas, existentes devido aos termos não nulos na matriz B. Os passos seguintes ilustram as etapas para o cálculo da matriz $\mathrm{ABBD}$. Os dados referentes às transformações de coordenadas das lâminas correspondem àqueles já ilustrados nas FIGURAS (4.2) a (4.5).

Considerando estes dados, é agora possível calcular a matriz ABBD e a sua inversa (necessária para o cálculo das tensões e deformações).

\begin{tabular}{|c|c|c|c|c|c|c|}
\hline [ABBD] & $\begin{array}{c}17,25 \\
6,63 \\
2,07 \\
-0,8467 \\
0,1177 \\
-0,2997\end{array}$ & $\begin{array}{c}6,63 \\
15,89 \\
3,72 \\
0,1177 \\
-0,0791 \\
-0,4033\end{array}$ & $\begin{array}{c}2,07 \\
3,72 \\
8,19 \\
-0,2997 \\
-0,4033 \\
0,0944\end{array}$ & $\begin{array}{c}-0,8467 \\
0,1177 \\
-0,2997 \\
0,392 \\
0,094 \\
-0,032\end{array}$ & $\begin{array}{c}0,1177 \\
-0,0791 \\
-0,4033 \\
0,094 \\
0,214 \\
-0,023\end{array}$ & $\begin{array}{c}-0,2997 \\
-0,4033 \\
0,0944 \\
-0,032 \\
-0,023 \\
0,121\end{array}$ \\
\hline
\end{tabular}

FIGURA 4.11 - Matriz ABBD 


\begin{tabular}{|c|c|c|c|c|c|c|}
\hline$\overline{\left[\mathrm{A}^{\prime} \mathrm{B}^{\prime} \mathrm{B}^{\prime} \mathrm{D}^{\prime}\right]}$ & & & & & & \\
\hline & 0,069 & $-0,028$ & $-0,005$ & $-0,9542$ & 0,6156 & $-0,3992$ \\
\hline & $-0,028$ & 0,082 & $-0,030$ & 0,6156 & $-0,9521$ & $-2,1132$ \\
\hline & $-0,005$ & $-0,030$ & 0,137 & $-0,3992$ & $-2,1132$ & 0,2980 \\
\hline & $-0,9542$ & 0,6156 & $-0,3992$ & 0,0000 & 0,0000 & 0,0000 \\
\hline & 0,6156 & $-0,9521$ & $-2,1132$ & 0,0000 & 0,0000 & 0,0000 \\
\hline & $\begin{array}{l}-0,3992 \\
\end{array}$ & $-2,1132$ & 0,2980 & 0,0000 & 0,0000 & 0,0000 \\
\hline
\end{tabular}

FIGURA 4.12 - Inversa da Matriz ABBD

Neste caso serão considerados os carregamentos $\mathrm{Nx}=10 \mathrm{~N} / \mathrm{m}$ e $\mathrm{Ny}=\mathrm{N} x y=0$, bem como momentos iguais a zero. Os resultados em termos de deformações são: $\varepsilon_{\mathrm{x}}=0,069, \varepsilon_{\mathrm{x}}=-0,027$ e $\varepsilon_{\mathrm{x}}=-0,040$. Para as curvaturas são encontrados $\mathrm{Kx}=$ $0,954, K y=0,615$ e $K x y=-0,399$. Os valores de tensões obtidos nas diferentes camadas são mostrados na Tabela (4.3), e graficamente nas FIGURAS (4.13), (4.14) e (4.15).

\begin{tabular}{|c|c|c|c|c|c|}
\hline Camada & Ângulo & $\begin{array}{c}\text { Espessura } \\
{[\mathbf{m m}]}\end{array}$ & $\begin{array}{c}\text { Tensão } \\
\text { normal x-x } \\
{[\text { GPa] }}\end{array}$ & $\begin{array}{c}\text { Tensão } \\
\text { normal y-y } \\
{[\text { GPa] }}\end{array}$ & $\begin{array}{c}\text { Tensão } \\
\text { cisal. x-y } \\
\text { [GPa] }\end{array}$ \\
\hline 1 & $0^{\circ}$ & 0,125 & 16,152 & $-1,008$ & 0,507 \\
\hline 2 & $90^{\circ}$ & 0,125 & 8,572 & $-2,158$ & 2,596 \\
3 & $45^{\circ}$ & 0,125 & 5,879 & 0,652 & 2,774 \\
4 & $-45^{\circ}$ & 0,125 & 6,546 & $-11,897$ & 1,397 \\
\hline
\end{tabular}

Tabela 4.3 - Tensões calculadas nas diferentes lâminas (camadas) do laminado para $2^{\circ}$ caso de estudo. 


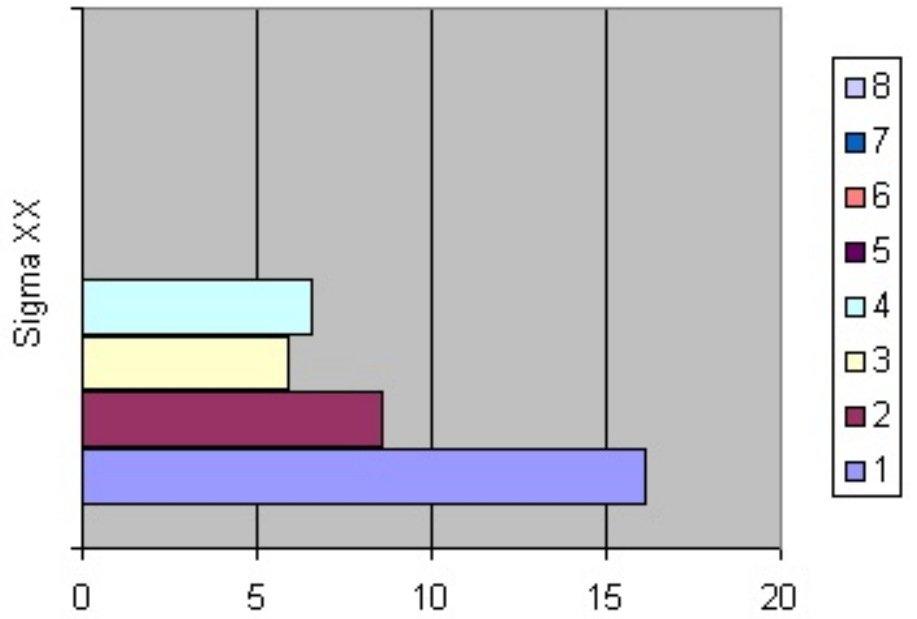

FIGURA 4.13 - Distribuição de tensões normais na direção x-x.

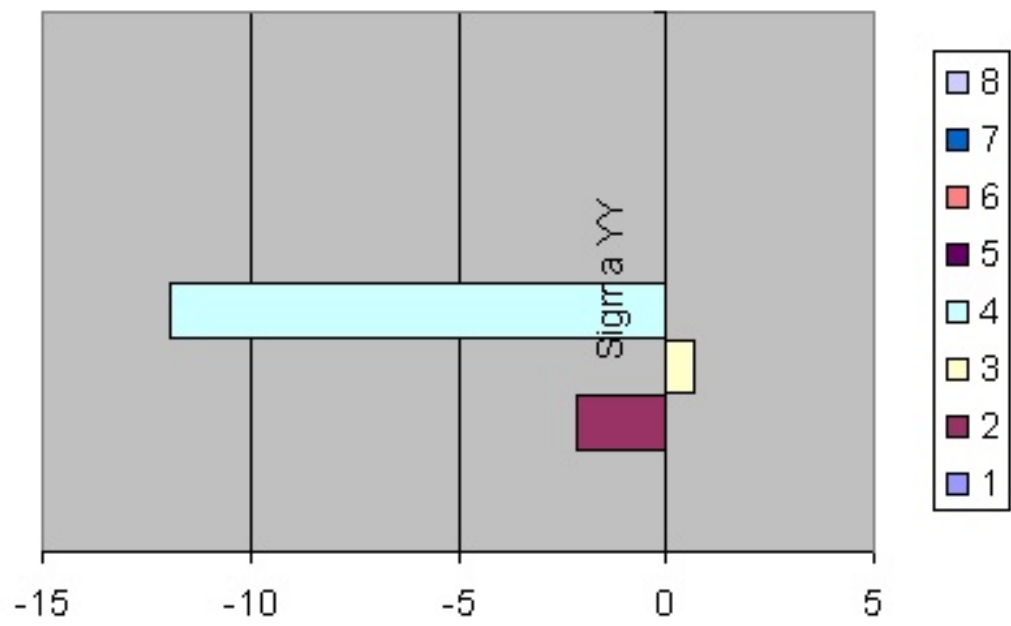

FIGURA 4.14 - Distribuição de tensões normais na direção y-y. 


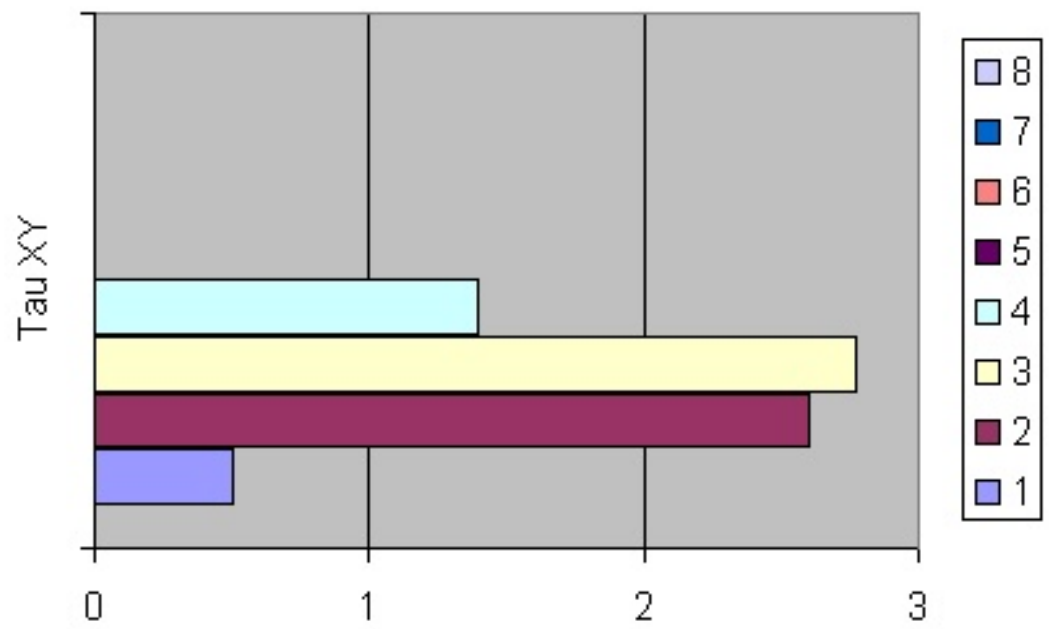

FIGURA 4.15 - Distribuição de tensões de cisalhamento na direção x-y.

Os valores calculados acima correspondem a valores encontrados na literatura e podem ser considerados satisfatórios. Os valores de tensões e deformações calculados podem ser utilizados para implementações futuras de cálculos de critérios de falhas, conforme citado anteriormente. 


\section{CAPÍTULO V}

\section{CONCLUSÕES E SUGESTÕES}

\subsection{Conclusões Gerais}

Durante os últimos anos tem-se observado um aumento crescente no uso de materiais compósitos. Isto se deve principalmente devido às vantagens que os mesmos apresentam em relação aos materiais convencionais tais como: alta resistência e rigidez associado à elevado desempenho estrutural, baixo peso e boa resistência à corrosão e oxidação, dentre outros.

Contudo, o uso de materiais compósitos em projetos estruturais exige um bom conhecimento de suas propriedades elásticas e ferramentas adequadas para aplicação de conceitos relacionados aos estados de tensões e deformações, fundamentais para aplicação de critérios de falhas destes materiais. Algumas ferramentas comerciais já foram desenvolvidas, entretanto estas ferramentas apresentam arquitetura fechada que, na maioria das vezes, não permitem implementações específicas para as necessidades de cada usuário.

A partir, do desenvolvimento deste trabalho podem-se tirar as seguintes conclusões:

a) A plataforma JAVA, ambiente integrado de desenvolvimento Netbeans, adotada para a implementação dos módulos do sistema SISLAM, apresentou bons resultados em termos de interface gráfica com o usuário e comunicação com a base de dados; 
b) O sistema gerenciador de banco de dados utilizado, HSQLDB, apresenta código aberto, facilitando sua utilização, tendo possibilitado a manipulação e integração dos dados obtidos nos cálculos.

c) O sistema SISLAM apresentou resultados nos testes de validação realizados;

d) A visualização gráfica dos cálculos gerados pelo sistema proporciona ao usuário uma visão completa da distribuição de tensões ao longo das camadas que constituem o laminado;

e) Embora o sistema implementado ainda não possibilite a verificação dos diferentes critérios de falha ao longo das camadas, foi dada uma grande contribuição no sentido de disponibilizar uma plataforma onde novas implementações possam ser facilmente desenvolvidas.

\subsection{Sugestões}

As sugestões propostas para a continuidade deste trabalho são:

a) Implementar novos módulos de cálculos para as diferentes propriedades elásticas dos compósitos., citando-se por exemplo, outras formulações disponíveis para a Regra das Misturas;

b) Implementar módulos para cálculos de diferentes critérios de falhas ao longo das camadas do laminado, com a correspondente representação gráfica;

c) Implementar módulos para a visualização do laminado deformado após a aplicação dos carregamentos; 
d) Integrar o sistema desenvolvido à plataformas de cálculo de processos, como por exemplo o processo de Filament Winding, de maneira que os dados do laminado sejam gerados diretamente das trajetórias de deposição das fibras; 


\section{REFERÊNCIAS BIBLIOGRÁFICAS}

AGARWAL, B.D.; BROUTMAN, L.J. (1990). Analysis and Performance of Fiber Composites, second edition. New York, John Wiley \& Sons, Inc.

ALMEIDA, WAGNER J. (2007). Otimização estrutural de protótipos fabricados pela tecnologia FDM utilizando o método dos elementos finitos. $107 \mathrm{f}$. Dissertação (Mestrado) - Escola de Engenharia de São Carlos, Universidade de São Paulo, São Carlos.

BEAUMONT, P.W.R. (1989). The Failure of Fibre Composites: an overview. Journal of Strain Analysis. V. 24, n.4, p.189 - 205.

CALLISTER W. D. (1994). Materials Science and Engineering: An introduction, third edition. P.521-531. New York, John Wiley \& Sons, Inc.

CARVALHO, J. (1996). Computer integrated desing optimisation and manufacturing of filament wound parts. $198 \mathrm{f}$. Tese (Doutorado) - Faculty of Applied Sciences, Division PMA, K.U. Leuven.

COSTA, H.C.B (1996). Banco de Dados - Universidade Federal de São Carlos, São Carlos.

Diretrizes para elaboração de dissertação e teses na EESC - USP (2004). São Carlos. Biblioteca Central. 
ECHAABI, J. ; TROCHU, F.; GAUVIN, R. (1996). Review of Failure Criteria of Fibrous Composite Materials. Polymer Composites, v.17, n.6, p.786 -798.

EDWARDS, K.L. (1998). An Overview of the Technology of Fibre - reinforced plastics for design purposes. Materials \& Design. v.19, p.1-10.

FILHO, GERALDO DANTAS S. (2001). Comportamento mecânico do poliuretano derivado de óleo de mamona reforçado por fibra de carbono: contribuição para o projeto de hastes de implante de quadril. 156 f. Dissertação (Mestrado) Escola de Engenharia de São Carlos, Universidade de São Paulo, São Carlos.

FURGERI, SÉRGIO (2003). JAVA 2: Ensino didático: Desenvolvendo e implementando aplicações. $3^{\mathrm{a}}$ ed. Ed. Érica. São Paulo.

GERALD, KOTONYA; SOMMERVILLE, IAN (1998). Requirements Engineering: Processes and Techniques, John Wiley \& Sons.

GOMES, E. S. (2008). Implementação de rotinas computacionais para o cálculo de trajetórias geodésicas no processo de filament winding. 155f. Dissertação (Mestrado) - Escola de Engenharia de São Carlos, Universidade de São Paulo, São Carlos.

GOODRICH, MICHAEL T.; TAMASSIA, ROBERTO (2007). Estruturas de Dados e Algoritmos em Java. 4.ed. Porto Alegre: Bookman. 
HAHN, H. T.(1980). Simplified formulas for elastic moduli of uniderectional continous fiber composites.Fall. Composites Technology Review.

HELEN, SHARP.et al. (2002) - Interaction Design: beyond human - computer interaction, 2.ed. John Wiley \& Sons.

HYER, M. W. (1998). Stress Analysis of Reinforced Composite Materials. Singapore, WCB/McGraw-Hill.

HULL, D. (1981). An introduction to composites materials. London, Cambridge University Press.

IAN SOMMERVILLE; PETE, SAWYER (1997). Requirements Engineering: A Good Practice Guide, $1^{\mathrm{a}}$.ed. John Wiley \& Sons.

JUSTULIN, FERNANDO (2008) - Desenvolvimento de sistema computacional para cálculo de trajetórias no processo de filament winding. 149 f. Dissertação (Mestrado) - Escola de Engenharia de São Carlos, Universidade de São Paulo, São Carlos.

KEUNINGS, R. (1992). Macromechanics of composites. Composites Science and Technology - european postgraduate education in polymer and composites engineering (EUPOCO), K. U. Leuven, v.2, Module 4. 
MACHADO, Felipe Nery R.; ABREU, Maurício P. (1996). Projeto de Banco de Dados - Uma visão Prática. $2^{\mathrm{a}}$ ed. Ed. Érica. São Paulo.

MACHADO, Felipe Nery R.; ABREU, Maurício P. (2005). Projeto de Banco de Dados - Uma visão Prática. $12^{\mathrm{a}}$ ed. Ed. Érica. São Paulo.

MAGELA, Rogerio (2006). Engenharia de Software Aplicada: Princípios (volume 1). Alta Books.

MAGELA, Rogerio (2006). Engenharia de Software Aplicada: Fundamentos (volume 2). Alta Books.

MATTHEWS, F.L.; RAWLINGS, R.D. (1994). Composite Materials: engineering and science. London, Chapman \& Hall.

MOLINARI, Leonardo (2007). Gerência de Configuração - técnicas e práticas no desenvolvimento do software. Florianópolis: Visual Books.

NOTON, B.R. (1987). Engineered Materials Handbook. v.1, Composites. p. 35-37. Ohio, ASM International.

PRESSMAN, R. (1995). Engenharia de Software. São Paulo, McGrawHill. p. 3-35; p. 177-229; p. 786-874. 
PRESSMAN, R.S. (2001). Software Engineering: a practitionier's approach (European Edition) . 5a Edição, London: Mc Graw Hill, 2001.

PRESSMAN, Roger (2005). Software Engineering: A Practitioner's Approach, 6aedição, Mc Graw Hill.

REINHART, T.J.; CLEMENTS, L.L. (1987). Engineered Materials Handbook. v.1, Composites. p.27 - 34. Ohio, ASM International.

REIS, Rodrigo Quites et. al. (2002) - Automação no Gerenciamento do Processo de Engenharia de Software, Belém, Outubro 2002. Acesso: 20 mai 2009.

REZENDE, M.C.; BOTELHO, E.C. (2000). O Uso de Compósitos Estruturais na Indústria Aeroespacial. Polímeros: Ciência e Tecnologia. v.10, n.2, abr/jun.

SHACKELFORD, J.F. (1996). Introduction to materials science for engineers, 4nd.ed. New Jersey, Prentice-Hall, Inc.

SILVEIRA, Z. C. (1999). Desenvolvimento de um sistema computacional de auxílio ao cálculo e desenho de elementos de máquina. 180 f. - Dissertação (Mestrado) - Escola de Engenharia de São Carlos, Universidade de São Paulo, São Carlos.

SMITH, W.F. (1993). Materials science and engineering, 2.ed. p.330. Singapore, McGraw-Hill, Inc. 
SOUZA, GILBERTO P. (2003). Avaliação de critérios de falhas de compósitos poliméricos reforçados aplicados a vigas sob carregamento de flexão. $107 \mathrm{f}$. Dissertação (Mestrado) - Escola de Engenharia de São Carlos, Universidade de São Paulo, São Carlos.

THOMPSON, MARCO A. (2003). Java 2 \& Banco de Dados: aprenda na prática a usar Java e SQL para acessar banco de dados relacionais. $2^{\mathrm{a}}$ ed. Ed. Érica. São Paulo.

TSAI, S.W.; HAHN, H.T. (1980). Introduction to composite materials. Lancaster, Technomic Publishing Company, Inc.

TSAI, S.W. (1986). Composites design 1986. Dayton, Think Composites.

TITA, V. (1999). Análise dinâmica teórica e experimental de vigas fabricadas a partir de materiais compósitos poliméricos reforçados. 125 f. Dissertação (Mestrado) - Escola de Engenharia de São Carlos, Universidade de São Paulo, São Carlos.

VINSON, J.R.; SIERAKOWSKI, R.L. (1987). Behavior of Structures Composed of Composite Materials. Dordrecht, Martinus Nijhoff 